UNIVERSIDADE DE BRASÍLIA - UNB INSTITUTO DE GEOCIÊNCIAS - IG

\title{
UnB
}

\section{A sismicidade induzida em Ijaci, sul de Minas Gerais e suas prováveis causas.}

\author{
Dissertação de Mestrado \\ Vinicius Martins Ferreira
}

Orientador: Prof. Dr. Lucas Vieira Barros 


\section{Agradecimentos}

Agradeço a Deus, pelo dom da vida e fé; renovada a cada provação que se apresenta e nos sonhos que se concretizam como este que agora se torna realidade

Fruto de muito trabalho e persistência a realização deste trabalho só foi possível graças a colaboração direta ou indireta de muitas pessoas as quais venho aqui prestar meus mais sinceros agradecimentos;

Pelo incondicional apoio dos meus pais, Dercio e Elisete, pelo amor, dedicação e por serem meu maior exemplo de vida.

A minha querida e amada filha Bárbara Cunha Ferreira, por ser muito mais do que eu sempre sonhei e pedi à Deus. Aos meus momentos de ausência peço-lhe desculpas e agradeço-te por tamanho amor que tem por seus pais.

À Valquíria, minha querida esposa, pelo companheirismo, apoio e pela compreensão dos inúmeros momentos de minha ausência.

Ao amigo e orientador, Prof. Lucas Barros pela oportunidade, confiança e apoio, mesmo nos momentos mais difíceis, em que esta realização parecia impossível de ser concretizada.

Aos meus colegas que estiveram diretamente envolvidos neste trabalho, Prof. Eloi Campos, Juraci Carvalho, Daniel Caixeta, Paulo Coutinho e outros que me ajudaram no decorrer deste projeto.

Aos meus amigos Marcus Vinicius, Osvaldo Araújo, Rafael Brant, Saulo Carreiro e Janílson Silva pelo incentivo e momentos de risos.

Aos professores do Instituto de Geociências da UnB pela qualidade das aulas

Ao Instituto de Geociências da UnB em especial ao Observatório Sismológico, professora Mônica G. Von Huelsen, pela disponibilização dos dados e provimento de todo suporte necessário. 


\section{Resumo}

Este trabalho consiste no estudo da sismicidade próximo a cidade de Ijaci, sul de Minas Gerais e sua possível relação com as atividades de mineração, rebaixamento do nível freático e o reservatório da UHE de Funil utilizando eventos sísmicos registrados entre dezembro de 2010 e junho de 2016.

Apesar de estar próximo de cidades com histórico de sismicidade, como é o caso de Bom Sucesso, MG, com relatos de sismos desde 1840 e no bordo sul do Cráton do São Francisco, Ijaci era considerada uma cidade assísmica, até que em 14 de agosto de 2011, quando um sismo de magnitude 3,2 assustou a população local. Outros três abalos de magnitudes similares foram

registrados nos meses seguintes. A área foi monitorada durante seis meses por uma rede sismográfica local com sete estações de banda larga, seis provisórias e uma permanente (FUN1).

Durante o período de operação, a rede local detectou mais de 1000 eventos, metade tectônicos, metade artificiais, dos quais 500 foram localizados e 276 dos quais classificados como tectônicos.

Estão instaladas na área quatro pedreiras de calcário, Mineração Alvarenga, Indústrias de Cal SN, de menor porte e as minas Sul e Santa Helena, de propriedade do Grupo Intercement, que juntas alimentam uma das maiores plantas de cimento do Brasil, além da Usina Hidroelétrica de Funil. O relevo cárstico do local sustenta um robusto aquífero, surgente no fundo das cavas, e responsável pelo aporte do volume médio, apenas na Mina Sul, de 350 m3/hora. A ativação das minas e o enchimento do lago ocorreram no mesmo período, ao final de 2002.

O estudo de mecanismo focal composto obtido pelo método de polaridades e pelo método de inversão de forma de onda dos eventos melhor localizados, além do mecanismo focal do evento principal demonstram um regime tectônico compressivo das falhas reversas responsáveis pela atividade sísmica no Graben de Ijaci.

Medidas de piezômetros e suas variações, restritas apenas ao entorno da mina indicam que não há conexão direta entre o lago e o fundo da cava e que o bombeamento que rebaixa o nível freático à razão de $350 \mathrm{~m} 3 / \mathrm{h}$, pouco influencia no regime de esforços. A localização dos eventos, associada aos dados de mecanismo focal, volume de material extraído e o comportamento da sismicidade nos últimos cinco anos permitem associar a ocorrência de sismicidade à extração de material, que atualmente se traduz em uma carga negativa aproximada de 60 milhões de tonelada, ou $5,9 \times 1011 \mathrm{~N}$. 


\section{Índice}

Agradecimentos................................................................................................................................ ii

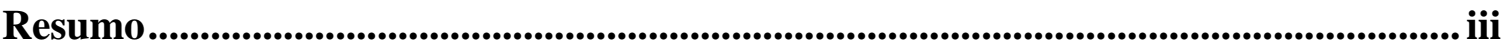

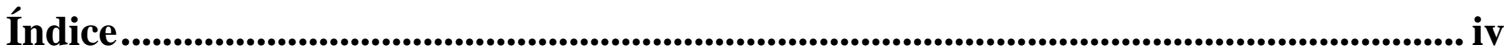

Lista de Figuras................................................................................................................... vi

Lista de Tabelas................................................................................................................................... xii

Capítulo 1 - Introdução ................................................................................................................... 1

1.1 Sismicidade próxima ao reservatório da UHE Funil...................................................2

1.2 Localização e vias de acesso ...................................................................................................4

Capítulo 2 - Contextualização geológica da área de estudo ................................................. 6

2.1 Geologia Regional................................................................................................6

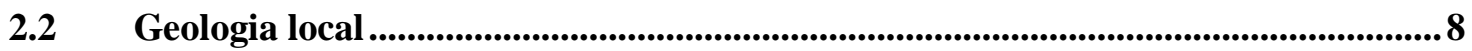

2.3 Evolução geológica e estrutural ......................................................................................11

2.4 Geologia Estrutural Local..............................................................................................12

Capítulo 3 - Sismicidade ................................................................................................................. 14

3.1 Introdução ..........................................................................................................14

3.2 Sismicidade desencadeada .............................................................................................14

3.3 Sismicidade prévia ao reservatório .............................................................................15

3.4 Evento principal de 14 de agosto de 2011 ........................................................17

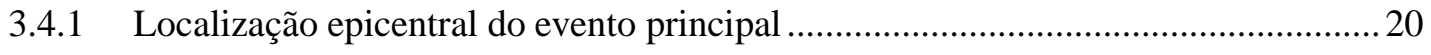

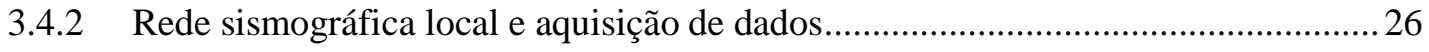

3.4.3 Análise da sismicidade detectada pela rede local...................................................2

3.4.4 Confiabilidade da localização dos epicentros ……………………………………..... 30

3.4.5 Localização epicentral...…………………………………………………………30

Capítulo 4 - Parâmetros de Fonte.............................................................................................. 33

4.1 Introdução .......................................................................................................................33

4.2 Mecanismo focal composto .........................................................................................33

4.2.1 Determinação do mecanismo focal composto.............................................................. 34

4.3 Inversão da forma de onda dos abalos secundários........................................................35 


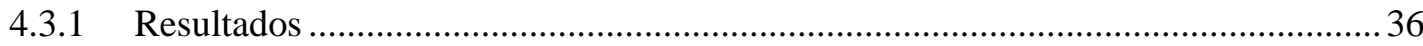

4.4 Mecanismo focal por inversão de formas de ondas do evento principal.................40

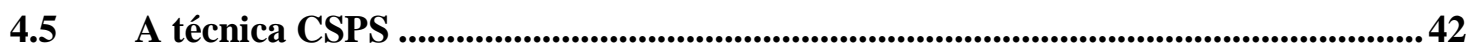

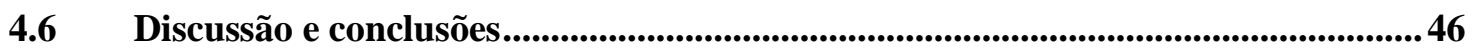

Capítulo 5 - A origem da Sismicidade .............................................................. 49

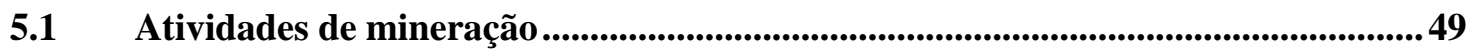

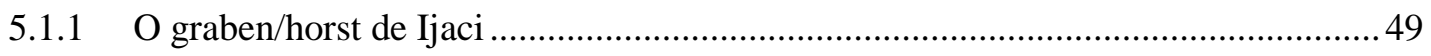

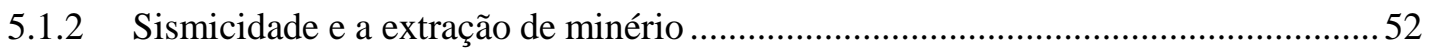

5.2 Extração de Fluidos .............................................................................................................56

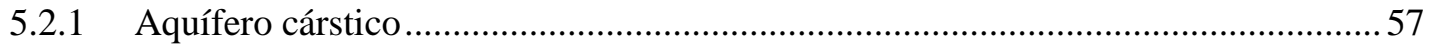

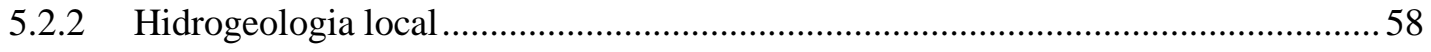

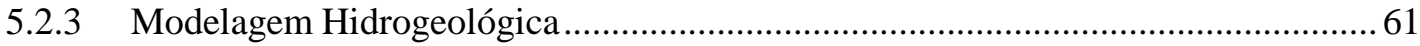

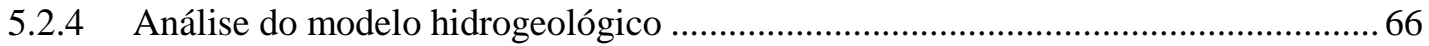

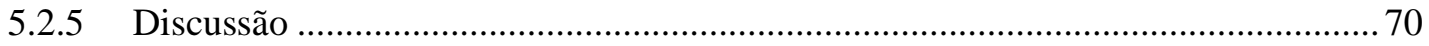

5.2.6 Sismicidade e extração de água................................................................................. 71

$5.3 \quad$ Reservatórios de barragens ................................................................................................... 72

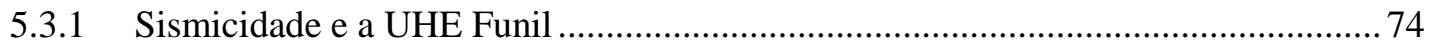

Capítulo 6 - Discussão e Conclusões.......................................................................... 77

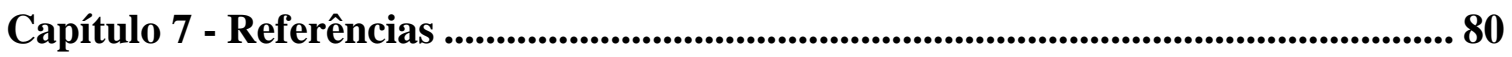




\section{Lista de Figuras}

Figura 1-1 - Mapa com a localização da região de estudo e a principal via de acesso (BR381) a partir de Belo Horizonte, MG 4

Figura 2-1 - Mapa com localização da área de estudo e o indicativo das principais zonas de cisalhamento da porção sul do Cráton do São Francisco e cinturão móvel costeiro (modificado de Ebert et al, 1988) 6

Figura 2-2 - Mapa tectônico da extremidade Sul do Cráton do São Francisco com a localização da área estudada (modificado de Ribeiro et al 1990). 7

Figura 2-3 - Mapa geológico da área de estudo com indicação das minas MS (Mina Sul), MSH (Mina Santa Helena, AV (Mineração Alvarenga) e SN (Indústria de Cal SN) (Quéméneur et al., 2003)

Figura 3-1 - Mapa da sismicidade observada em uma área de $100 \mathrm{~km}$ de raio a partir do epicentro do sismo de 14 de agosto de 2011, indicado pela estrela vermelha. Os círculos vermelhos estão de acordo com as magnitudes (veja legenda). Fonte: Base de Dados da Sismicidade Brasileira desde 1824. 17

Figura 3-2 - Registro das formas de ondas do sismo de Ijaci de 14 de agosto de 2011, às 13h50m (local). De cima para baixo são mostrados os movimentos de partículas do chão nas direções vertical, norte-sul e leste-oeste. As duas barras verticais indicam, da esquerda para a direita, as marcações das fases $\mathrm{P}$ e $\mathrm{S}$, respectivamente. 18

Figura 3-3 - Sismograma do principal evento de Ijaci de 14v de agosto de 2011 (componentes verticais) registrado pelas doze estações apresentadas na Figura 3-4. São também apresentadas as marcações das fases $\mathrm{P}$ e $\mathrm{S}$ em ordem crescente de chegada. $\mathrm{O}$ primeiro traço se refere a estação FUN1

Figura 3-4 - Mapa com a localização das estações sismográficas (triângulos) que foram utilizadas para determinar o hipocentro do sismo de Ijaci ocorrido em 14 de agosto de 2011, às 16h50m10.66s (UTC); 13h50m10.66s (horário local). Note que a estação FUN1 está localizada embaixo da estrela amarela que indica o epicentro do evento. Estações sismológicas do Observatório Nacional (ON) são indicadas pelos triângulos negros, as estações da USP, pelos triângulos vermelhos e em azul as estações operadas pela UnB. 20 
Figura 3-5 - Mapa com as localizações epicentrais feita com a rede regional de 12 estações (estrela amarela) e com dados da estação FUN1 (estrela vermelha). É apresentado também a localização da estação FUN1 (triângulo preto). As pedreiras (MS - Mina Sul, MSH - Mina Santa Helena, AV - Mineração Alvarenga e SN - Indústria de Cal SN) são também indicadas pelas poligonais vermelhas 21

Figura 3-6 - Diagrama Wadati gerado a partir dos melhores sismos de Ijaci. Na vertical estão as diferenças no tempo de chegada das fases P e S (Ts-Tp) e nas abcissas as diferenças entre os tempos de $\mathrm{P}$ e o tempo de origem. 22

Figura 3-7 - Sismogramas do evento de Ijaci/MG, de 14/08/2011 nas direções vertical, norte-sul e leste-oeste (traços superiores) e movimento de partículas nas direções Norte-Vertical, Leste-Vertical e Horizontal-Horizontal 23

Figura 3-8 - Localização epicentral do evento de 14/08/2011 com uma razão Vp/Vs = 1,72 e profundidade inicial (h) de $1 \mathrm{~km}$. Coordenadas geográficas de $45.567^{\circ}$ Longitude oeste e $21.095^{\circ}$ de Latitude sul.

Figura 3-9 - Registro das formas de onda do evento de Ijaci, de 14/08/2011, com as marcações das fases P (na vertical) e S (na horizontal leste-oeste). Observe que a máxima amplitude (104881 contagens digitais) da fase S está na componente Leste-Oeste, o que era de se esperar, considerando a localização epicentral do evento na Figura 3-8, quase a sul de FUN1. Portanto, a direção de vibração de partículas para a onda S, perpendicular à direção de propagação, neste caso a componente Norte-Sul rotacionadas de 15 graus 25

Figura 3-10 - Rotação das componentes horizontais norte-sul e leste-oeste nas direções radial (traço H R, centro) e tangencial (traço H T, inferior). Observe que o backazimute é de 195 graus, portanto, as componentes horizontais foram rotacionadas no sentido horário de 15 graus.

Figura 3-11 - Mapa com a localização da rede sismográfica local (triângulos pretos) instalada após o evento principal de 14/08/2011 (estrela vermelha). É também apresentado a localização das pedreiras (MS - Mina Sul, MSH - Mina Santa Helena, AV - Mineração Alvarenga e $\mathrm{SN}$ - Indústria de Cal $\mathrm{SN}$ ), indicadas pelas poligonais vermelhas 28

Figura 3-12 - Localização dos 25 eventos classificados como tectônicos e detectados por quatro ou mais estações. As estrelas azuis denotam os epicentros dos quatro eventos principais localizados com dados de FUN1. 31 
Figura 3-13 - Localização dos 39 eventos classificados como artificiais e detectados por quatro ou mais estações 32

Figura 4-1 - Mecanismo focal composto para a sequência sísmica de Ijaci, utilizando as polaridades das primeiras chegadas da onda $\mathrm{P}$, de um conjunto de oito eventos com 25 polaridades, duas apresentaram inconsistências. Círculo indica compressão e triângulo distensão. 35

Figura 4-2 - Solução de mecanismo focal para o evento de 22 de fevereiro de 2012, às 20:09:10.23, utilizando inversão de forma de onda e o software ISOLA. Adicionalmente, as polaridades das estações foram plotadas e nenhuma inconsistência foi encontrada. 37

Figura 4-3 - Resultados ISOLA da inversão de forma de onda para o evento de 22 de fevereiro de 2012, às 20:09:10.23, registrado por quatro estações (FUN3, FUN4, FUN5 e FUN6). 38

Figura 4-4 - Os sismogramas sintéticos (traços vermelhos) e observados (traços pretos) de quatro estações da rede local. Os traços das componentes NS das estações FUN3 e FUN4 não foram utilizadas na inversão da forma de onda devido a baixa razão Sinal Ruído (SNR) 38

Figura 4-5 - Representação Beach-Ball para os seis eventos apresentados na tabela 4.2. As barras amarelas representam a orientação do eixo-P. A média geral do eixo P tem orientação NNWSSE. 40

Figura 4-6 - Espectro do sinal (vermelho) e do ruído (preto) nos canais NS, EW e Vertical para a estação FUN1, localizada a cerca de $8 \mathrm{~km}$ da fonte. 41

Figura 4-7 - Espectro do sinal (vermelho) e do ruído (preto) nos canais NS, EW e Vertical para a estação BSCB, localizada a cerca de $28 \mathrm{~km}$ da fonte. 41

Figura 4-8 - Modelo de velocidade, azul (onda S) e vermelho (onda P). Para este caso utilizou-se uma razão Vp/Vs de 1,72, obtido no Capítulo 3 - a partir do diagrama de Wadati 42 Figura 4-9 - Soluções de planos nodais obtidos com 4 polaridades nas estações FUN1, BSCB, PMNB e SJMB sem nenhum erro de polaridade e uma busca de 30 graus. 43

Figura 4-10 - Formas de ondas dos dados sintéticos (vermelho) e observados (preto) nas estações FUN1 (superior) e BSCB (inferior). Os números azuis denotam a correlação entre os dados sintéticos e observados. O pior caso aconteceu para a componente EW da estação BSCB $(0,03)$ e o melhor para essa mesma componente na estação FUN1 $(0,97)$ 43 
Figura 4-11 - Profundidade da fonte por correlação. Observe que a profundidade para a qual a correlação é maior ocorre para profundidade de $0,2 \mathrm{~km}$, ligeiramente acima de 0,9 , com percentual DC de $94,2 \%$

Figura 4-12 - Resumo dos resultados da inversão de forma de onda para o evento principal registrado nas estações FUN1 e BSCB 45

Figura 4-13 - Solução de planos nodais. Plano 1: 198/54/59 (strike/dip/rake); Eixo P $($ strike/plunge $)=309 / 4,3 ;$ Plano 2: 63/46/125 $($ strike/dip/rake); Eixo T $($ strike/plunge $)=48 / 65.45$

Figura 4-14 - Solução de mecanismo focal obtidos para os três métodos: mecanismo focal composto; inversão de forma de onda dos pós abalos e evento principal por CSPS. C e D donotam polaridades compressiva e distensiva, respectivamente.

Figura 4-15 - Principais estruturas mapeadas na área por Quéméneur et al. (2003), Ribeiro et al. e (2003a), Hidrovia (2003) e relatórios internos da Intercement. Os números indicam a localização dos eventos da Tabela 4-1 Observe a clara correlação entre os resultados dos mecanismos focais com as falhas mapeadas em superfície de orientação geral NE-SW 48

Figura 5-1 - Perfil geológico esquemático AA’. Este perfil sintetiza as inferências feitas a partir das observações de campo e dos dados de sondagens, onde este perfil está assinalado; a escala vertical é arbitrária. Escala horizontal e localização apresentada na Figura 5-2. TER: Sedimentos Terciários; QTZ: Quartzito; MX: Biotita Quartzo Xisto; FL: Filitos; SAP: Saprolito; MS: Mármore Silicoso; RCGr: Rocha Carbonática; RSC: Rocha Sílico Carbonática; CX: Cálcio Xisto e GN: Embasamento Granítico. Modificado de Intercement (2016) 51

Figura 5-2 - Mapa geológico da região de ocorrência da sismicidade. O graben de Ijaci está restrito a área de ocorrência dos calcários da Formação Barroso. As cavas das minas MSH, MS, AV e SN estão localizadas nos blocos Horst, ou seja, nos blocos elevados em relação aos vizinhos e que aproximam as camadas de calcários da superfície, ficando os blocos de graben (blocos rebaixados) cobertos por material terrígeno e menos interessantes prospectivamente. A localização do perfil AA' (Figura 5-1) está indicado pela linha negra contínua ......................... 52

Figura 5-3 - O volume extraído na mina sul (linha azul), entre janeiro de 2010 e junho de 2015 é apresentado no eixo primário (esquerda). Observe o elevado volume de material movimentado durante os anos iniciais das minas Sul e Santa Helena. A evolução da sismicidade é representada no eixo secundário pelas barras vermelhas. 54 
Figura 5-4 - Círculo de Mohr representando a ruptura devido à redução em $\sigma_{3}$, a tensão mínima compressiva. Para os sismos de Ijaci, $\sigma_{3}$ é assumido como sendo vertical devido às falhas reversas existentes na área e cuja redução de $\sigma_{3}$, ocorre devido a retirada de material rochoso e bombeamento de água nas cavas hospedadas no hanging wall das falhas reversas do horst de Ijaci. A linha representada pelo critério de fratura Coulomb-Navier é indicada pela equação $\tau=\tau 0+\mu \sigma$ (modificado de Sbar e Sykes, 1973) 55

Figura 5-5 - Aquífero cárstico. Características de um aquífero cárstico como cavidades de dissolução, cavernas e fraturas com fluxo de água. Feições como cavernas e fraturas podem estar parcialmente ou totalmente submersas em água. Figura de Marshak, 2008 58

Figura 5-6 - Evolução das cotas de fundo das cavas das minas Sul (MS) e Santa Helena (MSH) em função dos estágios de avanço da lavra, com a indicação da cota de fundo atual de ambas as cavas (cota $840,0 \mathrm{~m}$ ) e da cota atual estimada para o nível freático (cota 830,0 m) (Hidrovia, 2006).

Figura 5-7 - Distribuição das cargas hidráulicas e dos vetores direcionais de fluxo das águas subterrâneas, representativos para o estágio de lavra a 37,5\% da cota de fundo planejada para as minas Sul e Santa Helena. Nota: As linhas em azul representam as curvas de isovalor de carga hidráulica. As setas em azul representam os vetores direcionais de fluxo. Os quadrados verdes indicam a localização dos piezômetros. Seção horizontal na cota 805 metros (modificado de Hidrovia, 2006)

Figura 5-8 - Distribuição das cargas hidráulicas e dos vetores direcionais de fluxo das águas subterrâneas, representativa para o estágio de lavra a 50,0\% da cota de fundo planejada para as minas Sul e Santa Helena. Nota: As linhas em azul representam as curvas de isovalor de carga hidráulica. As setas em azul representam os vetores direcionais de fluxo. Os quadrados verdes indicam a localização dos piezômetros. Seção horizontal na cota de 775 metros (modificado de Hidrovia, 2006)

Figura 5-9 - Evolução estimada da lavra da Mina Sul (MS) nos últimos 10 anos com base em comunicação pessoal (Intercement, 2015) . 66

Figura 5-10 - Variação nas medidas dos piezômetros entre janeiro de 2011 e agosto de 2016. As descontinuidades nas linhas (medidas das cotas) se referem a períodos sem coleta de medidas. Os números de 1 a 11 estão relacionados com os piezômetros apresentados pela Figura $5-11$. 
Figura 5-11 - Mapa com a localização dos piezômetros de monitoramento do nível freático nos arredores da MS (Mina Sul) e MSH (Mina Santa Helena). No empreendimento existem outros piezômetros, entretanto, neste trabalho serão considerados apenas os que apresentaram medidas em períodos superiores a 6 meses

Figura 5-12 - Variações no volume de bombeamento $\left(\mathrm{m}^{3}\right)$ d'água que é efetuado nas Mina Sul (MS) e Mina Santa Helena (MSH) com o objetivo de rebaixar o nível freático e liberar o fundo da cava para exploração do minério. A escala vertical está em milhares 70

Figura 5-13 - A estabilidade da cota do lago (linha azul), entre dezembro de 2002 e julho de 2016 é apresentado no eixo primário (esquerda). Observe que após o enchimento do reservatório (dezembro de 2002) a cota do lago variou entre 807,8 e 808m. A evolução da sismicidade entre abril de 2011 e junho de 2015 é representada no eixo secundário pelas barras vermelhas 75

Figura 5-14 - Área de inundação do reservatório da UHE Funil e indicação, em amarelo, da posição do barramento, distante aproximadamente $15 \mathrm{~km}$ da área de ocorrência dos sismos. A menor distância entre a margem do lago e os sismos é $1,3 \mathrm{~km}$ 76

Figura 6-1 - Cronologia dos eventos. Observe que tanto as Minas Sul (MS) e Mina Santa Helena (MSH) foram ativadas/reativadas concomitantemente ao enchimento do lago da UHE Funil 78 


\section{Lista de Tabelas}

Tabela 2-1 - Famílias de fraturas principais e secundárias. Fonte: Hidrovia (2003) ....... 13

Tabela 3-1 - Evolução mensal da sismicidade (natural e artificial) observada próxima à cidade de Ijaci/MG, entre 14 de agosto de 2011 e janeiro de 2012 ....................................... 28

Tabela 3-2 - Relação de eventos localizados e seu respectivo número de estações ......... 29

Tabela 3-3 - Parâmetros dos 4 sismos principais de Ijaci localizados com apenas uma estação, FUN1

Tabela 4-1 - Listagem dos eventos utilizados na solução do mecanismo focal composto e para inversão de forma de onda dos eventos pós abalo. Os eventos de número 1 e 10 não foram usados no MF composto. 34

Tabela 4-2 - Solução dos planos nodais composto para a sequência de Ijaci .................. 35

Tabela 4-3 - Resumo dos resultados de seis eventos invertidos para o momento tensor. 39

Tabela 4-4 - Parâmetros de mecanismo focal para os dois métodos: Mecanismo focal composto e inversão da forma de onda

Tabela 5-1 - Materiais litológicos distintos com a identificação das respectivas unidades hidroestratigráficas, compilado de Hidrovia (2003) 61 


\section{Capítulo 1 - Introdução}

Um sismo resulta da ruptura de uma parte frágil da litosfera em resposta à atuação de esforços. São mais frequentes no limite entre as placas tectônicas, região onde a litosfera está sob intenso regime de esforços e, portanto, mais susceptível à ocorrência de sismos. O Brasil, por estar situado no interior da Placa Sul Americana, região tectonicamente estável, tem histórico de baixa atividade sísmica, entretanto, já foram registrados 22 terremotos com magnitude maior ou iguais a 5, dois dos quais maiores do que 6 (6,1 e 6,2) (Barros et al., 2009). Apresenta um histórico expressivo de casos de SIR (Sismicidade Induzida por Reservatórios), com 26 casos de sismos relacionados com enchimento de reservatórios para produção de energia elétrica (Assumpção et al, 2002, Gomide, 1999; Ribotta, 1989, Chimpliganond, 2002, Ferreira et al., 1995; Ribotta et al., 2006a e 2006b; Veloso, 1992a., Berrocal et al., 1984, Barros e Caixeta, 2003, Barros e Ferreira, 2006, Barros et al, 2015).

Comprovadamente a ação do homem sobre o ambiente natural pode desencadear o aparecimento localizado dessa categoria de sismicidade induzida ou sismicidade desencadeada pelo homem. Grandes obras de engenharia podem afetar o estado dos esforços tectônicos em suas áreas de influência e disparar, por exemplo, um sismo que poderia acontecer naturalmente em algum tempo futuro. Entretanto, é necessária a existência de condições favoráveis na área de localização destas obras de engenharia, ou seja, as rochas devem estar submetidas a esforços quase críticos, próximas do limite de ruptura. A ação do homem seria apenas o gatilho no processo de surgimento da sismicidade (Talwani, 2000).

Os mecanismos considerados para caracterizar a sismicidade induzida incluem mudanças no estado dos esforços, mudanças na pressão dos poros, mudanças de volume, e forças ou cargas aplicadas. Estes mecanismos nem sempre são independentes e sua ação conjunta pode ser o gatilho necessário para o disparo da sismicidade.

Apesar da sismicidade antropogênica, em diferentes ambientes tectônicos, não ter sido rigorosamente comparada, ela aparenta ser mais elevada em regiões continentais estáveis devido à combinação de baixa taxa de deformação, que produz um baixo nível de sismicidade natural e um estado de estresse próximo à ruptura, o que é um fator chave para a ocorrência deste tipo de sismicidade (McGarr et al, 2002). 
Existem cinco tipos principais de atividades humanas que podem desencadear sismicidade e alterar o regime sismotectônico em suas áreas de influência. São elas:

- Atividades de mineração e pedreiras (Redmayne, D.W. (1988));

- Injeção profunda de fluídos sob alta pressão (Henry Fountain, 2013);

○ Extração de líquidos (Yamabe, 1999; Yamabe e Hanza, 1996; Assumpção et al., 2007, 2010);

○ Explosões subterrâneas (Kisslinger K., 1976);

- Enchimento de reservatórios na construção de barragens (Simpson et al., 1988, Gupta (1976, 1992), Assumpção, et al., 2002).

\subsection{Sismicidade próxima ao reservatório da UHE Funil}

A Barragem de Funil, localizada próxima à cidade de Ijaci/MG, represa águas do Rio Grande e está situada nos municípios de Lavras, Perdões, Ijaci, Bom Sucesso, Ibituruna e Itumirim. O lago foi formado em novembro de 2002 e, desde então, opera com três turbinas, cada uma gerando potência de $60 \mathrm{MW}$.

A estação digital de três componentes, código de identificação FUN1, foi instalada em 21 dezembro de 2010, com o objetivo de monitorar a sismicidade local e avaliar sua possível variação devido à presença do lago de Funil. Inicialmente armazenava os dados em disco local e, a partir de 26 de agosto de 2011, os dados passaram a ser armazenados em Brasília, por meio da transmissão dos dados em tempo real por link de internet.

No dia 14 de agosto de 2011, a estação FUN1 detectou, às 13h50m (hora local), um sismo de magnitude 3,2 na Escala Richter, que foi sentido mais fortemente na cidade de Ijaci, localizada na margem esquerda do lago de Funil. Outros três sismos de magnitudes semelhantes foram também registrados em 05 de outubro, 13 e 23 de novembro de 2011. Essas ocorrências vinham assustando a população de Ijaci ao ponto de terem motivado a população a mover, junto ao Ministério Público de Minas Gerais, uma ação contra as pedreiras que operam na área. Nesta ação os moradores associaram os tremores às detonações efetuadas pelas quatro pedreiras vizinhas a Ijaci.

O primeiro relatório trimestral gerado pelo Observatório Sismológico da Universidade de Brasília (janeiro a março de 2011) sobre a o monitoramento da estação FUN1, já indicou a 
ocorrência de eventos locais próximos ao reservatório. Entretanto, muito próximo da área epicentral desses eventos existem quatro pedreiras onde são feitas detonações que podem ser facilmente confundíveis com eventos naturais e/ou induzidos.

Devido ao acima exposto, o Consórcio FUNIL e o Observatório Sismológico da Universidade de Brasília, decidiram pela instalação de uma rede sismográfica local, cuja instalação ocorreu no período de 19 a 23 de dezembro de 2011, das primeiras quatro estações. As duas estações ressaltantes, foram instaladas entre 16 e 21 de janeiro de 2012, formando uma rede de sete estações digitais de três componentes.

A rede operou até maio de 2012, período em que foram registrados cerca de 1000 eventos sísmicos, metade natural e metade artificial. 


\subsection{Localização e vias de acesso}

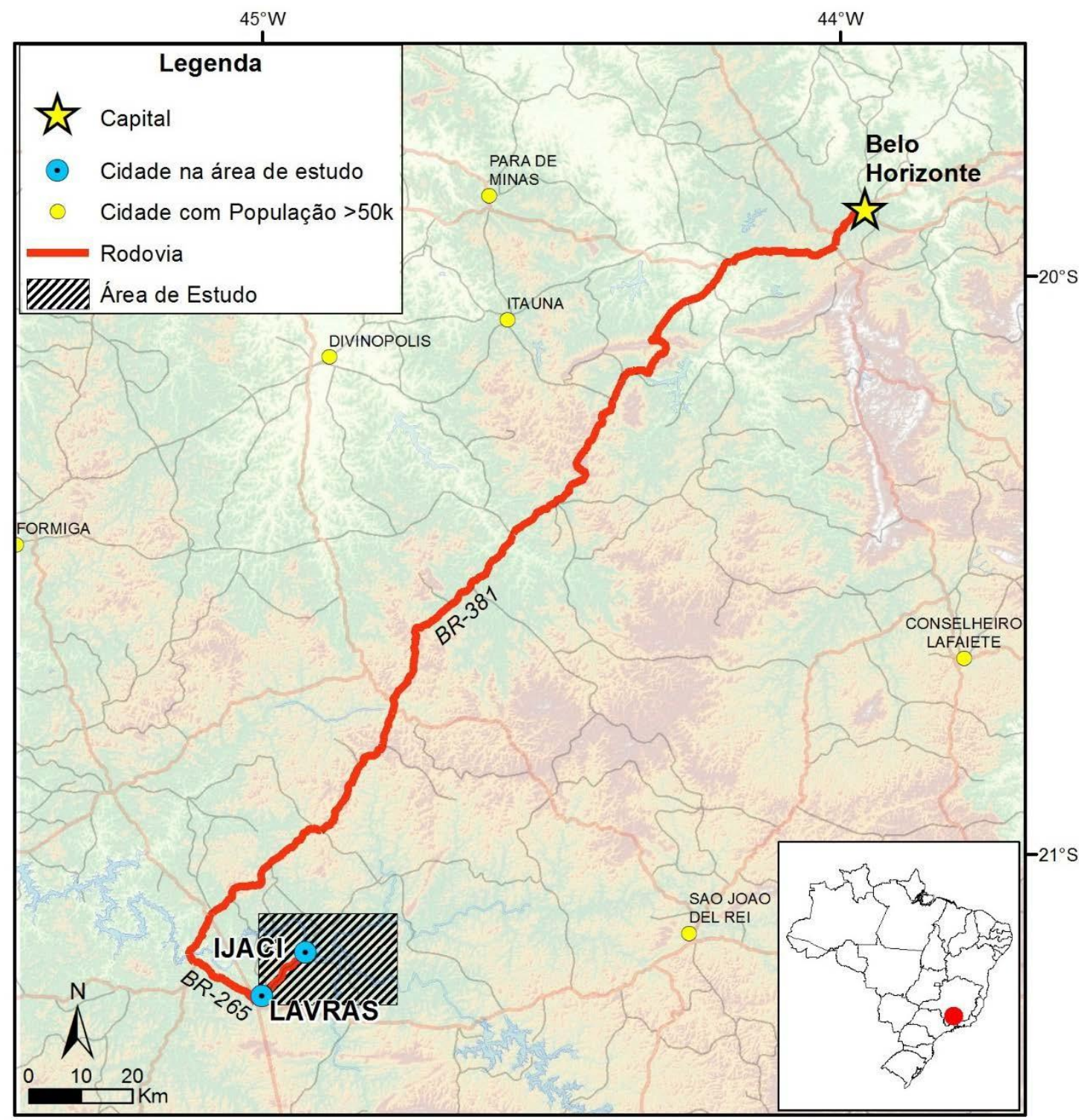

Figura 1-1 - Mapa com a localização da região de estudo e a principal via de acesso (BR-381) a partir de Belo Horizonte, $M G$.

A cidade de Ijaci está localizada no sul do Estado de Minas Gerais, dista aproximadamente $220 \mathrm{~km}$ da cidade de Belho Horizonte (Figura 1-1). Imediatamente na margem esquerda do lago da Usina Hidrelétrica (UHE) de Funil, próxima a várias pedreiras, onde sistematicamente são feitas detonações para o desmonte de calcário e bombeamento contínuo, por vezes superiores a 350 $\mathrm{m}^{3} /$ hora, com intuito de rebaixar o nível freático para exploração das jazidas

Em consequência das fortes vibrações causadas pelos sismos e explosões, que estavam assustando os moradores de Ijaci, o Observatório Sismológico da Universidade de Brasília, em 
parceria com o Consórcio Funil instalou uma rede sismográfica com seis estações, que operou por seis meses, quando foram registrados cerca de 1000 eventos. O evento principal foi registrado pela estação local FUN1 e por mais 11 estações da Rede Sismográfica Brasileira (RSBR), operadas pelo Observatório Nacional (4 estações), Universidade de São Paulo (4 estações) e Universidade de Brasília (3 estações).

Esta dissertação de mestrado tem como principal objetivo estudar a sismicidade de Ijaci e estabelecer, se possível, uma relação causal entre essa sismicidade e algum dos quatro fatores indutores de sismicidade que existem na área, separados ou conjuntamente, como:

- Atividades de mineração;

- Extração de líquidos;

○ Enchimento de reservatórios.

O estudo da sismicidade de Ijaci é importante porque (i) demonstra o quanto atividades antropogênicas podem influenciar na ocorrência de sismicidade, (ii) os sismos ocorrem em uma área relativamente povoada, o que inclui não apenas a cidade de Ijaci, mas também Lavras/MG, dentre outras, (iii) a fonte da sismicidade pode ser associada a falhas pré-existentes e ao trend das principais estruturas da região.

O trabalho está dividido em seis capítulos: Capítulo 1 - Introdução; Capítulo 2 Contextualização geológica da área de estudo; Capítulo 3 - Sismicidade; Capítulo 4 - Parâmetros de Fonte; Capítulo 5 - A origem da Sismicidade e Capítulo 6 - Discussão e Conclusões. 


\section{Capítulo 2 - Contextualização geológica da área de estudo}

\subsection{Geologia Regional}

A região de estudo compreende o bordo sul do Cráton do São Francisco, porção meridional do Estado de Minas Gerais (Figura 2-1).

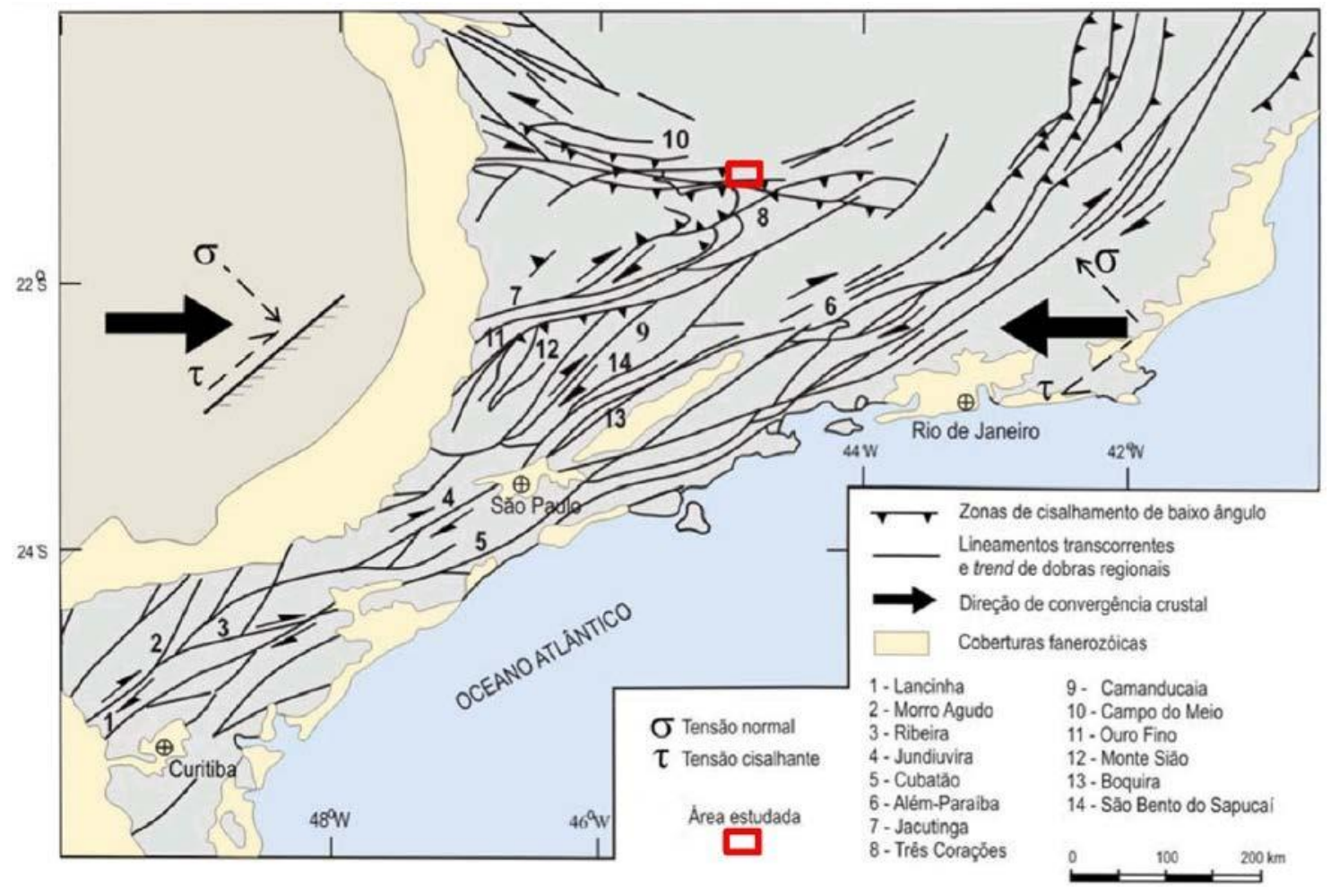

Figura 2-1 - Mapa com localização da área de estudo e o indicativo das principais zonas de cisalhamento da porção sul do Cráton do São Francisco e cinturão móvel costeiro (modificado de Ebert et al, 1988).

Os primeiros mapeamentos geológicos datam das décadas de 1950 e 60, iniciados por Ebert (1955, 1956a, 1956b, 1958 e 1968). Nesta ocasião foi definida a estratigrafia básica da região, constituída pelos Grupos São João Del Rei e Andrelândia de idade Algonquiana. Nos arredores de São João Del Rei foram reconhecidas rochas de idade Arqueanas, incluídas na Série Barbacena (Barbosa, 1954) (Figura 2-2).

A estratigrafia do Grupo São João Del Rei foi dividida, da base para o topo nas Formações Tiradentes, Carandaí e Prados (Ebert, 1956a), incluídas posteriormente as Formação Barroso (Ebert, 1956b) e Rio das Eivas na base do Grupo (Ebert, 1984). 
A Megasequência Carandaí é composta pelas formações Carandaí, Barroso, Prados e Macaia. Discordâncias intraformacionais permitiram identificar duas sequências, Barroso e Prados. A primeira contém depósitos de fluxos de detritos em borda de bacia e pelitos que registram a inundação marinha (Formação Carandaí) e gradam para calci-pelitos e calcários de mar alto (Formação Barroso) (Ribeiro et al., 2003a).

Na região de Ijaci, a existência de unidade sedimentar acima dos calcários da Formação Barroso, constituída por arenitos, grauvacas e arcóseos com características sedimentares que diferem da Formação Prados de outras regiões foi denominada de Formação Macaia (Ebert, 1984). Afloram embasamentos arqueano-paleoproterozóico e sucessões metassedimentares proterozóicas, próximo ao limite que separa esta unidade da Cunha de Guaxupé e da Faixa Alto Rio Grande (Wernick et al, 1981).

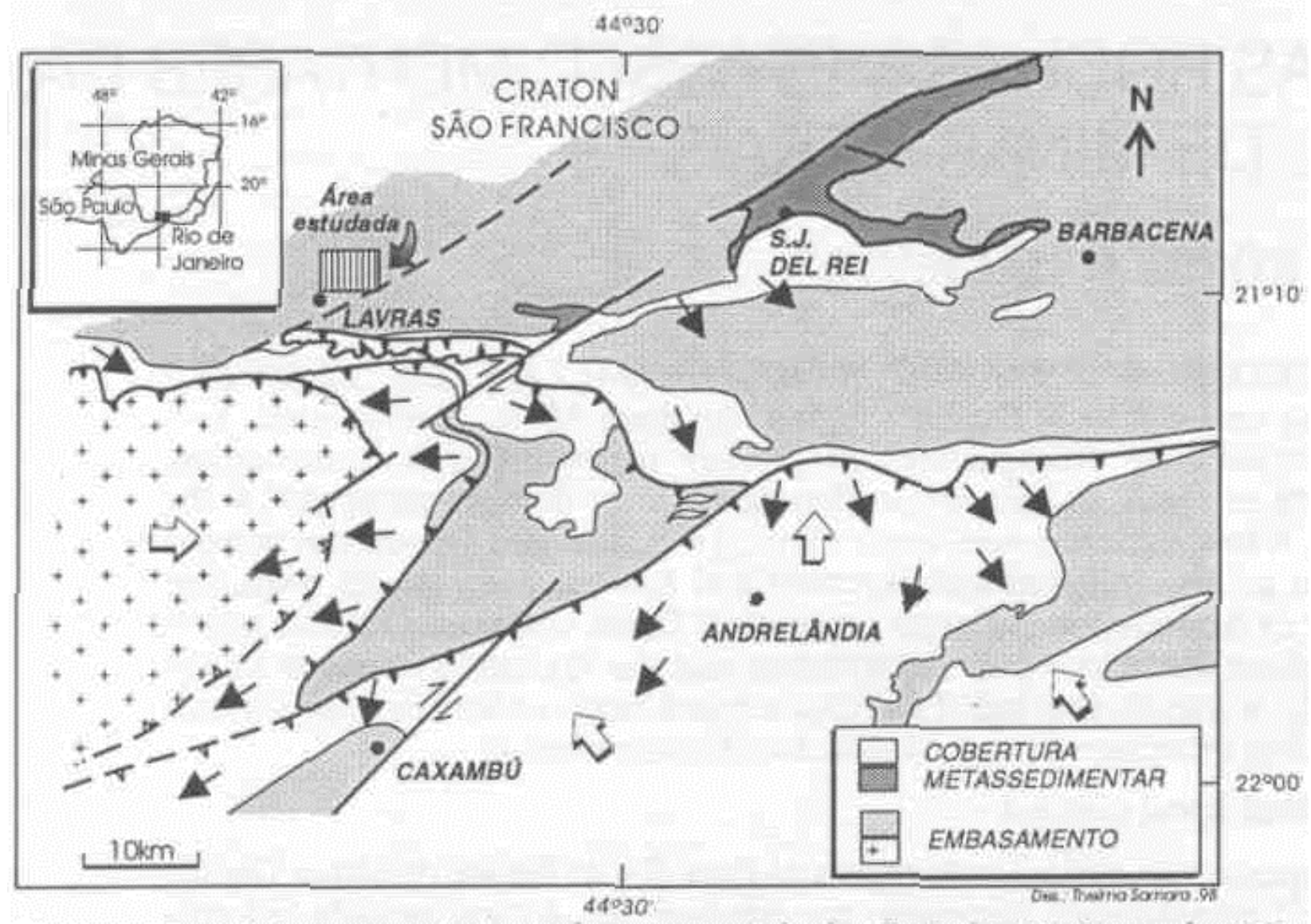

Figura 2-2 - Mapa tectônico da extremidade Sul do Cráton do São Francisco com a localização da área estudada (modificado de Ribeiro et al 1990). 
A zona de cisalhamento da Serra de Bom Sucesso, de orientação NE-SW, está localizada a SE da área em estudo e divide o embasamento em dois blocos. É formada por metassedimentos do Subgrupo Minas.

No bloco leste destacam-se greenstone belts afetados por metamorfismo de fácies anfibolito e constituído por rochas máficas e ultramáficas (Quéméneur et al. 2003).

O bloco oeste apresenta metamorfismo em fácies granulito e magmatismo bimodal. É constituído por gnaisses TTG enderbitos, metatonalito e metagabro.

A megaseqüência Carandaí ocorre no Graben de Ijaci, localizada no bloco oeste da zona de cisalhamento da Serra de Bom Sucesso, apresenta idade Mesoproterozóica e é constituída pelas sequências Barroso, constituída por metacalcários e metapelitos, e Prados, com predomínio de metapelitos (Quéméneur et al. 2003).

\subsection{Geologia local}

A área de estudo compreende a Megasequência Carandaí que ocorre no Graben de Ijaci, tendo ao centro a Serra do Ijaci.

A Megasequência Carandaí, com cerca de 600m de espessura, é composta por duas sequências: Barroso e Prados, separadas por um paleokarste e aparecem de forma discordante sobre os quartzitos da Megasequência São João Del Rei ou sobre o embasamento sendo recobertas por unidades da Megasequência Andrelância. As rochas da Megasequência Carandaí se apresentam metamorfizadas em fácies xisto verde com biotita, geralmente pouco deformadas (Ribeiro et al., 2003a).

Esta megasequência é formada por metacalcários cobertos por um espesso manto de alteração pedogenética, limitada a Leste e a Oeste por duas falhas paralelas à Serra de Bom Sucesso com direção SW-NE, assim como as principais estruturas observadas na área em questão. A norte os metacalcários parecem cobrir os enderbitos arqueanos por meio de um cavalgamento com vergência para norte (Quéméneur et al. 2003).

A sucessão estratigráfica simplificada do graben é a seguinte, da base para o topo:

- Metacalcários bandado com espessura entre 100 e $150 \mathrm{~m}$

- Calcoxisto, espessura entre 50 e $60 \mathrm{~m}$

○ Xisto com intercalações de quartzito, espessura entre 50 e $60 \mathrm{~m}$ 
A estratigrafia detalhada do local, com base nos perfis de sondagem obtidos junto aos relatórios internos da Intercement e a partir de Ribeiro et al., 2003, é a seguinte, da base para o topo:

○ Embasamento Gnáissico-Granítico: contém rochas granitoides/ granodioríticas /dioríticas / tonalíticas, cinzas a cinzas esbranquiçadas, de granulometria grossa a fina, contendo máficos na forma de lentículas com até $0,5 \mathrm{~cm}$ de espessura e fenocristais esparsos de feldspato branco com até $2 \mathrm{~cm}$ de comprimento. Estas rochas afloram principalmente no vale do Córrego Sarapilheira, ao sul da serra do Jaci. O contato da sequência carbonática com as rochas do embasamento é brusco, apresentando, muitas vezes, características de região falhada, com a ocorrência de brechas, regiões cisalhadas e acúmulo de veios de quartzo e/ou carbonato;

○ Cálcio-Xisto: não aflorante, é descrito nos testemunhos de sondagem como grafita cálcio xisto preto, com intercalações milimétricas de níveis redobrados de rocha quartzocarbonática e com a grafita formando planos junto com a mica. As intercalações são formadas pela alternância de lâminas sub-centimétricas carbonáticas granoblásticas, equigranulares muito finas e puras, de cor cinza claro a cinza médio, e de lâminas quartzosas de granulação fina e de lâminas carbonosas com grafita e moscovita demarcando microdobras;

- Mármore Silicoso: é uma rocha de textura e estrutura complexa mostrando uma sucessão de camadas milimétricas de mármores de diversos tipos, contínuas ou interdigitadas, contendo quantidades variáveis de micas que conferem uma textura mais lepidoblástica à granoblástica dos níveis carbonáticos puros;

- Calcário Granoblástico: é uma rocha de coloração cinza, textura granoblástica equigranular, com granulação dominante de 0,2 a 0,4 mm sem orientação marcante;

- Mármore Silicoso: predominantemente esverdeado com porções esbranquiçadas

- Saprolito: magnesífero, de coloração escura, derivado de alteração das camadas mais superficiais do mármore silicoso;

- Filito Sericítico: de coloração amarelada, bastante finos e ocasionalmente recortados por veios de quartzo; 
○ Biotita Xisto: são encontrados quase que exclusivamente decompostos, mesmo nos testemunhos de sondagem, e mostram-se como xistos argilosos, avermelhados a amarronzados. $\mathrm{O}$ contato inferior com as rochas carbonáticas é transicional sendo, algumas vezes, encontrados calcifilitos na região de transição.

○ Quartzito: formam o topo da sequência que aflora na região e são brancos, finos, laminados por bandas sub-centimétricas micáceas. Estas rochas sustentam a serra do Ijaci. Os contatos entre todas as rochas carbonáticas/silicosas são transicionais, mostrando claramente um aumento gradual da quantidade de carbonato da base para o topo da sequência, e uma diminuição do conteúdo silicoso, no mesmo sentido (Ribeiro, A. et al. 2003).

- Sedimentos Terciários: preenchem zonas escavadas por paleodrenagens, composto por argilas variegadas, níveis de seixos arredondados e areias finas.

- Filitos Sericíticos: de coloração amarelada e ocasionalmente recortados por veios de quartzo.

O mapa geológico do entorno do município de Ijaci está apresentado na Figura 2-3. 


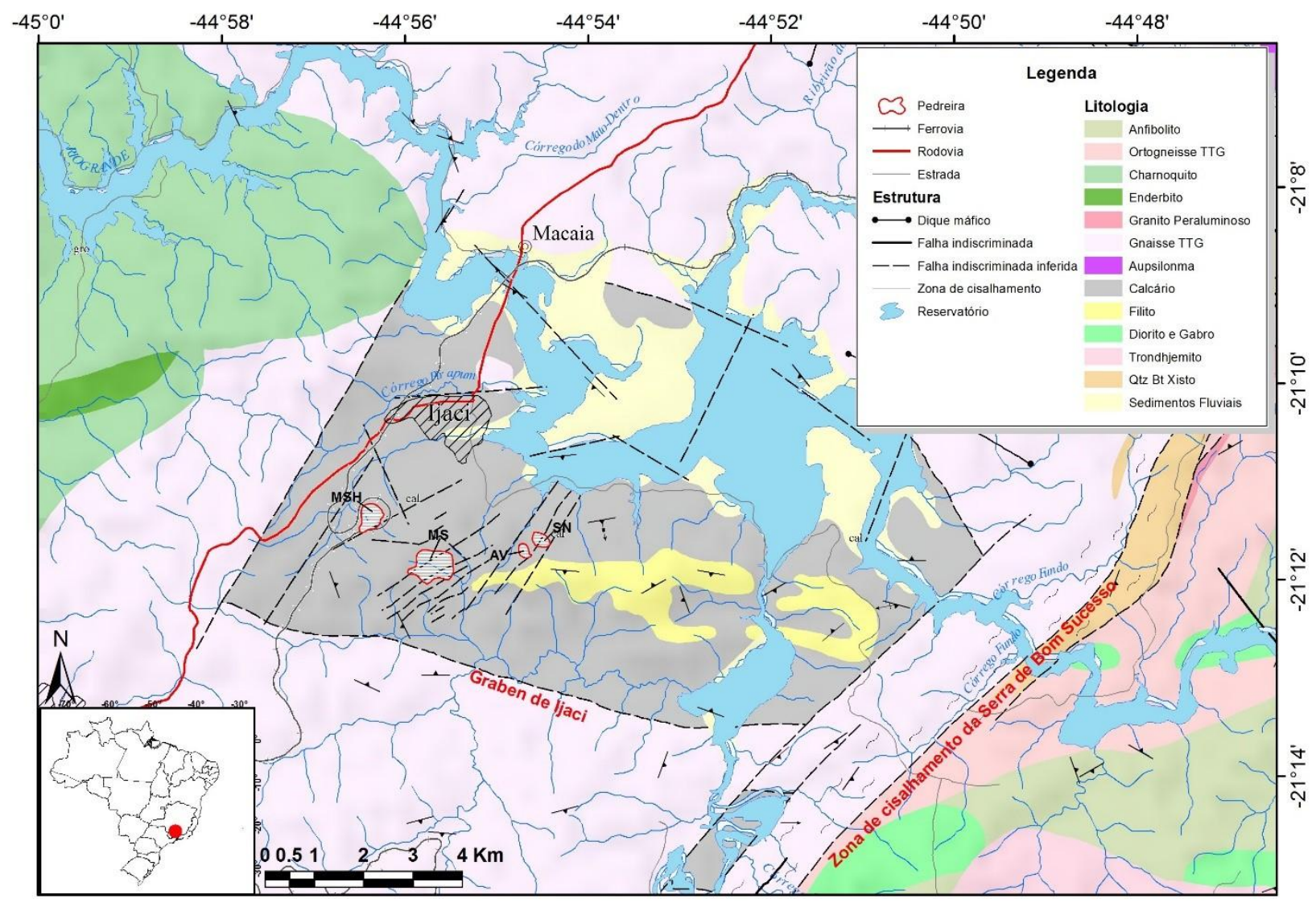

Figura 2-3 - Mapa geológico da área de estudo com indicação das minas MS (Mina Sul), MSH (Mina Santa Helena, AV (Mineração Alvarenga) e SN (Indústria de Cal SN) (Quéméneur et al., 2003).

\subsection{Evolução geológica e estrutural}

As rochas que compõem a região compreendida pela exploração de calcário tiveram origem com a sedimentação, provavelmente em ambiente marinho plataformal, sobre seu embasamento. A idade de sedimentação tem sido considerada por muitos autores como Mesoproterozóica (Campos Neto, 1990; Ribeiro et. al. 1990). Posteriormente este pacote sedimentar foi submetido a um evento metamórfico, responsável pela estruturação principal dos sedimentos, provavelmente de idade Brasiliana (Heilbron et. al. 1994). Associada a esta fase de deformação encontram-se dobras apertadas, localmente associadas à superfície de empurrão e dobras em bainha, consistentes com uma movimentação geral com vergência para Norte.

Posterior a fase compressiva, e como uma última etapa da evolução estrutural, ocorre a formação de zonas de cisalhamento de direção E-W e NNE, de caráter rúptil-dúctil, subparalelas às direções estruturais mais antigas encontradas no embasamento. Estas zonas de cisalhamento 
desempenham importante componente de movimentação normal, desempenhando papel decisivo na preservação dos metassedimentos (Dehler et. al. 1995)

\subsection{Geologia Estrutural Local}

As rochas supracrustais posicionam-se na forma de um monoclinal, de direção média N65E e mergulho em torno de $20^{\circ}$ para SE. Este arranjo simples é modificado por diversas falhas normais de direção N40W e N30-40E, subverticais, com rejeito decamétrico, que dividem as rochas em blocos altos e baixos. Algumas destas falhas estão assinaladas na Figura 2-3.

As falhas normais são importantes na definição da geometria dos corpos de calcário/mármore, pois são elas que definem blocos e limitam os corpos da rocha carbonática (Figura 5-1). A grande maioria das mineralizações de calcário nos arredores de Ijaci se posicionam em torno de uma destas falhas, de direção N35E. Estas falhas curvam os bandamentos e xistosidades nas rochas mais plásticas como os xistos, mas produzem poucas alterações nos calcários, ocasionalmente gerando brechas.

Alguns planos de falhamentos de empurrão foram observados na Mina Sul, sobrepondo calcários por sobre os biotita xistos (caso os materiais de alteração interpretados sejam mesmo calcários intemperizados). Estes empurrões têm atitude N50E/60SE, rejeito pequeno e devem ser "splays" menores de um sistema imbricado de falhamentos maiores. Um possível plano maior de empurrão seria o contato das supracrustais com o embasamento, ao sul da serra de Ijaci.

Os empurrões não parecem ser importantes na configuração espacial das rochas locais. Mas investigações mais detalhadas podem modificar esta afirmação. Uma mina abandonada foi observada a sul da Mina Sul onde afloram calcários provavelmente empurrados por sobre os quartzitos da serra.

Além desta importante inversão estratigráfica, os empurrões produzem apenas pequenas inversões de calcários sobre xistos que podem ser vistas na parte sul, talude oeste, da Mina Sul.

Diversos sistemas de fraturamento estão presentes nas minas Sul e Santa Helena e podem ser importantes não só como prováveis condutores de água, mas também como locais de concentração de ação intempérica, provocando o aprofundamento localizado do solo de capeamento. As principais famílias de falhas estão listadas na Tabela 2-1. 
Tabela 2-1 - Famílias de fraturas principais e secundárias. Fonte: Hidrovia (2003)

\begin{tabular}{|c|c|}
\hline Fraturas Principais & Fraturas Secundárias \\
\hline N20E/Vert & N30-50W/30-40SW \\
\hline N40-20W/70-90NE & N30E/55NW \\
\hline \multirow{3}{*}{} & NS/vert \\
\cline { 2 - 2 } & N70E/Vert \\
\cline { 2 - 2 } & EW/70N \\
\hline
\end{tabular}

As fraturas são fechadas ou abertas de poucos milímetros e raramente apresentam-se preenchidas por neominerais (quartzo e/ou calcita). As fraturas N20E/vert e N20-40W/70-90NE são as mais importantes, aparecendo com muita frequência, têm espaçamento em geral decimétrico a métrico, mas podem atingir localmente espaçamento centimétrico. 


\section{Capítulo 3 - Sismicidade}

\subsection{Introdução}

Neste capítulo é estudada a sismicidade de Ijaci, histórica e instrumental, com base nos dados de Berrocal et al (1984), da rede sismográfica brasileira (RSBR) e, mais recentemente, com base nos dados levantados desde a instalação da estação sismográfica FUN1. Discorre sobre a localização dos eventos e sobre o status atual da sismicidade na área. Antes, apresentamos uma seção sobre o fenômeno da sismicidade induzida.

\subsection{Sismicidade desencadeada}

Com o advento de novas tecnologias e consequente incremento na capacidade de detecção da sismicidade induzida, é observado no meio científico um aumento significativo no número de publicações, seja ela sobre a sismicidade desencadeada por grandes reservatórios (Simpson et al., 1988, Gupta (1976, 1992, 2002), por minas subterrâneas e a céu aberto (Simpson, 1986, Cook, 1976), ou até mesmo pela injeção/extração de fluidos (Henry Fountain, 2013). No Brasil, o maior número de publicações relacionadas à sismicidade induzida, está relacionado aos reservatórios de usinas hidroelétricas, muito provavelmente devido a obrigatoriedade de monitoramento destes empreendimentos (Assumpção, et al., 2002, Chimpliganond et al., 2007, Do Nascimento, 2002, Veloso, 1992b, Veloso et al. 1995, Barros, 2001).

O estudo de sismicidade antropogênica teve início quando foram sentidos os primeiros terremotos em Johannesburg, em 1894 (McDonald, 1982); em 1908 estes eventos foram associados à mina de ouro Witwatersrand, que tivera seu início de operação em 1886 (Cook et al., 1965).

Terremotos induzidos por reservatórios artificiais foram reportados pela primeira vez por Carder (1945) no Lago Mead, Estados Unidos, que iniciou seu enchimento em 1935. Um ano após, foi registrado um terremoto de magnitude $5 \mathrm{mb}$. Nos anos posteriores se tornou claro que a magnitude e frequência de pequenos sismos locais apresentavam relação com fatores antrópicos. Evans (1966) reportou que a injeção subterrânea de fluidos sob alta pressão em rochas précambrianas em Rocky Mountain Arsenal, desencadeava sismicidade. Gupta (1976) e Rastogi 
(1990) reportaram a correlação sismicidade e a elevação do nível d'água no reservatório de Koyna, Índia.

Alguns pesquisadores indicam que o aumento da pressão de poros em profundidade pode estar relacionado ao aumento da pressão elástica ou devido ao processo de difusão (Snow, 1972; Bell and Nur, 1978; Simpson, 1976; Roeloffe, 1988).

Talwani (2000) descreve dois tipos de sismicidade associada ao enchimento de reservatórios: Sismicidade induzida, quando a sismicidade ocorre devido a substancial mudança nos esforços crustais ou nas pressões de poro a partir de seu ambiente estável; e sismicidade desencadeada, quando a crosta se encontra suficientemente próxima do estado de ruptura, devido a processos tectônicos naturais, e que apenas uma pequena mudança de tensão ou pressão de poro dispara a sismicidade.

Apenas um pequeno percentual de reservatórios é capaz de desencadear sismicidade, de acordo com Gupta (1992 e 2002) e Assumpção et al. (2002) um total de 95 casos de sismicidade foram relacionados, do total de centenas de reservatórios ao redor do mundo. Deste total, 16 casos foram reportados no Brasil (Assumpção et al., 2002; Chimpliganond et al., 2007; Ferreira et al., 2008). Uma atualização desse número dá conta de 24 casos comprovados de SIR (Barros \& Fontenele (2012).

Referências mais recentes da SIR, apresentam respectivamente 115 casos no mundo (Klose, 2012) e 26 no Brasil (Barros et al., 2016).

Apesar da sismicidade associada a reservatórios e a injeção de fluidos serem relativamente comuns, terremotos associados exclusivamente a poços artesianos são extremamente raros. Assumpção et al., $(2007,2010)$ mostraram que a abertura de poços artesianos profundos e as variações de pressão em aquífero profundo foram fatores decisivos na geração de atividade sísmica no município de Bebedouro, SP, na Bacia do Paraná.

\subsection{Sismicidade prévia ao reservatório}

O mapa da Figura 3-1 mostra a sismicidade observada desde 1824, em uma área circular de raio $100 \mathrm{~km}$ a partir do epicentro do sismo de Ijaci de 14 de agosto de 2011 (estrela vermelha do mapa), anteriormente à instalação das grandes minas de exploração de calcário (minas operadas pela Camargo Corrêa S.A.) e formação do lago da UHE Funil. Apesar do mapa apresentar a sismicidade distribuída de forma mais ou menos uniforme, apresentando a porção norte mais 
sísmica, podemos destacar quatro áreas principais de ocorrência de sismicidade: Carmo do Cajuru, Itaguara, Bom Sucesso e Formiga.

Em Carmo do Cajuru, sismos induzidos pelo reservatório são observados desde 1970 (Berrocal et al. 1983), o evento de maior magnitude, 3,7 na Escala Richter, foi percebido com intensidade VI na Escala Mercalli Modificada (MM) e ocorreu em 23 de janeiro de 1972. Este reservatório tem o histórico de sismicidade mais longo no Brasil e até hoje desencadeia sismos. O reservatório é formado por uma barragem de apenas 22 metros de altura, represa $0.2 \mathrm{~km}^{3}$ de água e está localizado a exatos 100 km da estação FUN1 (Figura 3-1).

Em Bom Sucesso, aconteceu o sismo de maior magnitude na área circular representada na Figura 3-1: 4,0 na Escala Richter, às $8 \mathrm{~h} 10 \mathrm{~m}$ do dia 31 de janeiro de 1920. Este sismo foi percebido com uma intensidade V (MM). O primeiro evento de Bom Sucesso reportado no livro de Berrocal e outros (1983) aconteceu em 1840, foi sentido com uma intensidade IV (MM) e a partir da área afetada por este sismo, estimou-se uma magnitude microssísmica de 3,0. Não existem informação sobre a data e horário para este evento. Em Bom Sucesso foram sentidos vários sismos em várias datas, como por exemplo, nos anos de 1901, 1919, 1920, 1935, 1977 e 2005. Esta área sísmica está localizada a $25 \mathrm{~km}$ do epicentro do sismo de Ijaci.

Itaguara, localizada a aproximadamente $100 \mathrm{~km}$ do epicentro do sismo de Ijaci, apresentou entre 27/12/1993 e 11/08/1994 um surto sísmico, tendo sido registrados quatorze eventos, dez dos quais com magnitudes próximo a 3,0. O maior, com magnitude de 3,6, aconteceu em 27/12/1993, às $22 \mathrm{~h} 48 \mathrm{~m}$.

A quarta área sísmica apresentada na Figura 3-1 está localizada a NW da estação FUN1, em Formiga, cerca de $80 \mathrm{~km}$ da estação. O primeiro sismo detectado ocorreu às $02 \mathrm{~h} 29 \mathrm{~m}$ de 19/12/1980 e teve uma magnitude de 2,6. Em 1993, nos meses de março e maior, foram detectados três eventos, dois dos quais com magnitude 3,0. Em 30/12/2003 foi registrado um sismo de magnitude 3,2 , às $00 \mathrm{~h} 15 \mathrm{~m}$.

De forma conclusiva, historicamente não se tem notícia de ocorrências sísmicas próximas a Ijaci. Entretanto, é bem conhecido o histórico de sismicidade de Bom Sucesso, localizado a cerca de $25 \mathrm{~km}$ de Ijaci e com os primeiros relatos de sismicidade datando de 1840. 


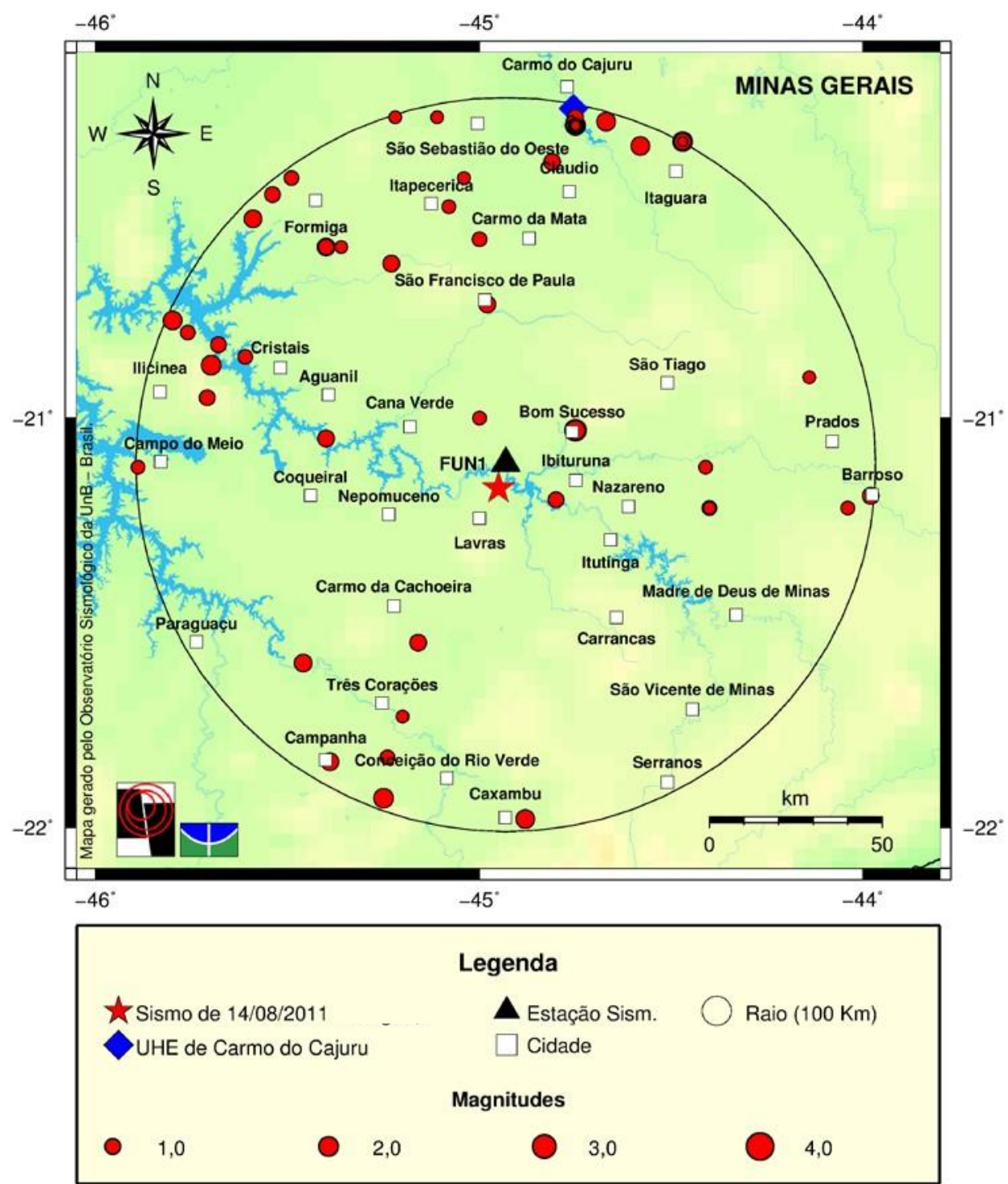

Figura 3-1 - Mapa da sismicidade observada em uma área de $100 \mathrm{~km}$ de raio a partir do epicentro do sismo de 14 de agosto de 2011, indicado pela estrela vermelha. Os círculos vermelhos estão de acordo com as magnitudes (veja legenda). Fonte: Base de Dados da Sismicidade Brasileira desde 1824.

\subsection{Evento principal de 14 de agosto de 2011}

O evento principal registrado em Ijaci ocorreu às $13 \mathrm{~h} 50 \mathrm{~m}$ (hora local) do dia 14 de agosto de 2011 e foi bem registrado pela estação FUN1 (Figura 3-2), e por outras 11 estações da Rede Sismográfica Brasileira (RSBR), quatro da Universidade de São Paulo (USP), Quatro do Observatório Nacional (ON) e outras três do Observatório Sismológico (OBSIS) (registros na Figura 3-3). As estações RSBR estão localizadas a distancias entre 200 e $600 \mathrm{~km}$ do epicentro (Figura 3-4). Informações microssísmicas dão conta de que o sismo foi sentido mais fortemente 
pela população da cidade de Ijaci, para o qual foi estimado magnitude de 3,2 na Escala Richter e intensidade IV-V na Escala Mercalli Modificada (MM).

Inicialmente o sismo foi localizado com o programa LocSat (Miljanovic, 2007), com o modelo de velocidades NewBr (Assumpção et al, 2010) usando os dados das 12 estações do mapa representado pela Figura 3-4. O epicentro foi localizado a cerca de três quilômetros a oeste da cidade de Ijaci, $10 \mathrm{~km}$ de Lavras, $21 \mathrm{Km}$ de Bom Sucesso e $175 \mathrm{~km}$ de Belo Horizonte.

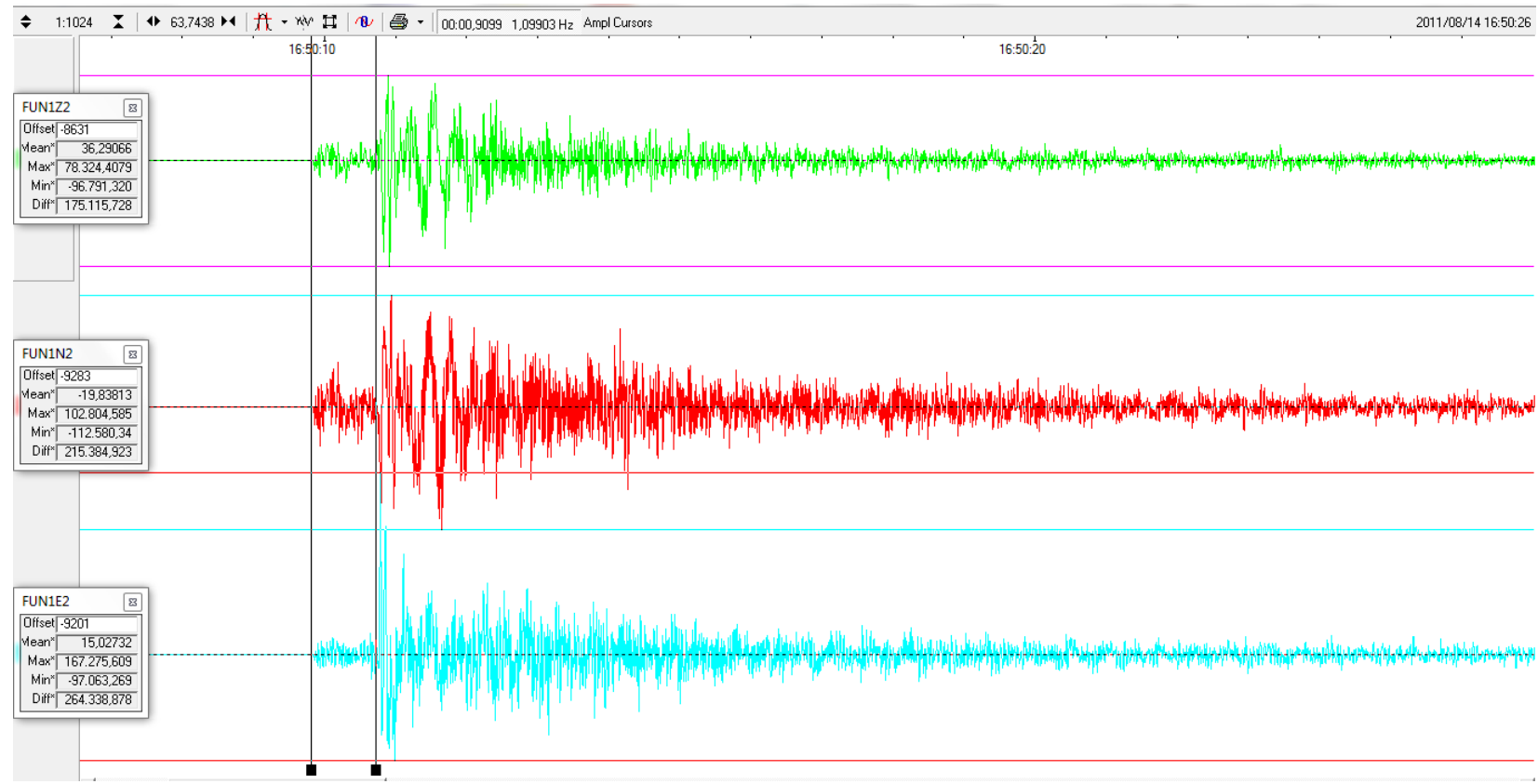

Figura 3-2 - Registro das formas de ondas do sismo de Ijaci de 14 de agosto de 2011, às 13h50m (local). De cima para baixo são mostrados os movimentos de partículas do chão nas direções vertical, norte-sul e leste-oeste. As duas barras verticais indicam, da esquerda para a direita, as marcações das fases $P$ e S, respectivamente. 


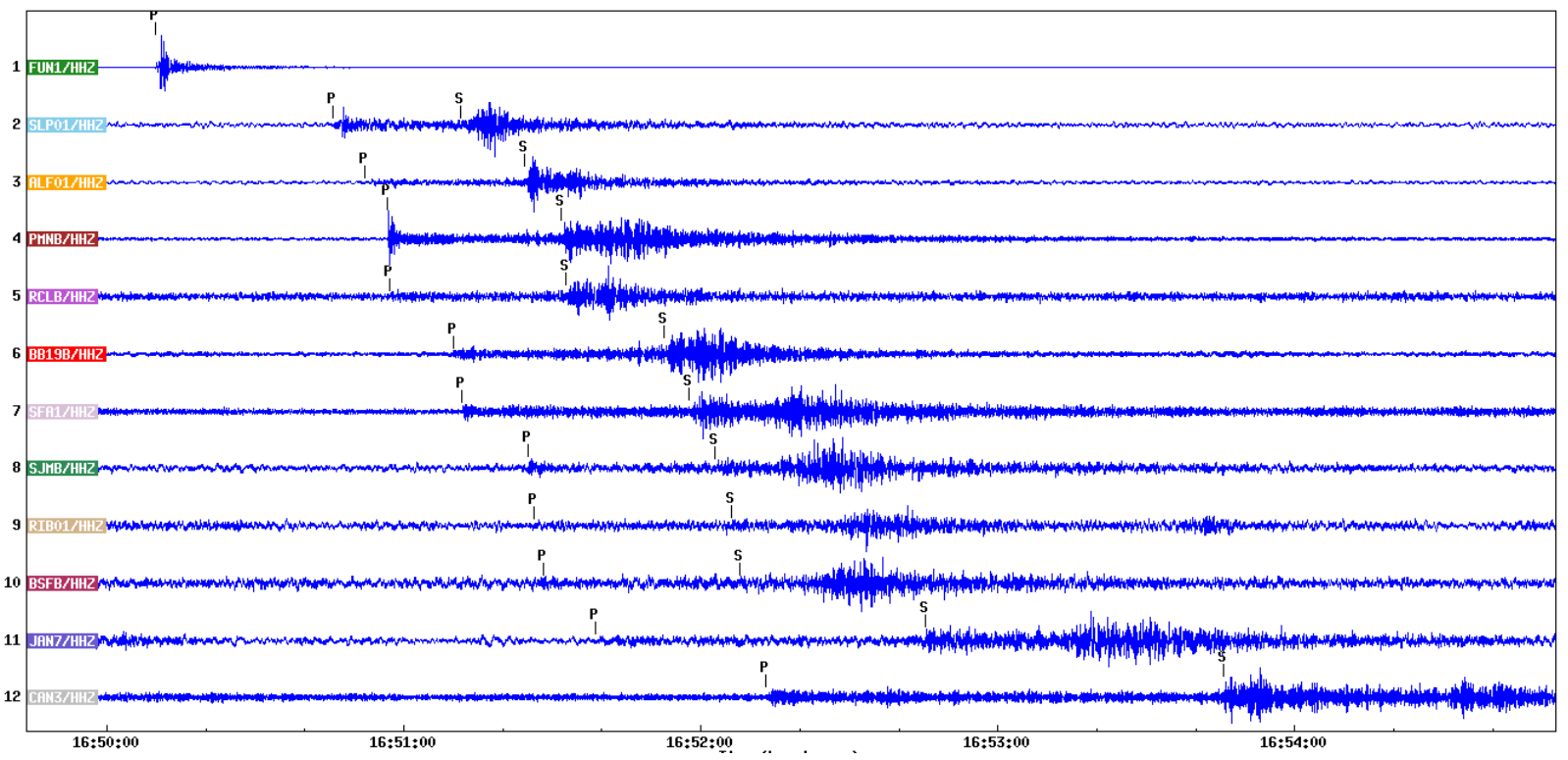

Figura 3-3 - Sismograma do principal evento de Ijaci de 14v de agosto de 2011 (componentes verticais) registrado pelas doze estações apresentadas na Figura 3-4. São também apresentadas as marcações das fases P e S em ordem crescente de chegada. O primeiro traço se refere a estação FUN1. 


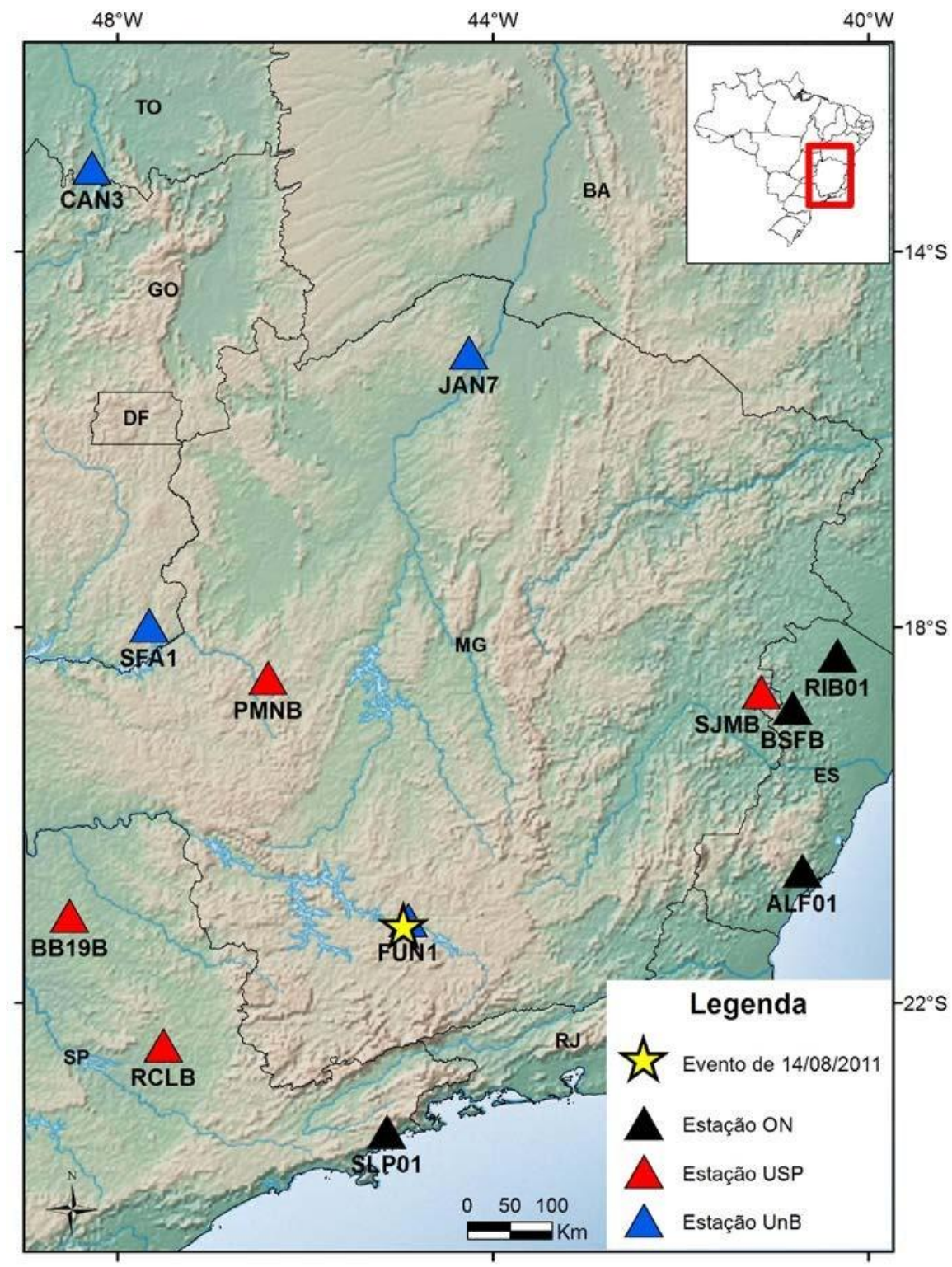

Figura 3-4 - Mapa com a localização das estações sismográficas (triângulos) que foram utilizadas para determinar o hipocentro do sismo de Ijaci ocorrido em 14 de agosto de 2011, às 16h50m10.66s (UTC); 13h50m10.66s (horário local). Note que a estação FUN1 está localizada embaixo da estrela amarela que indica o epicentro do evento. Estações sismológicas do Observatório Nacional (ON) são indicadas pelos triângulos negros, as estações da USP, pelos triângulos vermelhos e em azul as estações operadas pela UnB.

\subsubsection{Localização epicentral do evento principal}

Considerando as longas distâncias epicentrais do evento de Ijaci para as estações da RSBR, bem como a grande proximidade desse evento da estação FUN1, resolveu-se determinar o seu epicentro com dados de apenas FUN1. O epicentro do sismo foi localizado usando a razão entre 
as amplitudes do movimento do chão nas direções norte-sul e leste-oeste para determinar o backazimute, a distância epicentral foi determinada pela diferença dos tempos de percursos entre as ondas $\mathrm{S}$ e $\mathrm{P}(\mathrm{tS}-\mathrm{tP})$. Neste caso foi usado o código HYPOCENTER (Lienert, 1994) do pacote SEISAN (The Earthquake Analysis Software), Havskov e Ottomöller, 2016. A diferença na localização pelos dois métodos e de cerca de 2,0Km (Figura 3-5)

A profundidade foi fixada na superfície. Utilizou-se um modelo de semi-espaço com razão $\mathrm{Vp} / \mathrm{Vs}=1,72$, determinado pelo diagrama Wadati (Figura 3-6). Como velocidade do semi-espaço, utilizou-se $\mathrm{Vp}=6,0$, considerando que as estruturas sísmicas estão no Cráton do São Francisco.

A Figura 3-7 apresenta o movimento de partículas (2D) nas direções, da direita para a esquerda, horizontal (norte-sul) x vertical (z), horizontal (leste-oeste) x vertical (z) e no plano horizontal.

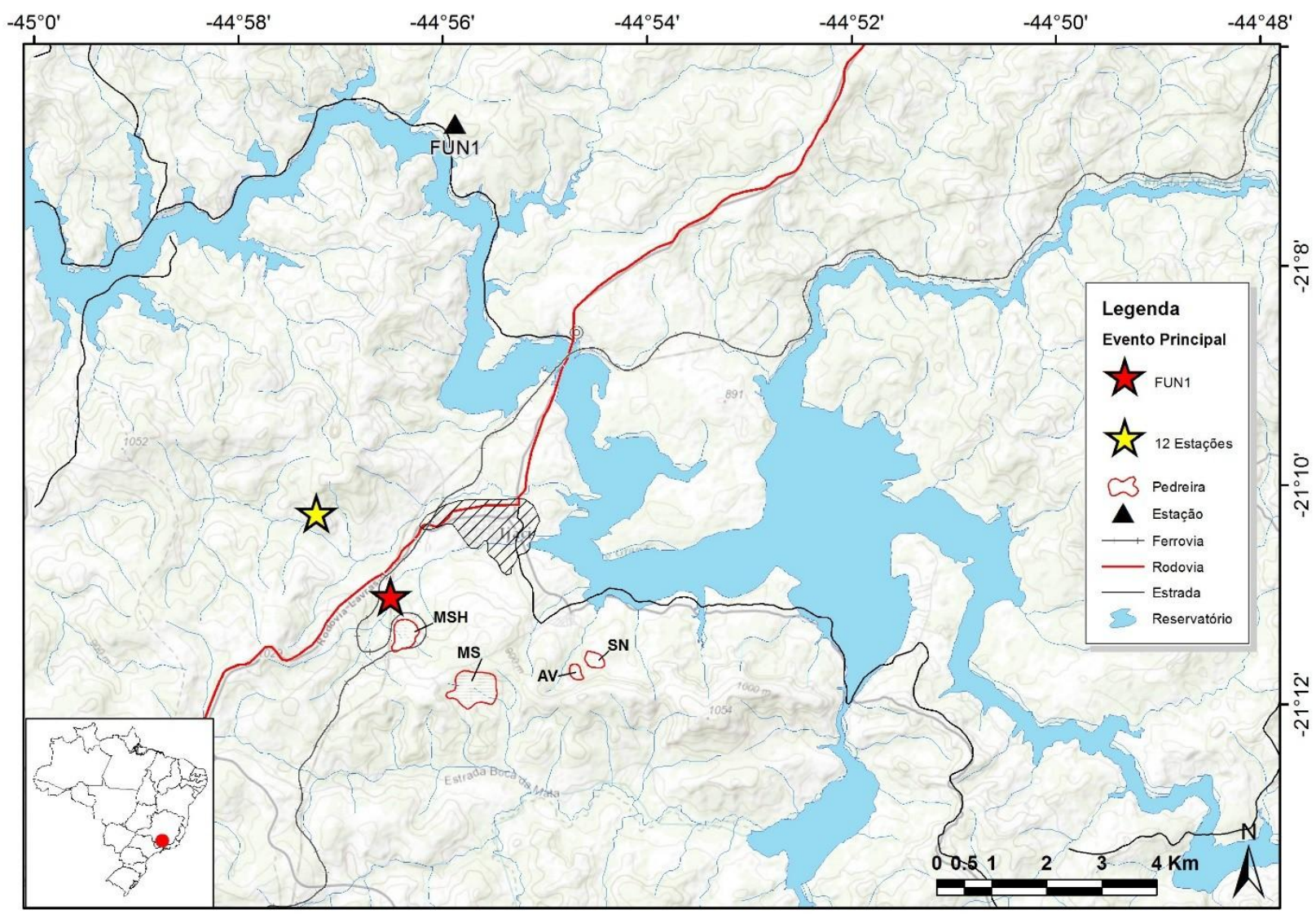

Figura 3-5 - Mapa com as localizações epicentrais feita com a rede regional de 12 estações (estrela amarela) e com dados da estação FUN1 (estrela vermelha). É apresentado também a localização da estação FUN1 (triângulo preto). As pedreiras (MS - Mina Sul, MSH - Mina Santa Helena, AV - Mineração Alvarenga e SN-Indústria de Cal SN) são também indicadas pelas poligonais vermelhas. 


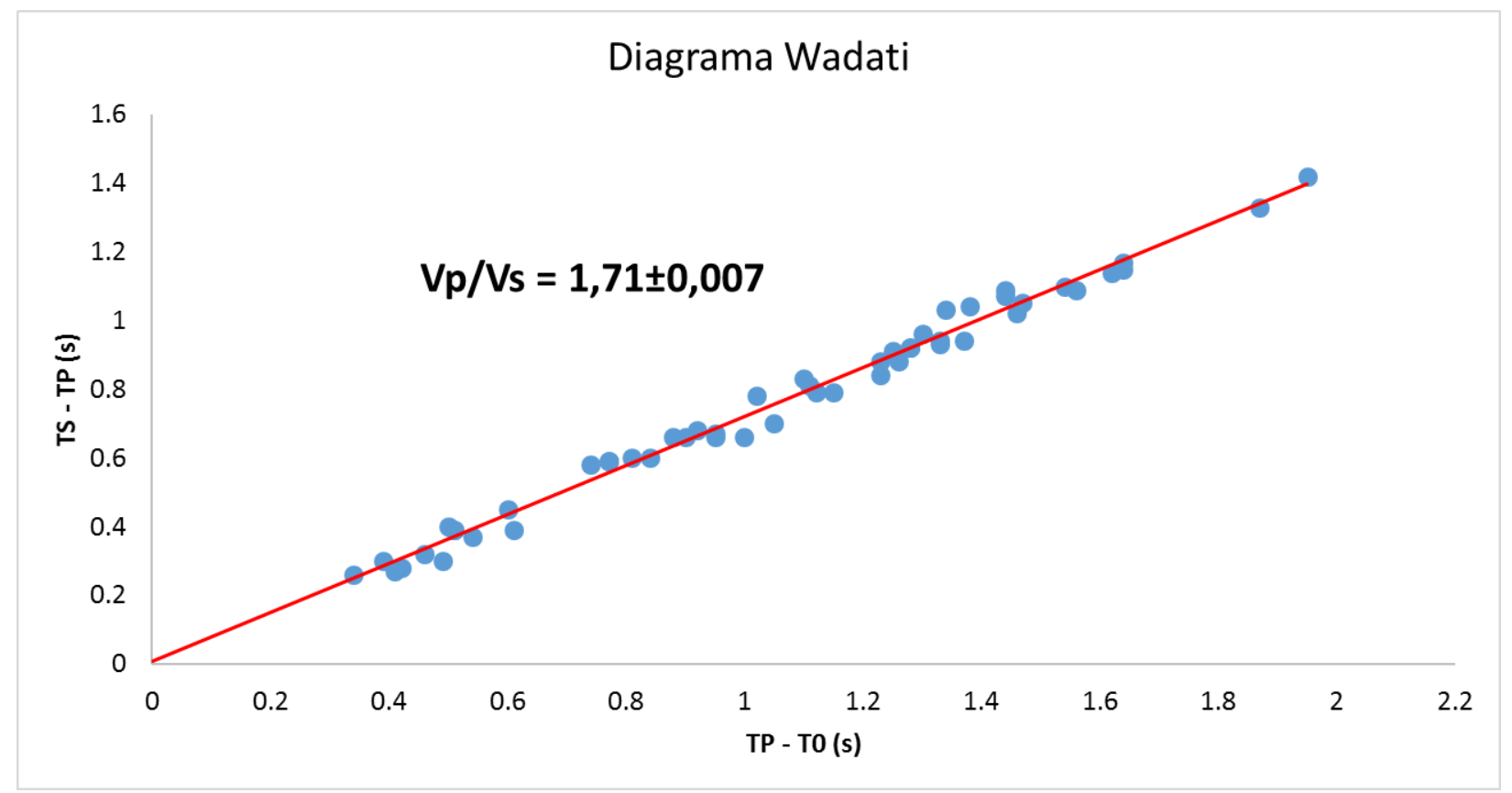

Figura 3-6 - Diagrama Wadati gerado a partir dos melhores sismos de Ijaci. Na vertical estão as diferenças no tempo de chegada das fases P e S (Ts-Tp) e nas abcissas as diferenças entre os tempos de P e o tempo de origem. 


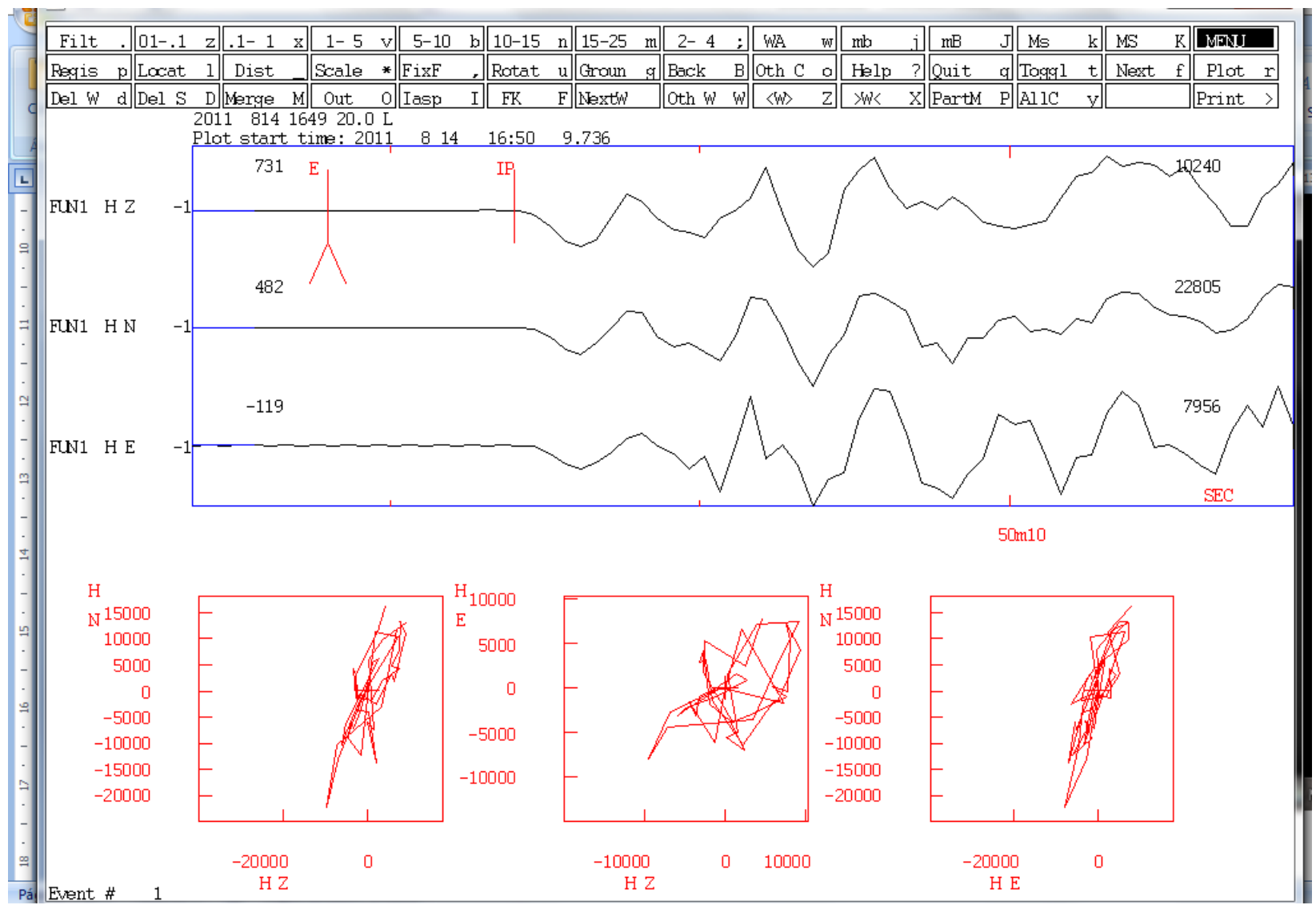

Figura 3-7 - Sismogramas do evento de Ijaci/MG, de 14/08/2011 nas direções vertical, norte-sul e leste-oeste (traços superiores) e movimento de partículas nas direções Norte-Vertical, Leste-Vertical e Horizontal-Horizontal. 


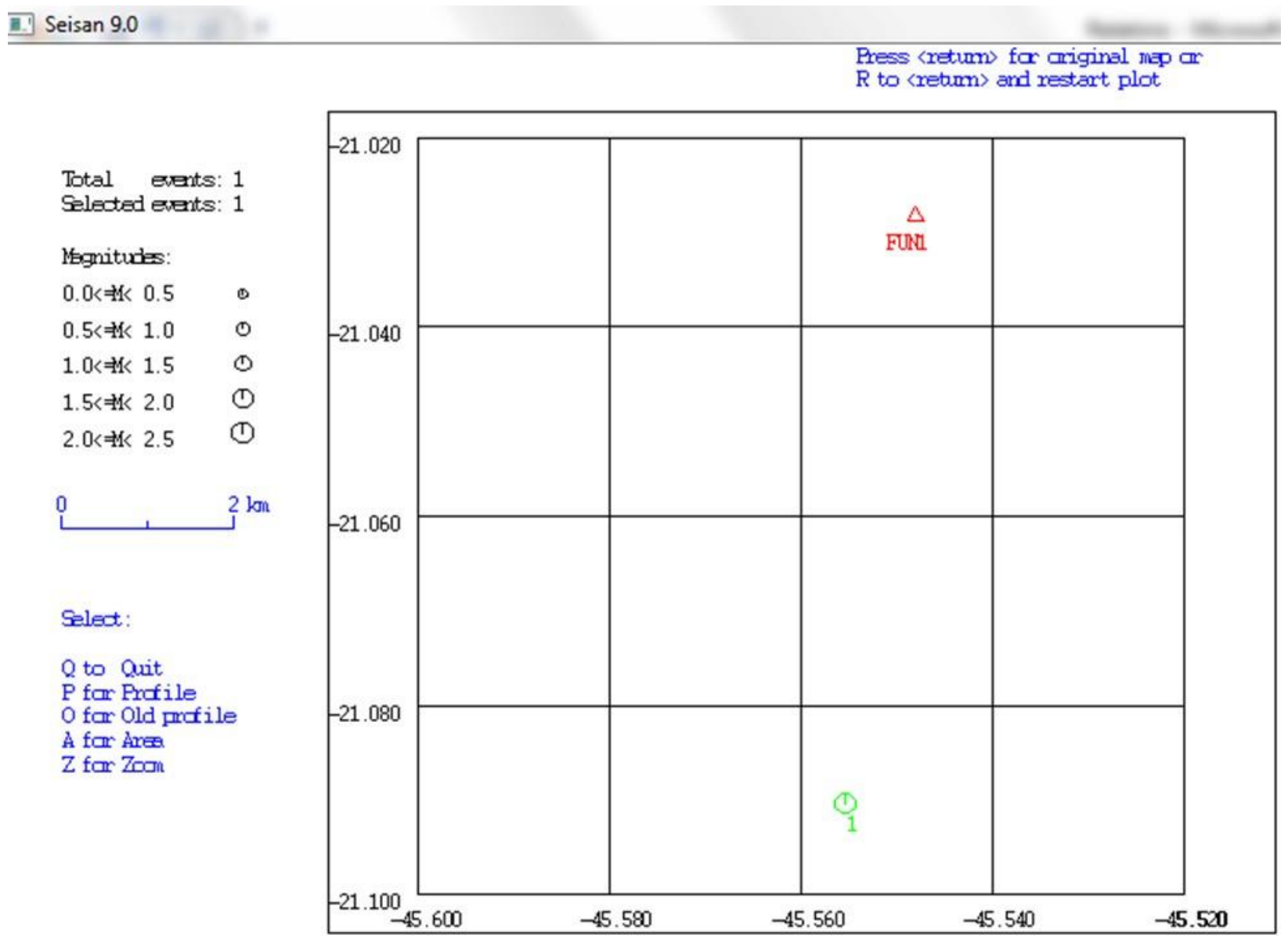

Figura 3-8 - Localização epicentral do evento de 14/08/2011 com uma razão Vp/Vs=1,72 e profundidade inicial (h) de $1 \mathrm{~km}$. Coordenadas geográficas de $45.567^{\circ}$ Longitude oeste e $21.095^{\circ}$ de Latitude sul. 


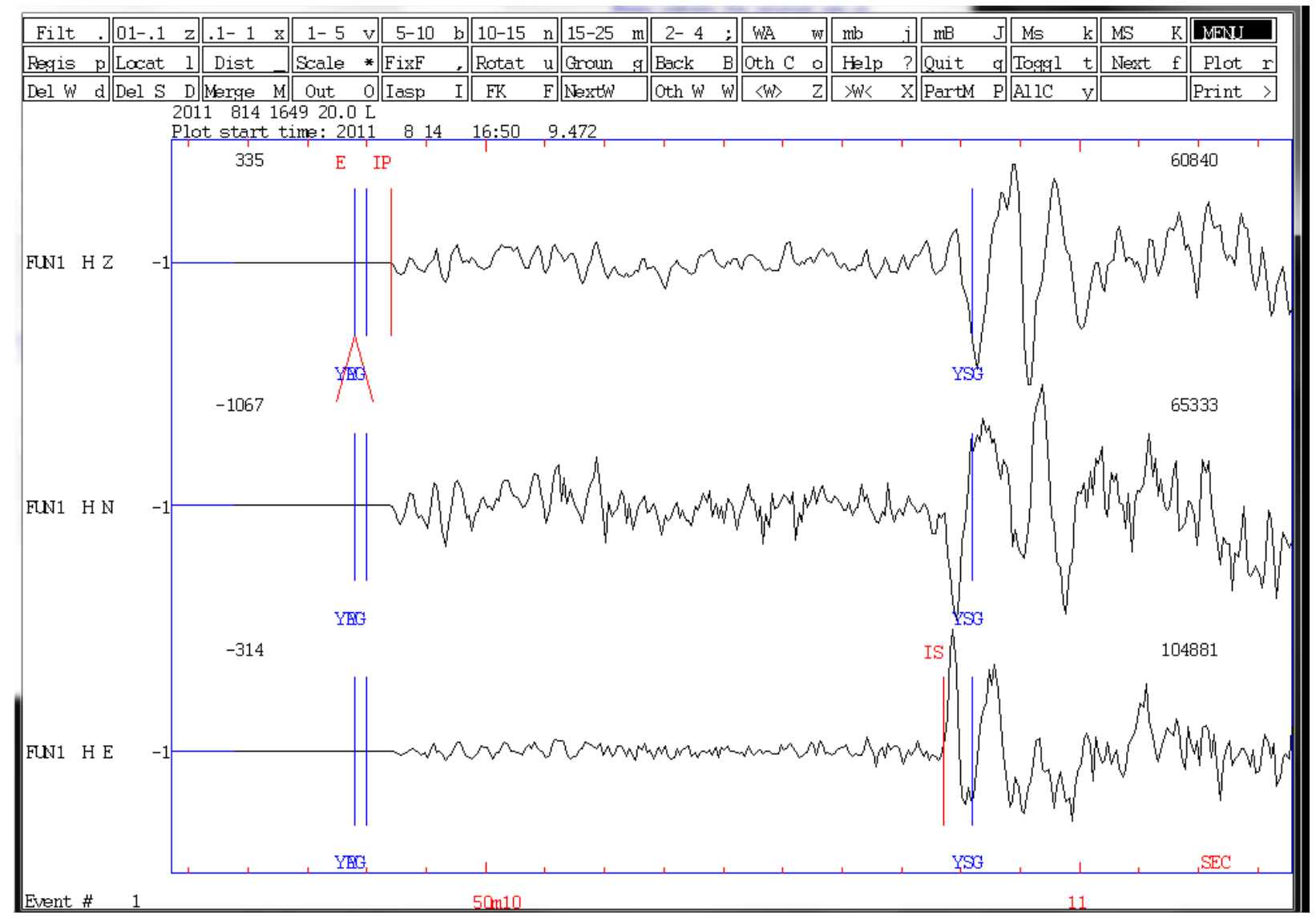

Figura 3-9 - Registro das formas de onda do evento de Ijaci, de 14/08/2011, com as marcações das fases $P$ (na vertical) e S (na horizontal leste-oeste). Observe que a máxima amplitude (104881 contagens digitais) da fase S está na componente LesteOeste, o que era de se esperar, considerando a localização epicentral do evento na Figura 3-8, quase a sul de FUN1. Portanto, a direção de vibração de partículas para a onda $S$, perpendicular à direção de propagação, neste caso a componente Norte-Sul rotacionadas de 15 graus.

A rotação das componentes horizontais norte-sul e leste-oeste nas direções radial e tangencial está mostrada na Figura 3-10. Como se observa, a amplitude da onda S melhorou na componente tangencial, cuja amplitude aumentou de 104.881 (Figura 3-9) contagens digitais (na componente leste-oeste) para 113.312 contagens digitais, na componente tangencial. Isso mostra a consistência da localização epicentral apresentada na Figura 3-8 e na Figura 3-5 (estrela amarela). 


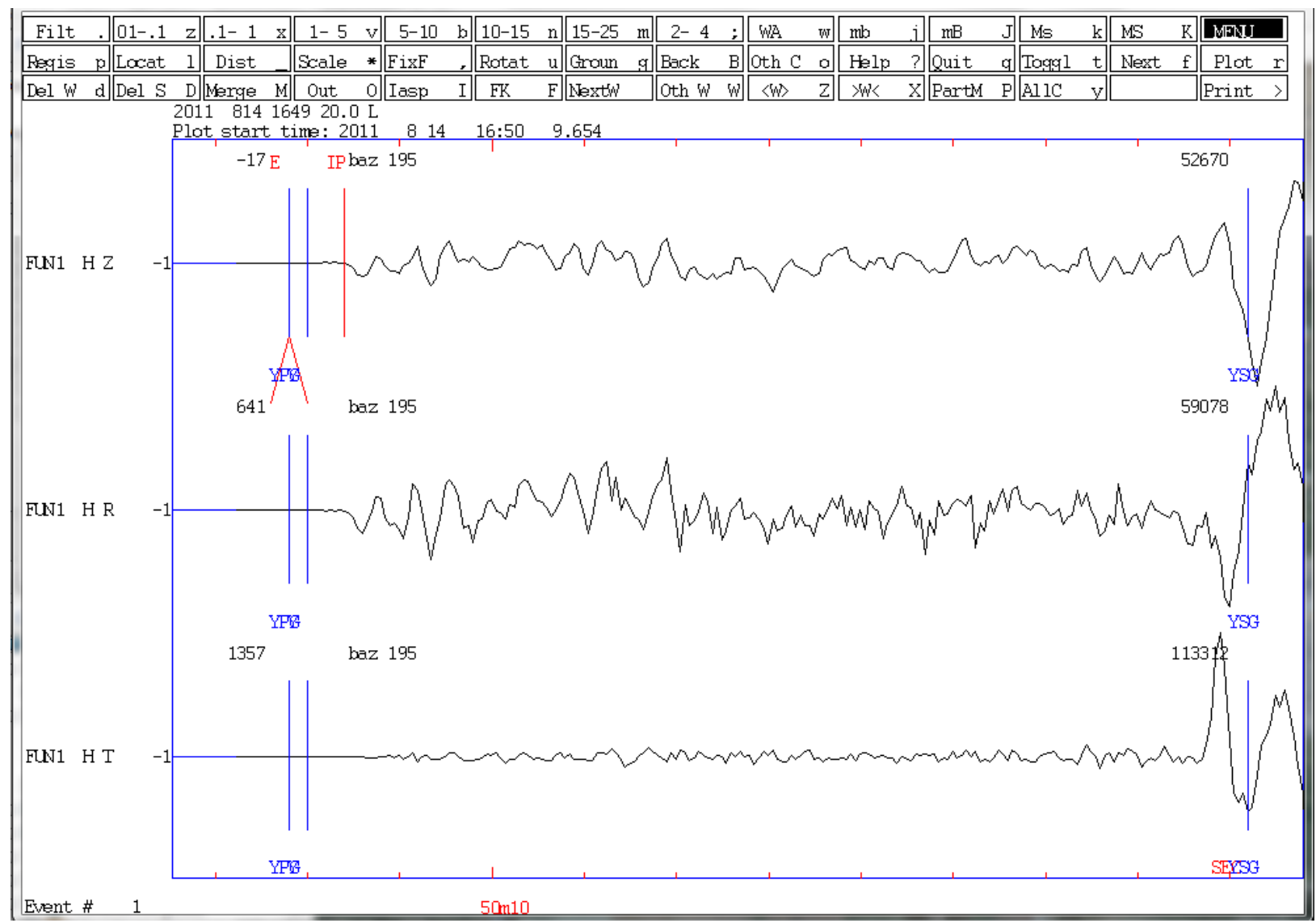

Figura 3-10 - Rotação das componentes horizontais norte-sul e leste-oeste nas direções radial (traço $H$, centro) $e$ tangencial (traço H T, inferior). Observe que o backazimute é de 195 graus, portanto, as componentes horizontais foram rotacionadas no sentido horário de 15 graus.

\subsubsection{Rede sismográfica local e aquisição de dados}

Com a ocorrência do sismo de 14 de agosto de 2011 e devido à possibilidade de o mesmo ter sido desencadeado pelo reservatório de Funil, decidiu-se pela realização de estudos mais aprofundados com o objetivo de conhecer melhor os parâmetros da sismicidade e a partir de aí estabelecer a natureza desse evento.

A rede sismográfica foi instalada em duas etapas. A primeira entre 19 e 23 de dezembro de 2011 (estações FUN2, FUN3, FUN4, FUN5 e FUN6), a segunda entre 16 e 21 de janeiro de 2012, estação FUN7 e substituição dos instrumentos da estação FUN4, que apresentaram problemas. Portanto, a partir de 22 de janeiro a rede sismográfica da UHE de Funil passou a operar com sete estações, considerando a estação permanente FUN1 e as seis estações provisórias. A Figura 3-11 mostra o mapa com a distribuição das estações, à montante e na margem direita do reservatório, 
localização do epicentro do evento de 14/08/2011, bem como as localizações das quatro pedreiras existentes na área (MSH, MS, AV e SN).

Devido ao caráter temporário da rede sismográfica, os sismômetros de todas as estações foram acondicionados no interior de um caixote de madeira. Um tubo de PVC acondicionou o sismômetro e o abrigo foi coberto com lona. Para evitar efeitos de gradientes de temperatura entre o dia e a noite, as caixas foram cobertas com telhas e os instrumentos cobertos com areia. A areia tem a função de manter o sensor em uma temperatura mais ou menos constante e com isso, evitar a geração de ruídos de longos períodos, já que os sismômetros são de banda larga.

Somente a estação FUN2 foi instalada sobre sedimentos inconsolidados, as demais foram instaladas sobre rocha fresca aflorante.

Os instrumentos, foram produzidos pela GURALP SYSTEMS LTD e operam na banda de 30s a 100Hz. Os dados foram amostrados a uma taxa de 100sps. A rede temporária foi desmobilizada em 25 de maio de 2012, restando no local apenas a estação permanente FUN1. Durante o período de funcionamento da rede, mais de 1000 eventos foram detectados, destes 500 foram localizados, conforme Tabela 3-1. 


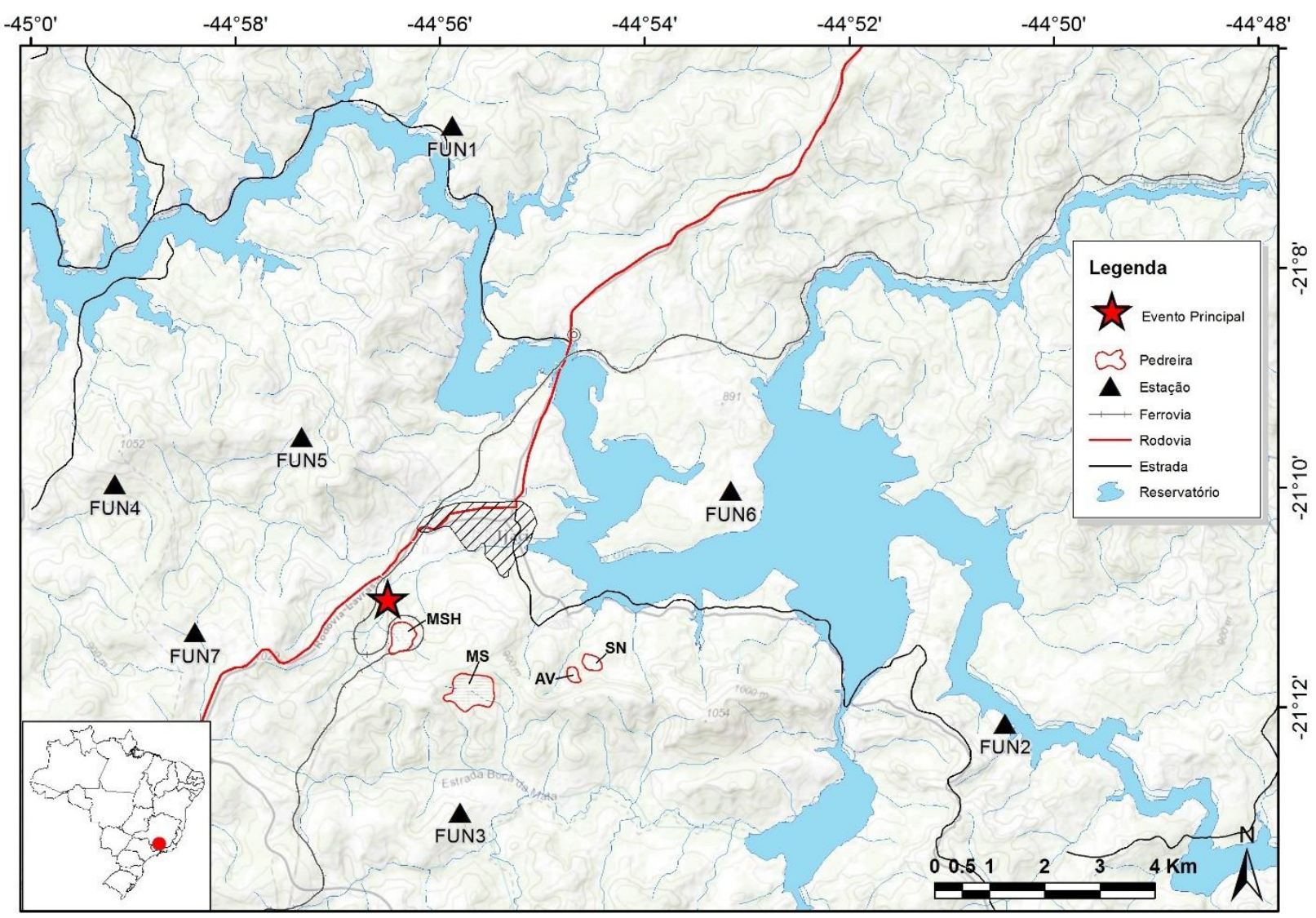

Figura 3-11 - Mapa com a localização da rede sismográfica local (triângulos pretos) instalada após o evento principal de 14/08/2011 (estrela vermelha). É também apresentado a localização das pedreiras (MS - Mina Sul, MSH - Mina Santa Helena, AV - Mineração Alvarenga e SN - Indústria de Cal SN), indicadas pelas poligonais vermelhas.

Tabela 3-1 - Evolução mensal da sismicidade (natural e artificial) observada próxima à cidade de Ijaci/MG, entre 14 de agosto de 2011 e janeiro de 2012

\begin{tabular}{|c|c|c|c|c|}
\hline Mês & $\begin{array}{c}\text { Eventos } \\
\text { detectados }\end{array}$ & $\begin{array}{c}\text { Localizados } \\
\text { (detonações) }\end{array}$ & $\begin{array}{c}\text { Localizados } \\
\text { (tectônico) }\end{array}$ & $\begin{array}{c}\text { Localizado } \\
\text { (total) }\end{array}$ \\
\hline Ago/2011 & 21 & 8 & 12 & 20 \\
\hline Set/2011 & 83 & 9 & 42 & 51 \\
\hline Out/2011 & 110 & 8 & 48 & 56 \\
\hline Nov/2011 & 178 & 16 & 41 & 57 \\
\hline Dez/2011 & 182 & 13 & 18 & 31 \\
\hline Jan/2012 & 135 & 22 & 21 & 43 \\
\hline
\end{tabular}




\subsubsection{Análise da sismicidade detectada pela rede local}

Foram analisados os dados adquiridos entre 14 de agosto de 2011, data do evento principal de Ijaci, e 25 de maio de 2012, quando a rede local foi desmobilizada, restando apenas FUN1 para monitoramento local. Durante este período, 1020 eventos foram detectados e, aproximadamente, 500 foram localizados, destes 241 foram considerados como artificiais (detonações) e 276 como eventos tectônicos. Eventos classificados como artificiais (detonações) tiveram datas e horários comparadas com as informações de detonações presentes nas listas fornecidas pelas pedreiras. A maior parte dos eventos foi localizado com dados de uma estação, especialmente FUN1 (Tabela 3-2). As principais pedreiras da região são apresentadas na Figura 3-11. MSH - Mina Santa Helena e MS - Mina Sul são pedreiras de maior porte e pertencentes a Intercement, subsidiária do Grupo Camargo Correia, AV - Mineração Alvarenga e SH - Indústria de Cal SN são pedreiras de menor porte e efetuam volume reduzido de detonações. A diferenciação entre eventos tectônicos e artificiais foi dificultada devido as proximidades de localização de fontes e magnitudes das formas de onda semelhantes. A Tabela 3-2 apresenta o número de eventos localizados e o número de estações utilizadas.

As localizações foram determinadas com o código HYPOCENTER (Lienert, 1994) executado em ambiente SEISAN (The Earthquake Analysis Software), Havskov e Ottomöller, 2016, utilizando um modelo de velocidade de semi-espaço determinado pelo diagrama Wadati.

Utilizou-se o método desenvolvido por Barros et al., 2016 para discriminar os registros das detonações próximas a Ijaci dos sismos com localização e magnitude semelhantes.

Tabela 3-2 - Relação de eventos localizados e seu respectivo número de estações

\begin{tabular}{|c|c|c|c|}
\hline Eventos localizados e número de estações & Detonação & Tectônico & Total \\
\hline Eventos localizados por 1 ou mais estações & 241 & 276 & 517 \\
\hline $\begin{array}{l}\text { Eventos localizados por } 2 \text { ou mais estações } \\
\text { Eventos localizados por } 3 \text { ou mais estações }\end{array}$ & 144 & 87 & 251 \\
\hline $\begin{array}{l}\text { Eventos localizados por } 4 \text { ou mais estações } \\
\text { Eventos localizados por } 5 \text { ou 6 estações }\end{array}$ & 77 & 50 & 156 \\
\hline
\end{tabular}




\subsubsection{Confiabilidade da localização dos epicentros}

A precisão da localização dos epicentros, além de outros fatores, depende do número de estações que registraram os eventos, distâncias entre estações e o epicentro e o valor de gap azimutal na cobertura das estações. Eventos detectados por várias estações próximas e epicentros localizados em uma área circunscrita por uma rede de estações geralmente apresentam localização mais precisa. Apesar de terem sido localizados um grande número de eventos, ambos naturais e artificiais, neste trabalho foram considerados os casos onde a precisão da localização do epicentro está entre 1 e $2 \mathrm{~km}$. Desta forma, foram impostas restrições apropriadas para a obtenção de eventos com maior segurança e confiabilidade em sua localização. Sendo assim, os epicentros de eventos naturais e artificiais foram plotados como se segue.

\subsubsection{Localização epicentral}

Foram selecionados vinte e cinco (25) eventos naturais detectados por quatro ou mais estações, com um gap azimutal máximo de $250^{\circ}$ e distância mínima de 3,0km. A Figura 3-12 apresenta os epicentros dos vinte e cinco (25) eventos tectônicos (círculos vermelhos). Os eventos 1, 2, 3 e 4, indicados pelas estrelas azuis, se referem aos quatro principais eventos de Ijaci e estão apresentados na Tabela 3-3. 


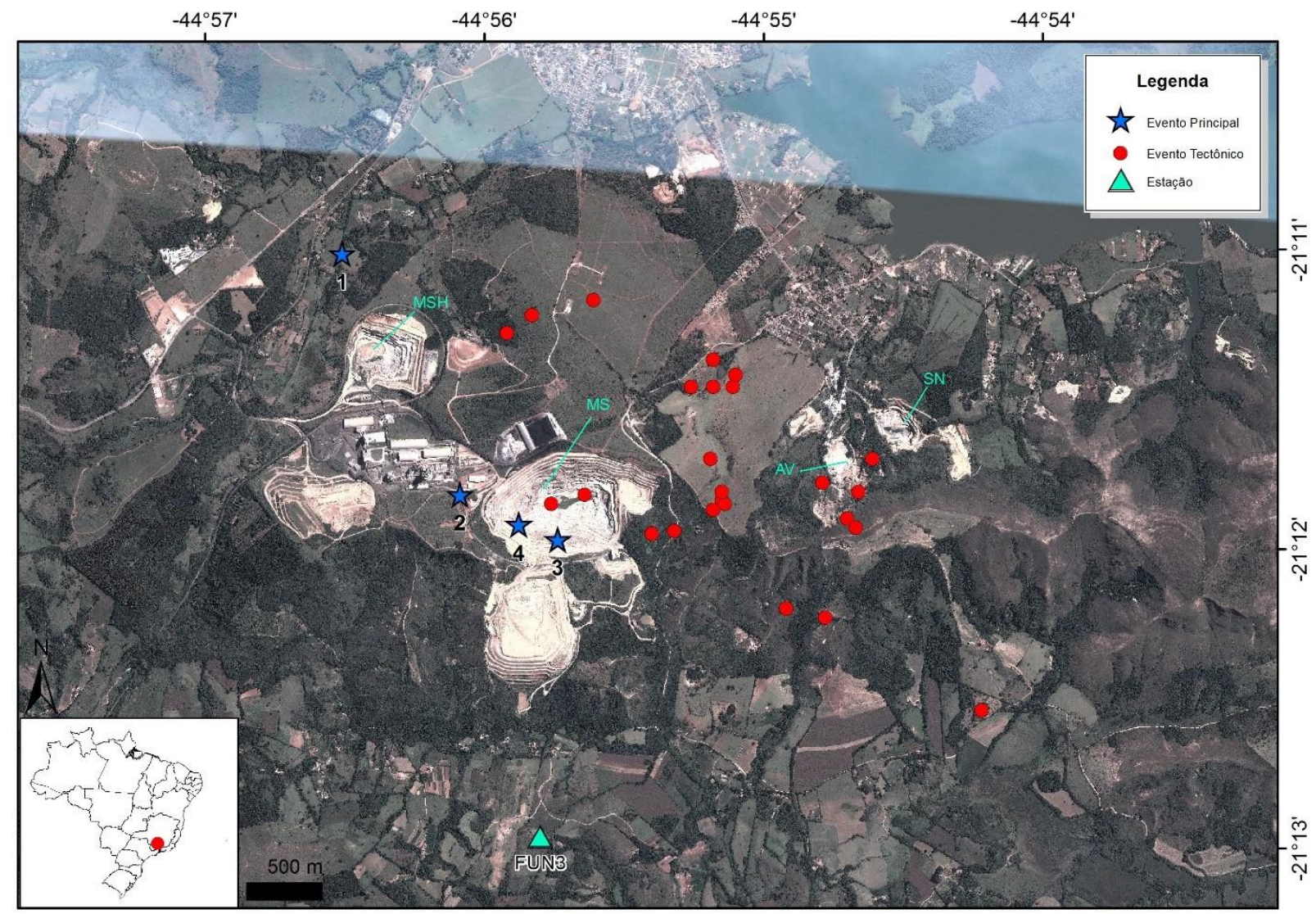

Figura 3-12 - Localização dos 25 eventos classificados como tectônicos e detectados por quatro ou mais estações. As estrelas azuis denotam os epicentros dos quatro eventos principais localizados com dados de FUN1.

Tabela 3-3 - Parâmetros dos 4 sismos principais de Ijaci localizados com apenas uma estação, FUN1.

\begin{tabular}{c|c|c|c|c|}
$\begin{array}{c}\text { Número } \\
\text { do evento }\end{array}$ & $\begin{array}{c}\text { Data } \\
\text { (yyyy/mm/dd) }\end{array}$ & $\begin{array}{c}\text { Tempo de } \\
\text { origem (UTC) }\end{array}$ & $\begin{array}{c}\text { Coordenadas } \\
\text { (Lat, Long) }\end{array}$ & Mag \\
\hline 1 & $2011 / 08 / 14$ & $16: 50: 08.48$ & $-21.1835-44.9418$ & 3.2 \\
\hline 2 & $2011 / 10 / 05$ & $18: 09: 30.83$ & $-21.1969-44.9347$ & 2.6 \\
\hline 3 & $2011 / 11 / 13$ & $07: 39: 26.69$ & $-21.1994-44.9289$ & 2.6 \\
\hline \multirow{2}{*}{3} & $2011 / 11 / 23$ & $07: 09: 15.79$ & $-21.1986-44.9312$ & 2.6 \\
\hline
\end{tabular}


A seleção dos eventos artificiais foram mais restritivas e consideraram apenas aqueles detectados por quatro ou mais estações e com o gap azimutal máximo de $180^{\circ}$.

Foram selecionados trinta e nove (39) eventos, os quais estão plotados na Figura 3-13.

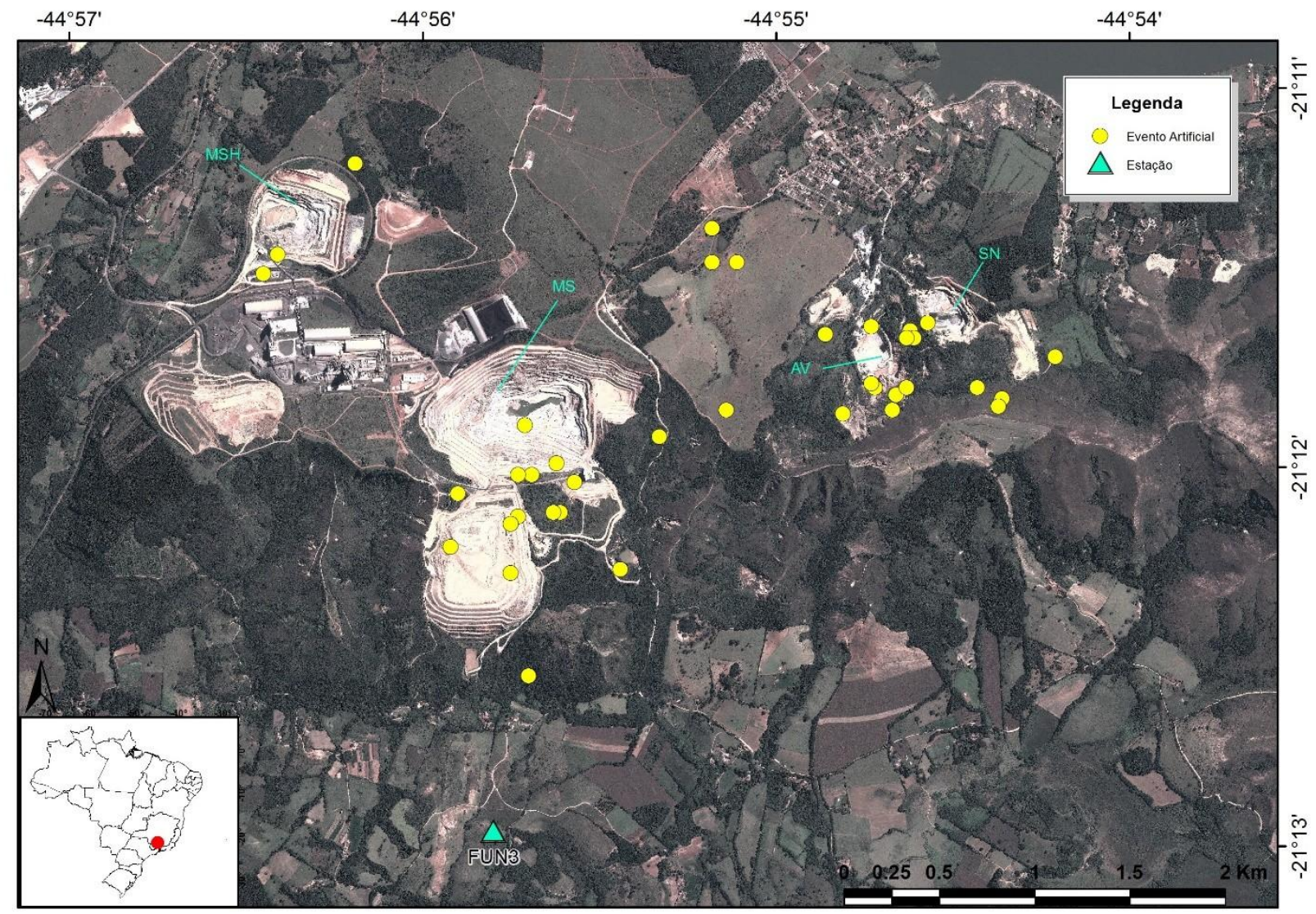

Figura 3-13 - Localização dos 39 eventos classificados como artificiais e detectados por quatro ou mais estações. 


\section{Capítulo 4 - Parâmetros de Fonte}

\subsection{Introdução}

Os parâmetros de fonte para os sismos de Ijaci foram obtidos por meio de três técnicas; 1 . Polaridade do primeiro movimento da onda P, 2. Inversão de forma de onda e 3. Técnica CSPS. No primeiro caso foi utilizado o mecanismo focal composto e, no segundo a inversão de forma de onda de seis abalos secundários e a inversão da forma de onda do evento principal registrado nas estações FUN1 (8km) e BSCB (28km).

Neste capítulo são apresentados os parâmetros de fonte sísmica obtidos para essas três técnicas.

\subsection{Mecanismo focal composto}

A obtenção da solução do mecanismo focal composto, utilizando as polaridades do primeiro movimento das ondas $\mathrm{P}$, foi conseguida com uma seleção de oito eventos tectônicos, com magnitudes variando entre 1,0 e 1,6, detectados por quatro ou mais estações, seguindo o critério de precisão na localização hipocentral: Gap azimutal na cobertura de estações mínimo de 100 graus e máximo de 200 graus (média $=150^{\circ}$ ); distância epicentral mínima entre 2 e $3 \mathrm{~km}$; RMS do resíduo máximo $=0,02 \mathrm{~s}$. Oito eventos foram detectados pela estação FUN3, a mais próxima (Tabela 4-1, exceto os eventos 1 e 10). 
Tabela 4-1 - Listagem dos eventos utilizados na solução do mecanismo focal composto e para inversão de forma de onda dos eventos pós abalo. Os eventos de número 1 e 10 não foram usados no MF composto.

\begin{tabular}{|c|c|c|c|c|c|}
\hline $\begin{array}{l}\text { Número } \\
\text { do evento }\end{array}$ & $\begin{array}{c}\text { Data } \\
\text { (yyyy/mm/dd) }\end{array}$ & $\begin{array}{c}\text { Tempo de } \\
\text { origem (UTC) }\end{array}$ & $\begin{array}{l}\text { Coordenadas } \\
\text { (Lat, Long) }\end{array}$ & $\begin{array}{c}\text { Prof } \\
\text { Magnitude* }\end{array}$ & RMS \\
\hline 1 & $2012 / 02 / 24$ & 20:09:10.23 & $-21^{\circ} 10.81-44^{\circ} 52.88$ & $0.4 / 1.4$ & 0.01 \\
\hline 2 & $2012 / 04 / 21$ & 03:22:42.39 & $-21^{\circ} 11.70-44^{\circ} 55.88$ & $0.6 / 1.0$ & 0.01 \\
\hline 3 & $2012 / 04 / 22$ & $15: 15: 54.36$ & $-21^{\circ} 11.46-44^{\circ} 55.11$ & $0.5 / 1.2$ & 0.00 \\
\hline 4 & $2012 / 04 / 22$ & $15: 52: 10.45$ & $-21^{\circ} 11.85-44^{\circ} 55.14$ & $0.3 / 1.4$ & 0.01 \\
\hline 5 & 2012/03/01 & 20:02:26.69 & $-21^{\circ} 11.37-44^{\circ} 55.18$ & $0.1 / 1.3$ & 0.05 \\
\hline 6 & 2012/03/06 & $05: 45: 16.97$ & $-21^{\circ} 11.84-44^{\circ} 55.15$ & $0.0 / 1.6$ & 0.02 \\
\hline 7 & 2012/03/06 & $05: 48: 27.10$ & $-21^{\circ} 11.87-44^{\circ} 55.18$ & $0.0 / 0.3$ & 0.02 \\
\hline 8 & $2012 / 05 / 18$ & $02: 46: 21.08$ & $-21-12.54-44-54.22$ & $0.6 / 1.1$ & 0.01 \\
\hline 9 & $2012 / 05 / 18$ & 22:00:14.51 & $-21-11.95-44-55.40$ & $0.3 / 0.9$ & 0.01 \\
\hline 10 & 2012/05/19 & $21: 40: 42.26$ & $-21-11.57-44-52.47$ & $0.0 / 1.0$ & 0.02 \\
\hline
\end{tabular}

*Profundidade está em Km e a magnitude é dada pela duração da coda do sinal. Os eventos de número 1 e 10 não foram utilizados no mecanismo focal composto,

\subsubsection{Determinação do mecanismo focal composto}

O software FOCMEC (Snoke, 2003) foi utilizado para determinar o mecanismo focal composto, a partir da seleção acima. De um total de 25 polaridades, duas apresentaram inconsistência (Figura 4-1). A Tabela 4-2 resume os resultados do mecanismo focal apresentados na Figura 4-1. 
Tabela 4-2 - Solução dos planos nodais composto para a sequência de Ijaci.

\begin{tabular}{c|c|c|c|} 
& Strike & Dip & Rake \\
\hline Plano 1 & 10 & 42 & 53 \\
\hline Plano 2 & 235 & 58 & 119 \\
\hline Eixo T & 197 & 65 & \\
\hline Eixo P & 305 & 8,5 & \\
\hline
\end{tabular}

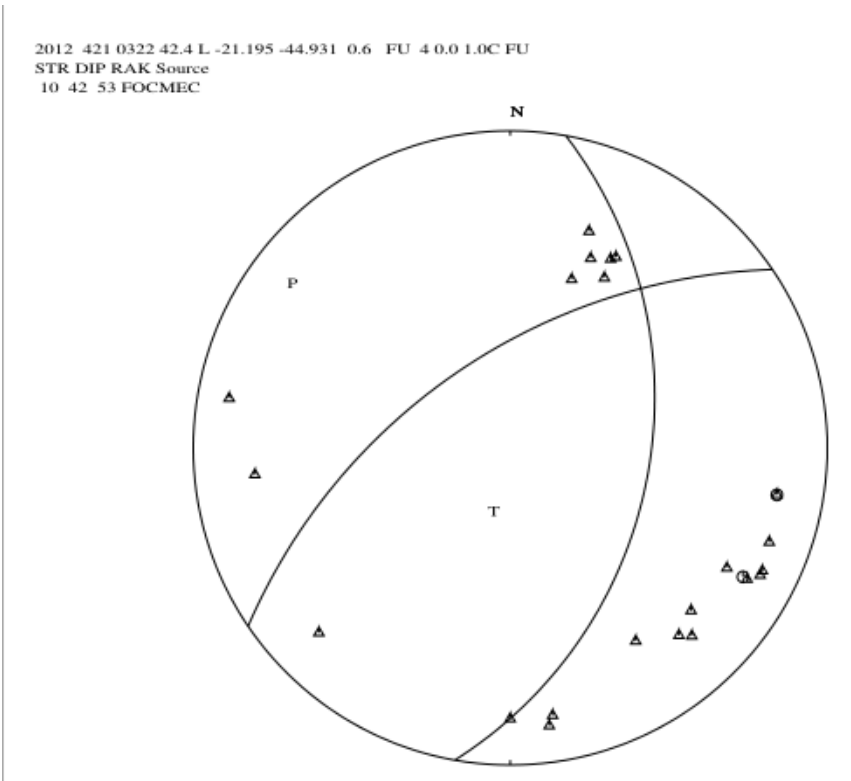

Figura 4-1 - Mecanismo focal composto para a sequência sísmica de Ijaci, utilizando as polaridades das primeiras chegadas da onda $P$, de um conjunto de oito eventos com 25 polaridades, duas apresentaram inconsistências. Círculo indica compressão e triângulo distensão.

\subsection{Inversão da forma de onda dos abalos secundários}

A inversão foi efetuada com código computacional ISOLA (Zahradník et al, 2005; Sokos and Zahradinik 2008, 2013) e o MATLAB, usando um método interativo, similar ao Kikuchi Kanamori (1991). As funções de Green foram calculadas utilizando um modelo de semi-espaço $(\mathrm{Vp}=6,0 \mathrm{~km} / \mathrm{s}$ e razão $\mathrm{Vp} / \mathrm{Vs}=1,72)$ e o método de número de onda discreto de Bouchon (1981).

Como os resíduos de localização dos eventos foram da ordem aproximada de $20 \mathrm{~ms}$, i.e., as localizações foram precisas; os cálculos da função de Green foram feitos com a posição da fonte 
fixa, variando apenas na vertical (profundidade). Iniciando na profundidade de $0,5 \mathrm{~km}$ indo até $3,0 \mathrm{~km}$, em passos de $0,5 \mathrm{~km}$.

Tentou-se inverter para o Momento Tensor (MT) as formas de ondas de todos os dez eventos da Tabela 4-1. Entretanto, não foi possível fazê-lo para quatro eventos devido à baixa relação sinal ruído (SNR) (Tabela 4-3).

\subsubsection{Resultados}

Apresentamos na sequência os resultados para o Evento 1 da Tabela 4-3. Foram invertidas as formas de ondas, na banda de $1 \mathrm{~Hz}$ a $2 \mathrm{~Hz}$, dos registros feitos em quatro estações da rede local (FUN3, FUN4, FUN5 e FUN6). Esta Tabela sintetiza os resultados para seis eventos, entretanto, apenas os resultados do Evento 1 serão apresentados como referência. Para os demais, a mesma explicação é válida. O Evento 1 ocorreu em 24/04/2012, às 20:09:10.23. As soluções encontradas foram: Plano 1 strike/dip/rake, respectivamente 221/53/123, Plano 2 = 354/48/54; Azimute e plunge no Eixo $\mathrm{P}=289 / 3$, Eixo T = 193/64; Magnitudes de duração (mD)/magnitude de momento sísmico $(\mathrm{MW})=1,4 / 1,1 ;$ Profundidade $($ inicial/encontrada $)=0,4 / 0,6$; Percentagem de DC (doublecouple $)=96 \%$; Condition Number $(\mathrm{CN})=4$; Variance Reduction $(\mathrm{VR})=0,36 ; \mathrm{SNR}=1$; Cheque de Polaridades $=$ OK, sem inconsistência; Beach-Ball (mecanismo focal resultante); Porcentagem de VOL/DC/CLVD = 0,3/96,1/3,69, a fonte encontrada é quase completamente do tipo Double Couple (96.1\%) (Figura 4-2).

A Figura 4-2 apresenta um resumo dos resultados da inversão obtidos pela inversão de forma de onda do evento de 24 de fevereiro de 2012, às 20:09:10.23. Os seguintes parâmetros do evento foram inseridos no ISOLA: Magnitude da onda de coda $=1,4 \mathrm{Md}$; Profundidade $=0,4 \mathrm{~km}$ e Epicentro em 21,180S e 44,881W. Como resultado, foi obtida uma magnitude de $1,1 \mathrm{M}_{\mathrm{w}}$ e tempo de origem do centroide igual ao tempo de origem do hipocentro somado a 150 milissegundos. O centroide do momento tensor foi localizado a uma profundidade de $600 \mathrm{~m}$. Devido à boa precisão da localização do epicentro, as soluções foram testadas apenas com variações verticais. A inversão obteve 98,4\% de DC (double couple) (Figura 4-3).

A melhor correlação entre sinal sintético e observado ocorre nos registros da estação FUN6, como esperado, pois é a mais próxima do epicentro (Figura 4-4). 
Uma falha SW-NE é uma possível solução para a determinação do mecanismo focal composto (Figura 4-2) com os seguintes parâmetros: Strike=220, Dip=53 e Rake=122. A Figura 4-2 apresenta o mecanismo focal correspondente para o evento Evento 1 da Tabela 4-3.

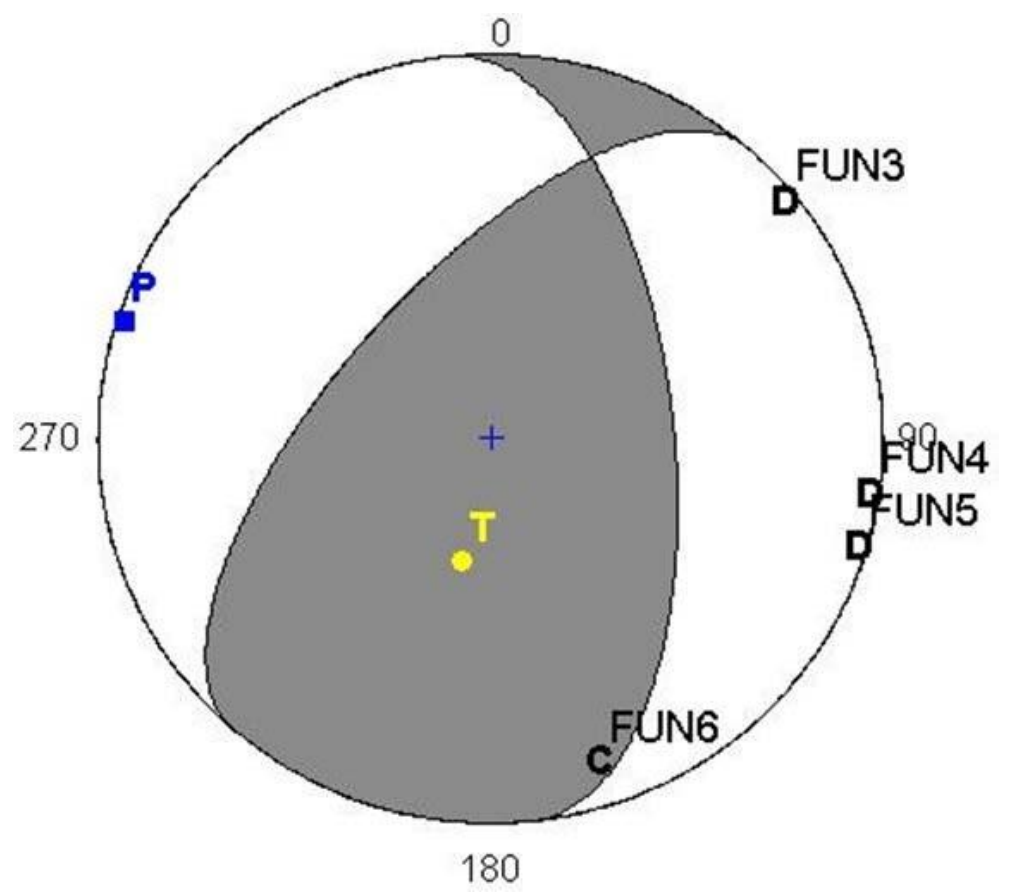

Figura 4-2 - Solução de mecanismo focal para o evento de 22 de fevereiro de 2012, às 20:09:10.23, utilizando inversão de forma de onda e o software ISOLA. Adicionalmente, as polaridades das estações foram plotadas e nenhuma inconsistência foi encontrada. 


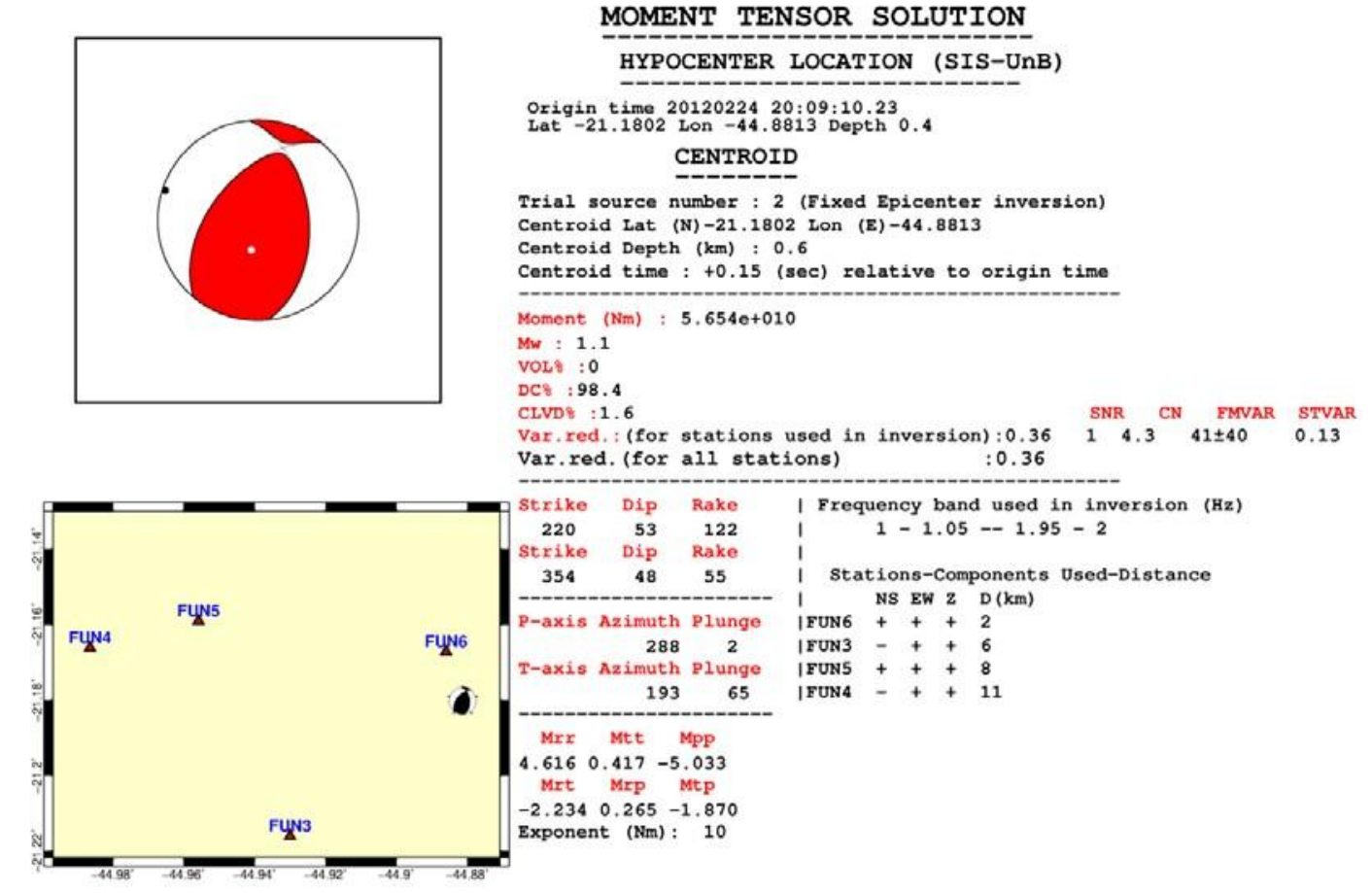

Figura 4-3 - Resultados ISOLA da inversão de forma de onda para o evento de 22 de fevereiro de 2012, às 20:09:10.23, registrado por quatro estações (FUN3, FUN4, FUN5 e FUN6).

Event date.time: $122402 \_20 \_09 \_10.23$
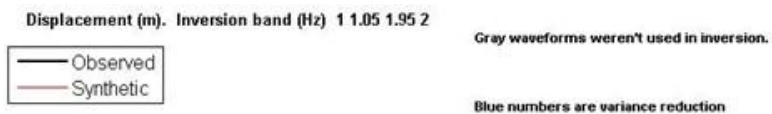

Blue numbers are variance reduction
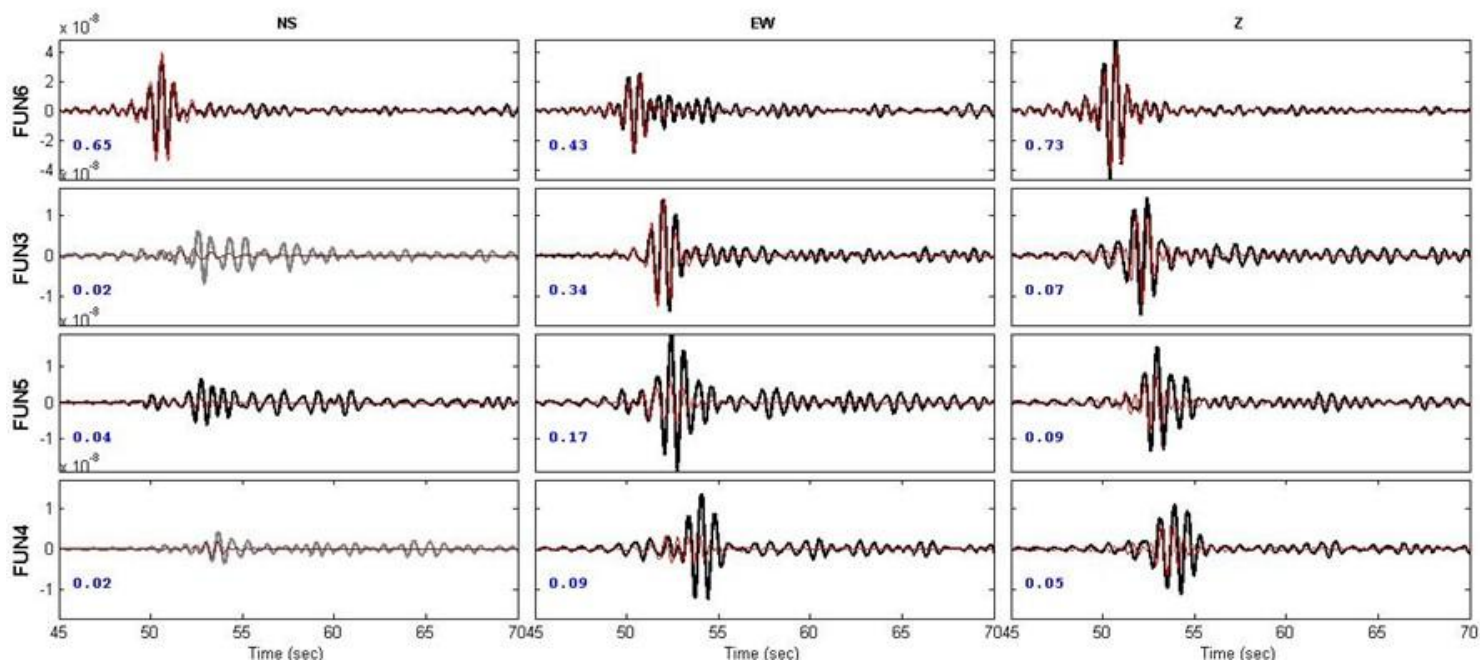

Figura 4-4 - Os sismogramas sintéticos (traços vermelhos) e observados (traços pretos) de quatro estações da rede local. Os traços das componentes NS das estações FUN3 e FUN4 não foram utilizadas na inversão da forma de onda devido a baixa razão Sinal Ruído (SNR). 
Tabela 4-3 - Resumo dos resultados de seis eventos invertidos para o momento tensor.

\begin{tabular}{|c|c|c|c|c|c|c|c|c|c|c|c|c|c|c|}
\hline Event & $\begin{array}{l}\text { YrYYMMDD } \\
\text { HH:MM:SS.SS }\end{array}$ & $\begin{array}{l}\text { Stations } \\
\text { Processed }\end{array}$ & Frequency band $(\mathrm{Hz})$ & $\begin{array}{l}1-S / D / R \\
2-S / D / R\end{array}$ & $\begin{array}{l}\text { P-Az/Plug } \\
\text { T-Az/Plug }\end{array}$ & $\mathrm{M}_{\mathrm{o}} / \mathrm{Mw}$ & $\begin{array}{c}\text { depth (Km) } \\
\text { Ev/Cent }\end{array}$ & $\mathrm{DC} \%$ & $\begin{array}{c}\mathrm{CN} \\
\text { Eig (min/Max) }\end{array}$ & VR & SNR & $\begin{array}{c}\text { Polarity } \\
\text { Agreement }\end{array}$ & Beachball & VOL/DC/CLVD \\
\hline EV1(1) & \begin{tabular}{|c|}
20120224 \\
$20: 09: 10.23$
\end{tabular} & $6,3,5,4$ & $1.0-2.0$ & $\begin{array}{l}221 / 53 / 123 \\
354 / 48 / 54\end{array}$ & $\begin{array}{l}289 / 3 \\
193 / 64\end{array}$ & $\mid 1.4 / 1.1$ & $0.4 / 0.6$ & 96 & 4.0 & 0.36 & 1 & ok & te & $-0.3 / 96.1 / 3.6$ \\
\hline EV2(4) & $\begin{array}{l}\text { 20120421 } \\
\text { 03:22:28 }\end{array}$ & Low SNR & $1.0-2.0$ & & & & & & & & & & & \\
\hline EV3(5) & \begin{tabular}{|c|}
20120422 \\
$15: 15: 54.36$
\end{tabular} & $3,5,4,1$ & $1.0-2.0$ & $\begin{array}{c}45 / 57 / 83 \\
238 / 34 / 101\end{array}$ & $\begin{array}{l}140 / 12 \\
292 / 77\end{array}$ & $1.2 / 1.0$ & $0.5 / 0.5$ & 50 & 2.9 & 0.14 & 1 & n/a & & \\
\hline $\mathrm{EV} 4(6)$ & \begin{tabular}{|c|}
20120422 \\
$15: 52: 10.45$
\end{tabular} & $3,5,4,1$ & $1.0-2.0$ & $\begin{array}{c}73 / 57 / 66 \\
292 / 40 / 121\end{array}$ & $\begin{array}{c}180 / 9 \\
293 / 68\end{array}$ & $1.4 / 1.1$ & $0.3 / 0.7$ & 95 & 2.8 & 0.28 & 2 & $n / a$ & & $61.3 / 30.9 / 7.7$ \\
\hline EV5(2) & \begin{tabular}{|c|} 
20120301 \\
20:02:26.69
\end{tabular} & & & & & & & & & & & & & \\
\hline EV6(3) & $\begin{array}{c}\text { 20120306 } \\
\text { 05:45:16.97 }\end{array}$ & $3,6,7,4, \underline{2}$ & $1.0-2.0$ & $\begin{array}{l}83 / 61 / 86 \\
272 / 29 / 98\end{array}$ & $\begin{array}{l}176 / 16 \\
342 / 73\end{array}$ & 1.6/1.1 & $0.1 / 0.2$ & 77 & 2.9 & 0.54 & 2 & $n / a$ & & $27.1 / 56.6 / 16.3$ \\
\hline EV7(-) & \begin{tabular}{|c|} 
20120306 \\
05:48:27.10
\end{tabular} & Low SNR & & & & & & & & & & & & \\
\hline EV8(7) & $\begin{array}{l}\text { 20120518 } \\
02: 46: 07\end{array}$ & Low SNR & & & & & & & & & & & & \\
\hline EV9(8) & $\begin{array}{c}\text { 20120518 } \\
\text { 22:00:14.51 }\end{array}$ & $3,5,4,2$ & $1.0-2.0$ & $\begin{array}{c}74 / 53 / 78 \\
274 / 38 / 106\end{array}$ & $\begin{array}{l}172 / 8 \\
300 / 78\end{array}$ & $0.9 / 0.85$ & $0.3 / 0.7$ & 74 & 3.2 & 0.33 & 1 & $n / a$ & & $27 / 57.8 / 15.2$ \\
\hline EV10(9) & $\begin{array}{c}\text { 20120519 } \\
\text { 21:40:42.26 }\end{array}$ & $2,3,5,4$ & $1.0-2.0$ & $\begin{array}{l}70 / 49 / 105 \\
228 / 43 / 73\end{array}$ & $\begin{array}{l}150 / 3 \\
43 / 78\end{array}$ & 1.0/1.1 & $0.1 / 0.7$ & 88 & 4.4 & 0.26 & 2 & $\mathrm{n} / \mathrm{a}$ & & 21.5/64.9/13.6 \\
\hline
\end{tabular}

A Tabela 4-3 resume os resultados da inversão do momento tensor. Observe que foi invertido evento de magnitude até 1,0. A menor magnitude já invertida foi 2,0 em Fujitekov (2014).

A Figura 4-5 apresenta os mecanismos focais para os seis eventos da Tabela 4-3 para os quais foi possível inverter. As barras amarelas indicam a direção do eixo de compressão (P). Como se observa, existem basicamente duas famílias de resultados, NW-NE (2 eventos) e NNW-SSE (4 eventos). Para esta orientação de esforços, foram produzidas falhas reversas de orientação média NE-SW. 


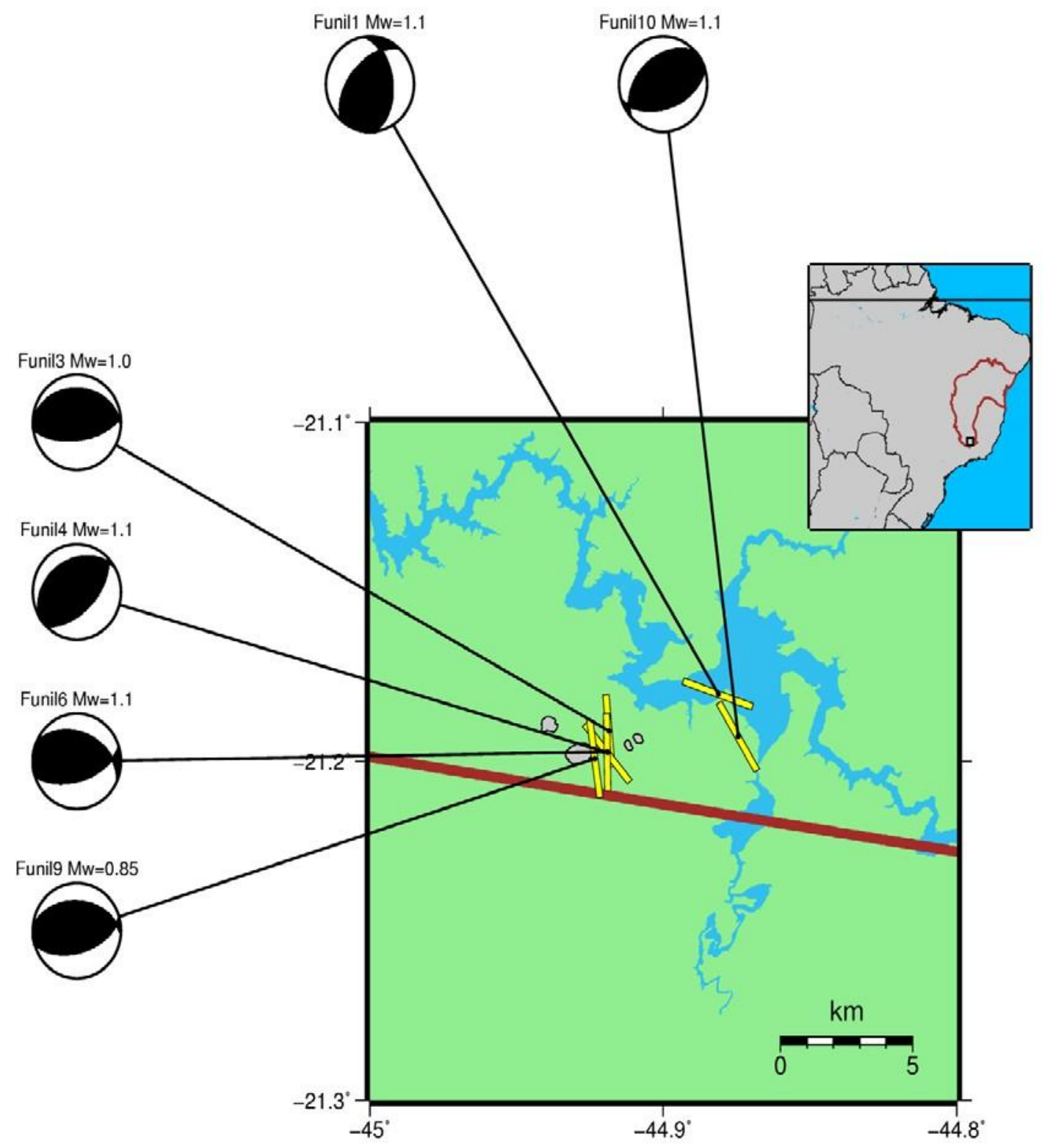

Figura 4-5 - Representação Beach-Ball para os seis eventos apresentados na tabela 4.2. As barras amarelas representam a orientação do eixo-P. A média geral do eixo P tem orientação NNW-SSE.

\subsection{Mecanismo focal por inversão de formas de ondas do evento principal}

A solução dos planos nodais para o sismo de Ijaci, de 14 de agosto de 2011, foi também determinada por inversão de suas formas de ondas nas estações FUN1 (8km) e BSCB (Bom Sucesso) (25 km), com a utilização da técnica CSPS (Ciclic Scanning Polarity Solution). 
Antes de proceder à inversão foi analisado o sinal no que diz respeito ao seu conteúdo de energia em relação ao ruído natural do local das duas estações. Determinou-se a Relação Sinal Ruído (SNR) para as duas estações mais próximas. FUN1(Figura 4-6) e BSCB (Figura 4-7).

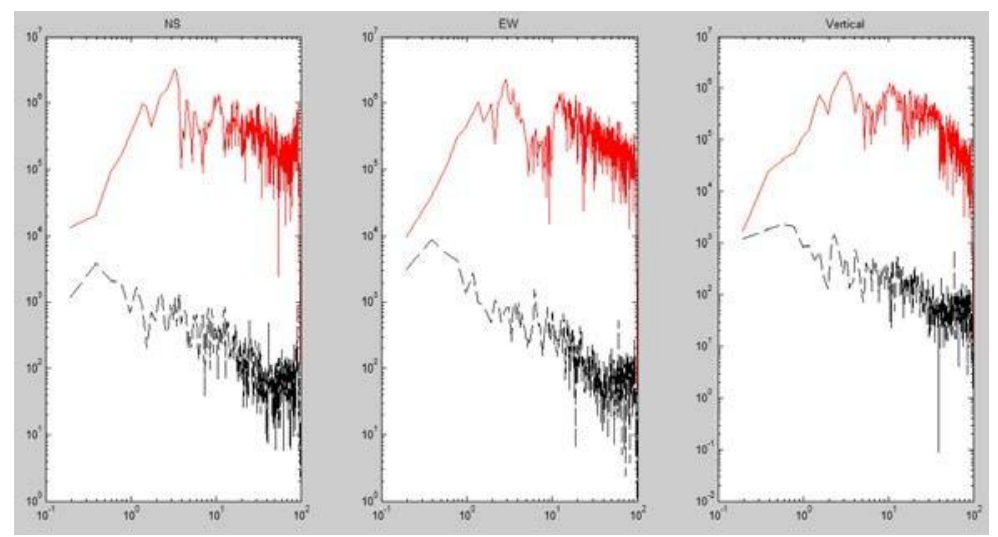

Figura 4-6 - Espectro do sinal (vermelho) e do ruído (preto) nos canais NS, EW e Vertical para a estação FUN1, localizada a cerca de $8 \mathrm{~km}$ da fonte.

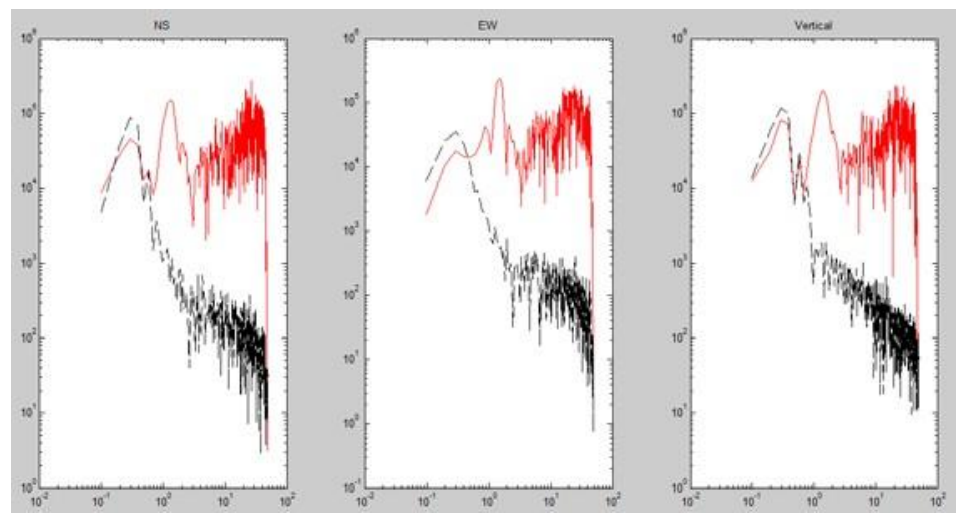

Figura 4-7 - Espectro do sinal (vermelho) e do ruído (preto) nos canais NS, EW e Vertical para a estação BSCB, localizada a cerca de $28 \mathrm{~km}$ da fonte.

Como pode ser observado, o sinal está acima do ruído nas duas estações (FUN1 e BSCB). Portanto, possível de ser feita a inversão. Os gráficos apresentam em que banda de frequência é possível efetuar a inversão, para este caso, na banda de frequência 0,5 a $0,8 \mathrm{~Hz}$.

Diferentemente da inversão dos aftershocks, que usamos um semi-espaço como modelo de velocidade, para o evento principal foi utilizado um modelo acamadado, mais complexo (Figura 4-8). 


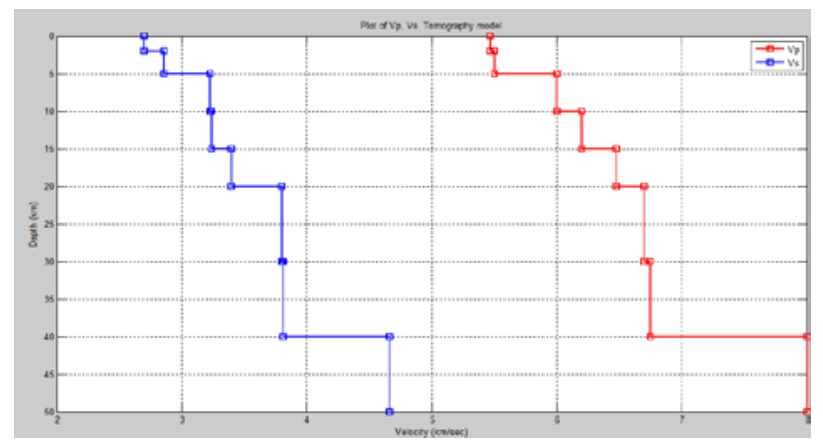

Figura 4-8 - Modelo de velocidade, azul (onda S) e vermelho (onda P). Para este caso utilizou-se uma razão Vp/Vs de 1,72, obtido no Capítulo 3 - a partir do diagrama de Wadati.

Apesar de ter sido detectado por 12 estações da Rede Sismográfica Brasileira (RSBR), além da estação FUN1, a inversão das formas de onda do evento principal com o programa ISOLA (Zahradník et al, 2005; Sokos and Zahradinik 2008, 2013) não foi possível devido a sua baixa magnitude.

\subsection{A técnica CSPS}

Das 12 estações que registraram o evento de 14/8, foi possível ler polaridades apenas em quatro estações: FUN1 (D), BSCB (C), PMNB (C) e SJMB (C). Com essas polaridades foram determinados todos os planos nodais possíveis com o FOCMEC (Snoke, 2003) e um determinado ângulo de busca (Figura 4-9). A inversão de forma de onda busca, dentre todas as soluções obtidas por polaridade (Figura 4-9), aquela que apresenta melhor correlação entre os dados observados e sintéticos. A Figura 4-10 apresenta a correlação entre formas de onda dos dados observados (preto) e sintéticos (vermelho) para as duas estações. Como pode ser observado, a melhor correlação foi obtida para a componente EW da estação FUN1. Na Figura 4-11 é apresentado na vertical a correlação e na horizontal a posição da fonte. A maior correlação foi obtida com a fonte de profundidade igual a 0,2 km. Para este caso, a porcentagem de Double-Couple (DC\%) é 94.2\%.

Na Figura 4-12 é apresentado um resumo dos parâmetros de fonte da melhor solução encontrada, ou seja, a melhor solução de mecanismo focal para o evento principal com a técnica CSPS. 


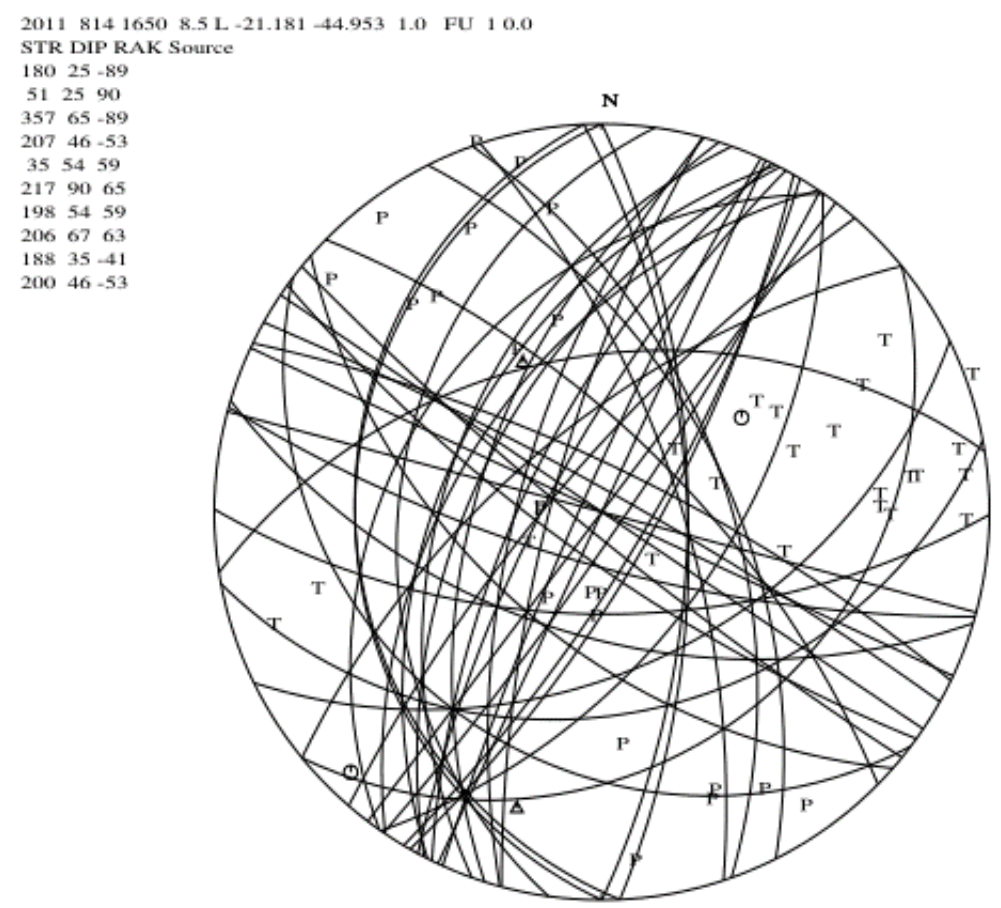

Figura 4-9 - Soluções de planos nodais obtidos com 4 polaridades nas estações FUN1, BSCB, PMNB e SJMB sem nenhum erro de polaridade e uma busca de 30 graus.

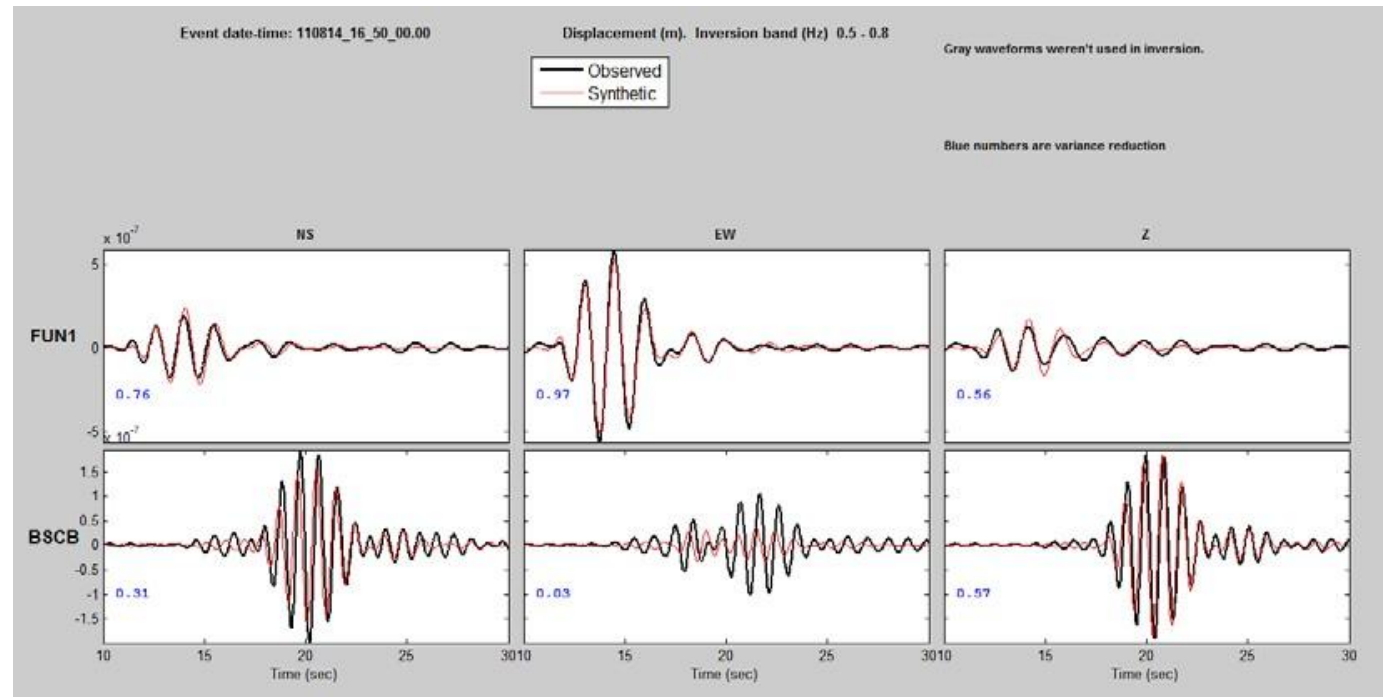

Figura 4-10 - Formas de ondas dos dados sintéticos (vermelho) e observados (preto) nas estações FUN1 (superior) e BSCB (inferior). Os números azuis denotam a correlação entre os dados sintéticos e observados. O pior caso aconteceu para a componente EW da estação BSCB (0,03) e o melhor para essa mesma componente na estação FUN1 $(0,97)$. 


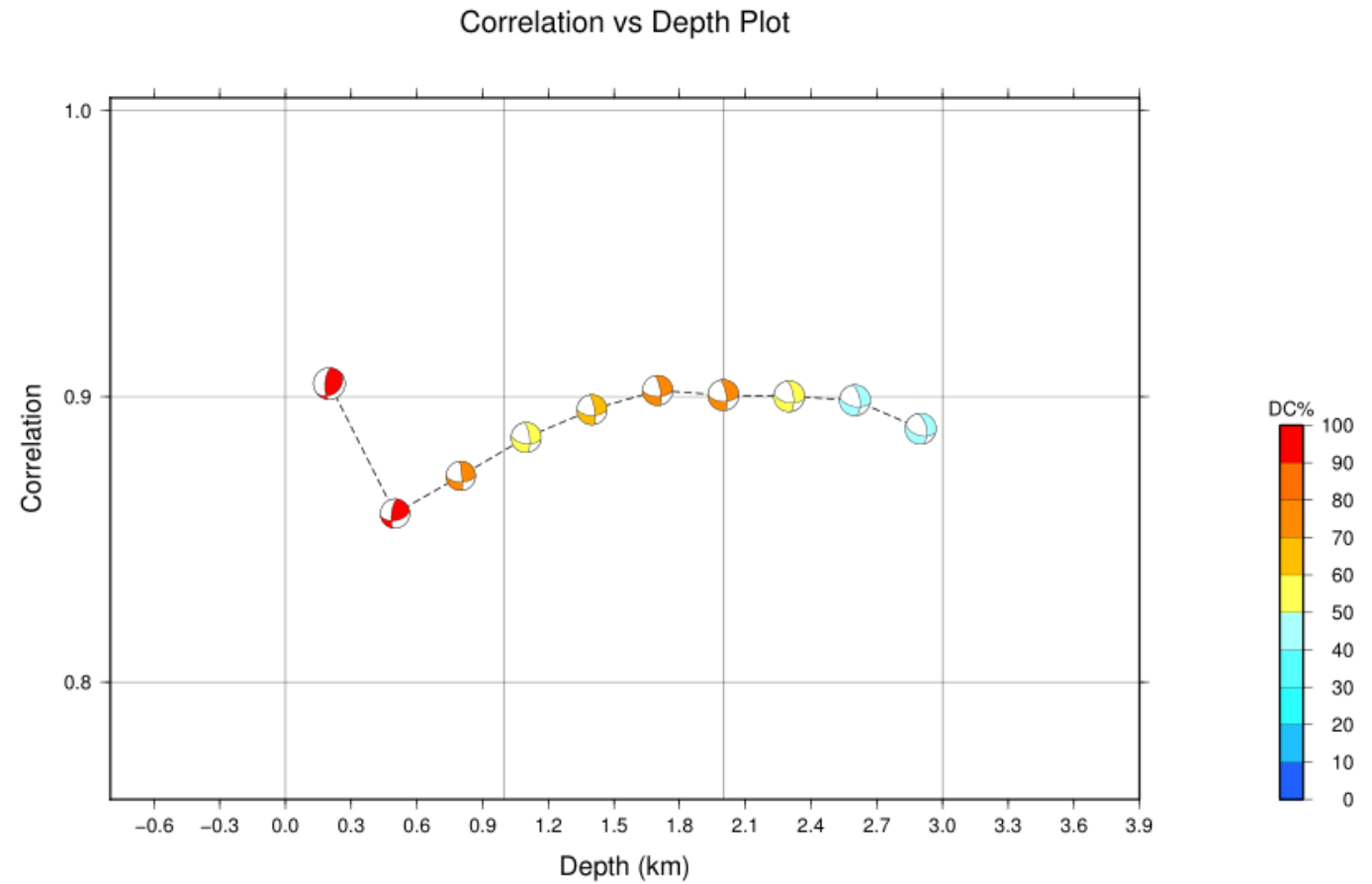

Figura 4-11 - Profundidade da fonte por correlação. Observe que a profundidade para a qual a correlação é maior ocorre para profundidade de 0,2 km, ligeiramente acima de 0,9, com percentual DC de 94,2\%. 

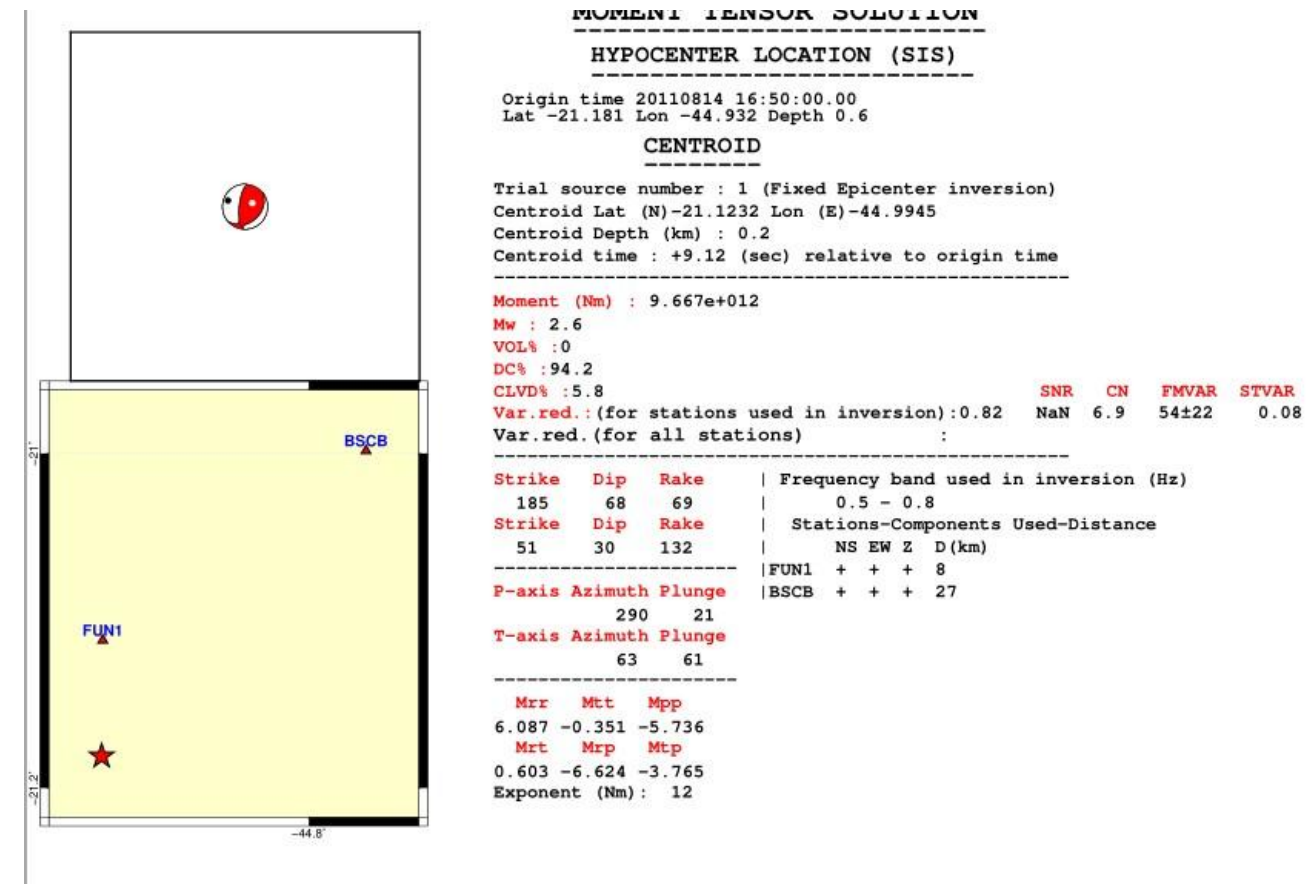

Figura 4-12 - Resumo dos resultados da inversão de forma de onda para o evento principal registrado nas estações

$$
\text { FUN1 e BSCB. }
$$

Source depth (assumed for this plot) $0.6 \mathrm{~km}$

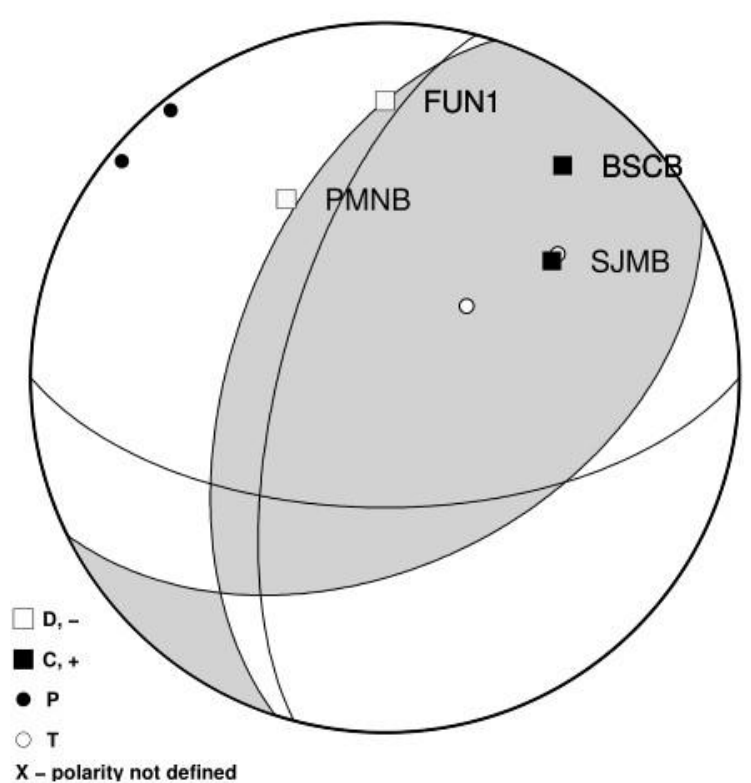

Solutions above VR threshold : 2 Minimum allowed VR : 0.70 Optimum VR : 0.74 Optimum mechanism S/D/R NP1 $=198 / 54 / 59$ NP2 $=64 / 46 / 125$ Moment-Magnitude range 2.4-2.5 Depth range $(\mathrm{km}) \quad 0.2-0.5$

Figura 4-13 - Solução de planos nodais. Plano 1: 198/54/59 (strike/dip/rake); Eixo P (strike/plunge) = 309/4,3; Plano 2: 63/46/125 (strike/dip/rake); Eixo T (strike/plunge) = 48/65. 


\subsection{Discussão e conclusões}

Apresentamos neste capítulo os resultados de estudo de fontes sísmicas para a sequência de Ijaci de 2011 a 2012. Utilizou-se as técnicas de polaridade (Mecanismo Focal Composto), Inversão de formas de ondas para os pós-abalos e para o evento principal de 14/08/2011 com a técnica CSPS. Os resultados estão sintetizados na Tabela 4-4.

Tabela 4-4 - Parâmetros de mecanismo focal para os dois métodos: Mecanismo focal composto e inversão da forma de onda.

\begin{tabular}{|c|c|c|c|c|c|}
\hline Método & Strike & Dip & Rake & $\begin{array}{c}\text { P } \\
\text { (Strike/Plunge) }\end{array}$ & $\begin{array}{c}\mathrm{T} \\
\text { (Strike/Plunge) }\end{array}$ \\
\hline Mecanismo composto & $150 / 35$ & $47 / 47$ & $69 / 111$ & $255 / 3$ & $345 / 75$ \\
\hline Inversão dos aftershocks & $221 / 354$ & $53 / 48$ & $123 / 55$ & $288 / 2$ & $193 / 64$ \\
\hline Inversão principal (CSPS) & $198 / 63$ & $54 / 46$ & $59 / 125$ & $309 / 4,3$ & $48 / 65$ \\
\hline
\end{tabular}

As três soluções obtidas pelas três técnicas apresentam resultados concordantes, conforme Tabela 4-4 e Figura 4.14. Em todos os casos são obtidas falhas inversa de orientação aproximada NE-SW. Essas falhas são consistentes com a orientação de estruturas presentes na área, conforme Figura 4.14.

Também, com base nos valores obtidos para os ângulos de Kagan (Kagan, 2013), que medem as diferenças/semelhanças entre dois mecanismos focais, e tomando o mecanismo focal composto como referência (mecanismo hachurado na Figura 4.14), podemos concluir: Referência $($ strike/dip/rake $)=10 / 42 / 43$ com o mecanismo do aftershocks $(221 / 53 / 123)($ Kagan $=42)$, mecanismos similares; referência com o mecanismo do evento principal (198/54/59) (Kagan =18), temos mecanismos semelhantes. Os mecanismos se distanciam para ângulos maiores que 50 graus (O valor do Kagan está compreendido entre 0 e 120) (Zahradník \& Custódio, 2012). 


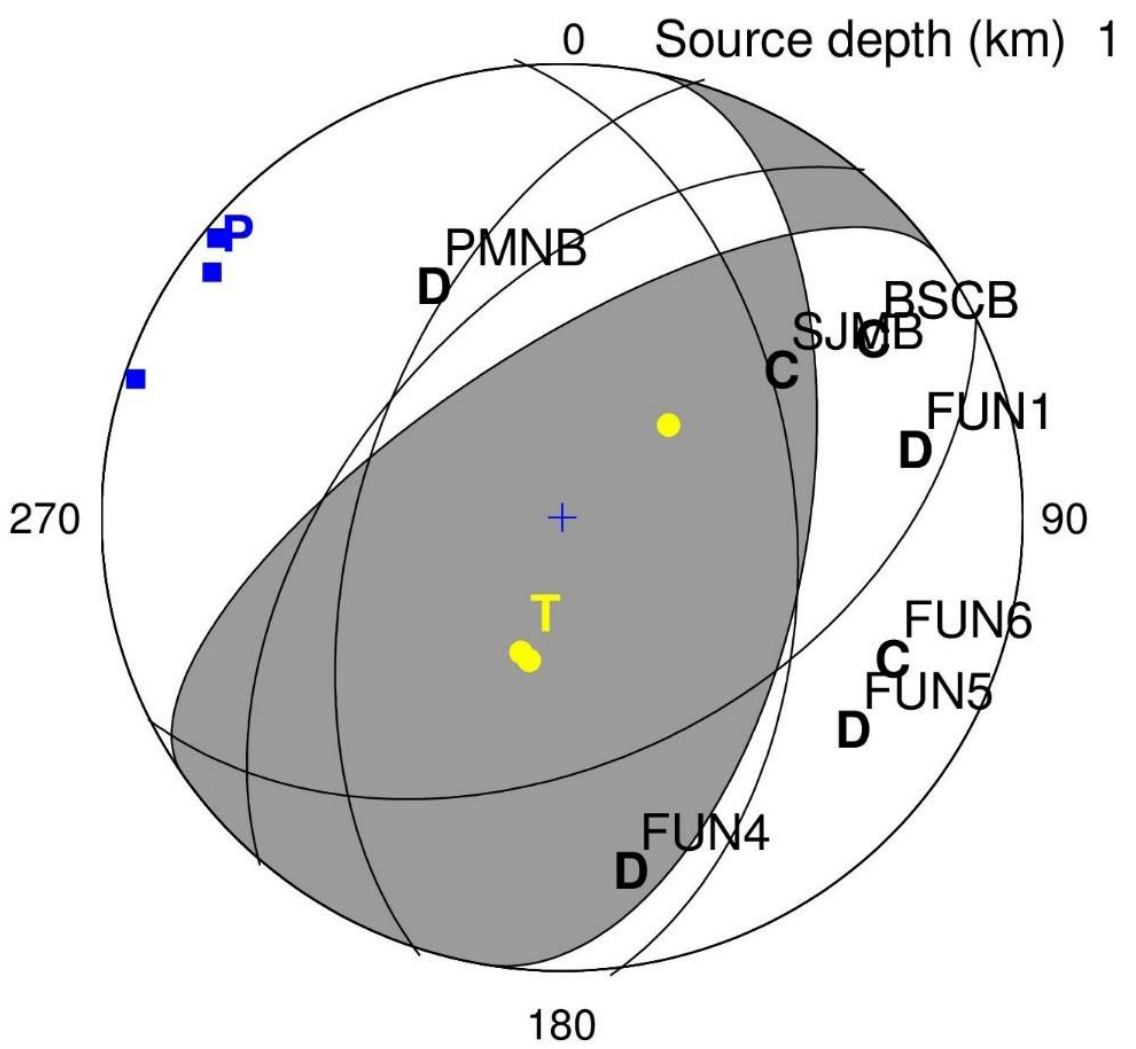

Figura 4-14 - Solução de mecanismo focal obtidos para os três métodos: mecanismo focal composto; inversão de forma de onda dos pós abalos e evento principal por CSPS. C e D donotam polaridades compressiva e distensiva, respectivamente. 


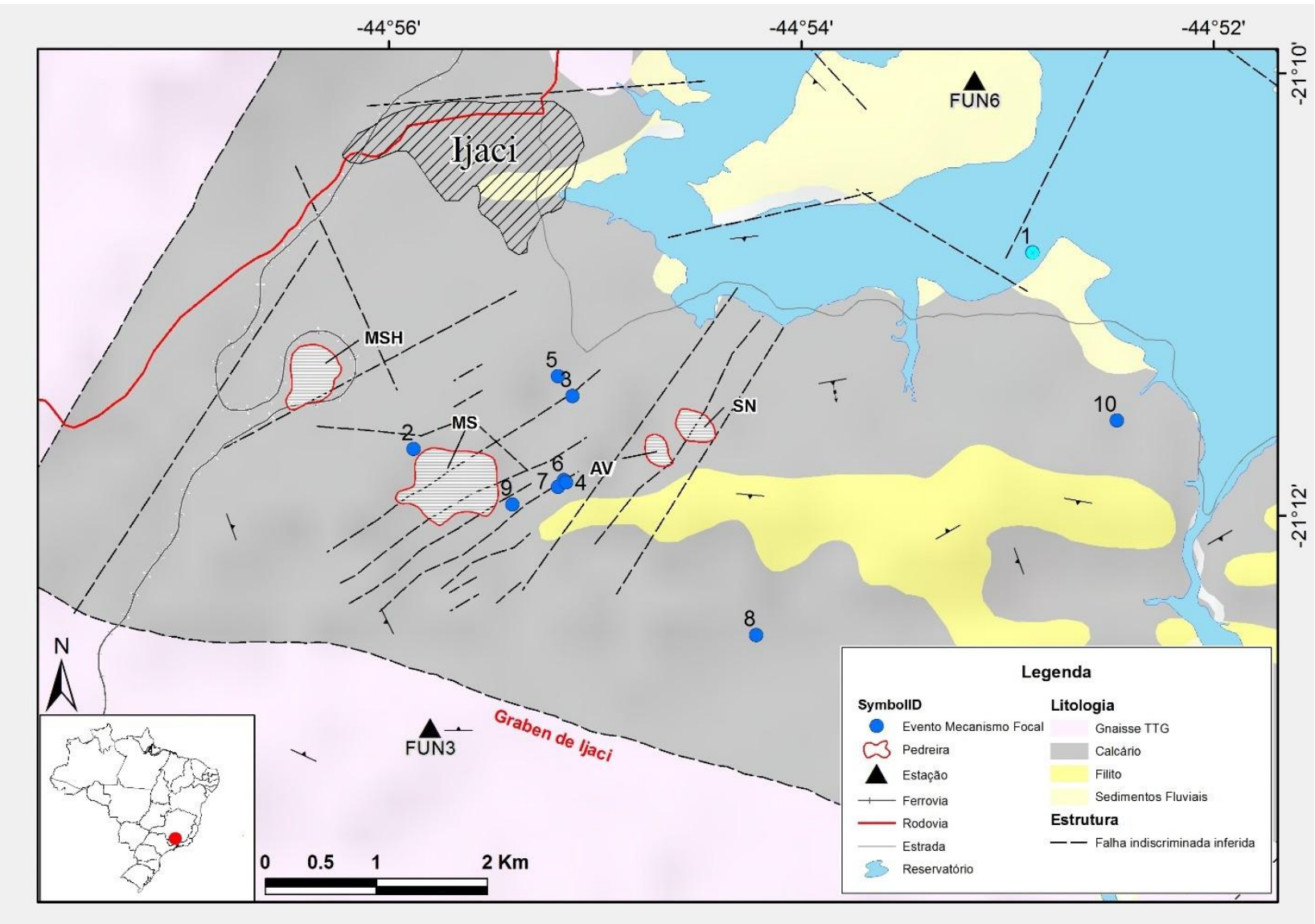

Figura 4-15 - Principais estruturas mapeadas na área por Quéméneur et al. (2003), Ribeiro et al. e (2003a), Hidrovia (2003) e relatórios internos da Intercement. Os números indicam a localização dos eventos da Tabela 4-1 Observe a clara correlação entre os resultados dos mecanismos focais com as falhas mapeadas em superfície de orientação geral NE-SW. 


\section{Capítulo 5 - A origem da Sismicidade}

\subsection{Atividades de mineração}

Em termos simplista, a sismicidade induzida por mineração ocorre em circunstâncias onde o estresse do terreno excede o estresse da massa de rocha movendo-se a um novo ponto de equilíbrio e liberar energia. Diferentemente da sismicidade natural, não é necessário haver uma instabilidade na massa de rocha e quando as atividades de mineração pararem, o equilíbrio será imediatamente reestabelecido e a sismicidade induzida cessará.

A relação entre as atividades de mineração e sismicidade tem sido observada em regiões mineiras ao redor do mundo. Estatísticas atuais dão conta que aproximadamente $25 \%$ de todos os sismos registrados pelo Serviço Geológico da África do Sul, com epicentro na formação Transvaal e Orange Free State podem ter resultados das operações mineiras de alta profundidade nesta região (Fernàndez, 1998). Investigações adicionais nos grandes campos de carvão britânicos indicaram que sismicidade induzida por mineração apresenta uma estreita relação com os cronogramas de trabalho das minas, onde é observado acentuado declínio na atividade sísmica durante feriados ou em épocas em que a mina não operou.

Grandes minas à céu aberto, em rochas sã, reduzem o estado de esforço vertical sob a mina e tendem a gerar sismos em ambientes de falhas reversas. Um dos exemplos mais significantes deste processo foi o evento raso de magnitude 5,0 ocorrido a poucos quilômetros, a sudeste da cidade de Kalgoorlie, estado de Perth, Austrália, e sob o pit de Kalgoorlie Super Pit, em 20 de abril de 2010 (Hao, 2010).

A precisão na localização dos eventos ocorridos durante a operação da rede de monitoramento local, a baixa profundidade dos hipocentros e o detalhado conhecimento geológico da área, principalmente nos entornos das pedreiras de calcário, permitem uma associação impar entre a sismicidade observada e estruturas tectônicas pré-existentes.

\subsubsection{O graben/horst de Ijaci}

A área epicentral está localizada na porção sul do Cráton do São Francisco, onde foram observados casos de sismicidade desencadeada (reservatório de Carmo do Cajuru, MG) e natural 
(município de Bom Sucesso, MG). O trend regional, claramente demarcado pela zona de cisalhamento da Serra de Bom Sucesso, indica intensa deformação com direção SW-NE. Falhas locais normais e reversas de direção N40/30E são importantes na definição da geometria das mineralizações de calcário. A correlação entre as unidades metassedimentares de Ijaci com as unidades reconhecidas no bordo sul do Cráton do São Francisco é dificultada pelo fato das unidades em questão não apresentarem ligação física com as possíveis unidades correlatas.

Estruturalmente, as unidades da região em estudo foram indicadas por diversos autores como tendo tectônica compressiva, com vergência geral para $\mathrm{N}, \mathrm{NNW}$, em direção ao então denominado “antepaís assíntico” (Ebert, 1956, 1968; Campos Neto et. al., 1990; Trow, 1995)

A sismicidade está associada à região compreendida pela extensão areal da Formação Barroso, que está posicionada em uma grande zona deprimida, conformada por blocos estruturais falhados e abatidos, tipo "grabens e horsts".

A partir de perfis de sondagem efetuados no entorno das minas Sul e Santa Helena, foi elaborado um estudo do comportamento do embasamento através da confecção de um modelo de topo rochoso, dado pelo contato entre as rochas supracrustais e infracrustais. Apesar do pequeno número de furos de sondagem que atingiram o embasamento, considerando que a maioria foi interrompida antes de atingir este contato, alguns resultados interessantes podem ser obtidos:

Existe uma queda brusca na profundidade do embasamento, indicando a existência de falhas normais/reversas.

O embasamento apresenta tendência a ser menos profundo, tanto na Mina Sul quanto na Mina Santa Helena, e aprofunda-se na região de ocorrência dos sedimentos terciários, entre as duas cavas, conforme apresentado na Figura 5-1. 


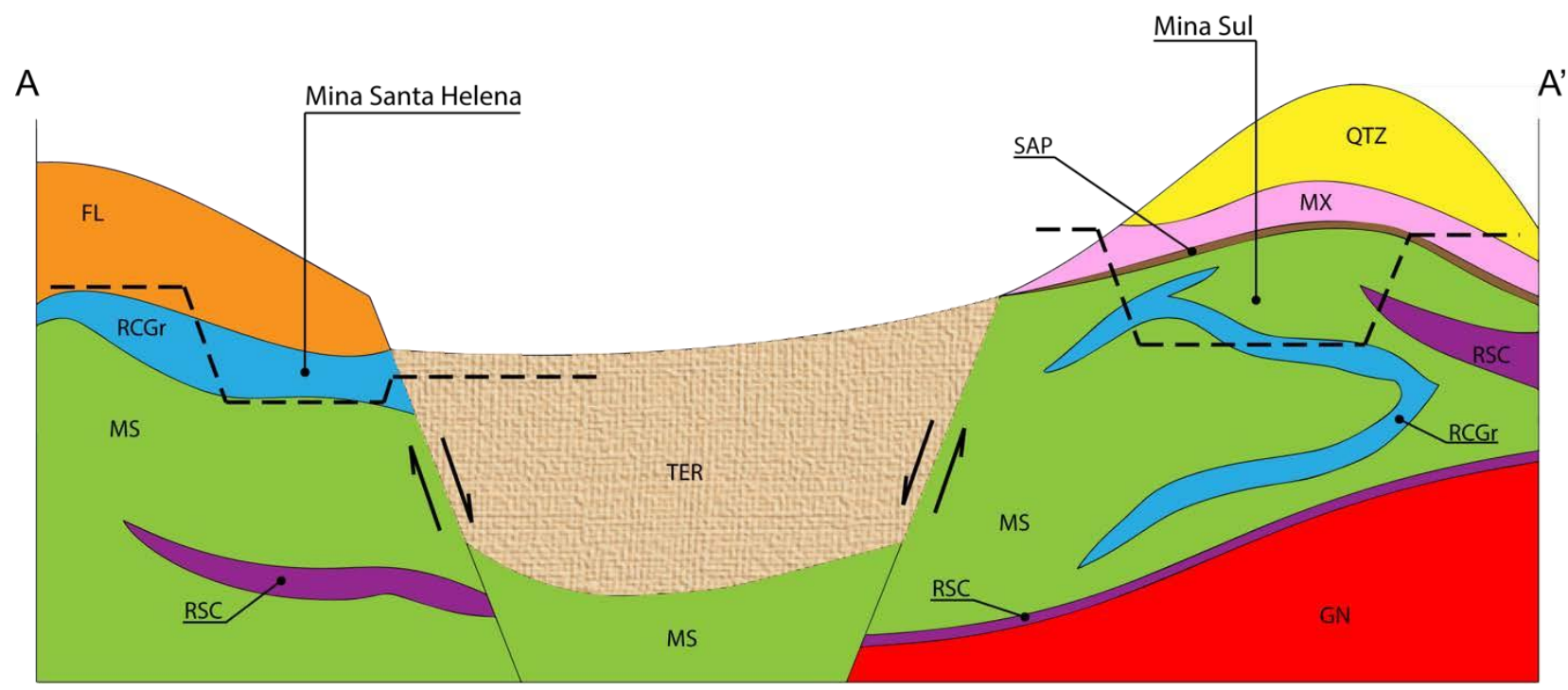

Figura 5-1 - Perfil geológico esquemático AA'. Este perfil sintetiza as inferências feitas a partir das observações de campo e dos dados de sondagens, onde este perfil está assinalado; a escala vertical é arbitrária. Escala horizontal e localização apresentada na Figura 5-2. TER: Sedimentos Terciários; QTZ: Quartzito; MX: Biotita Quartzo Xisto; FL: Filitos; SAP: Saprolito; MS: Mármore Silicoso; RCGr: Rocha Carbonática; RSC: Rocha Súlico Carbonática; CX: Cálcio Xisto e GN: Embasamento Granítico. Modificado de Intercement (2016).

O rejeito calculado no perfil AA' é aproximadamente $60 \mathrm{~m}$, podendo chegar a $70 \mathrm{~m}$, considerando os contatos das supracrustais.

Este sistema de horst e graben aparentemente ocorre por toda a extensão da unidade carbonática e sua expressão em superfície permitiu indicar o traço de um conjunto falhas com direção NE/SW onde se concentram as cavas, como pode ser visto na Figura 5-2. 


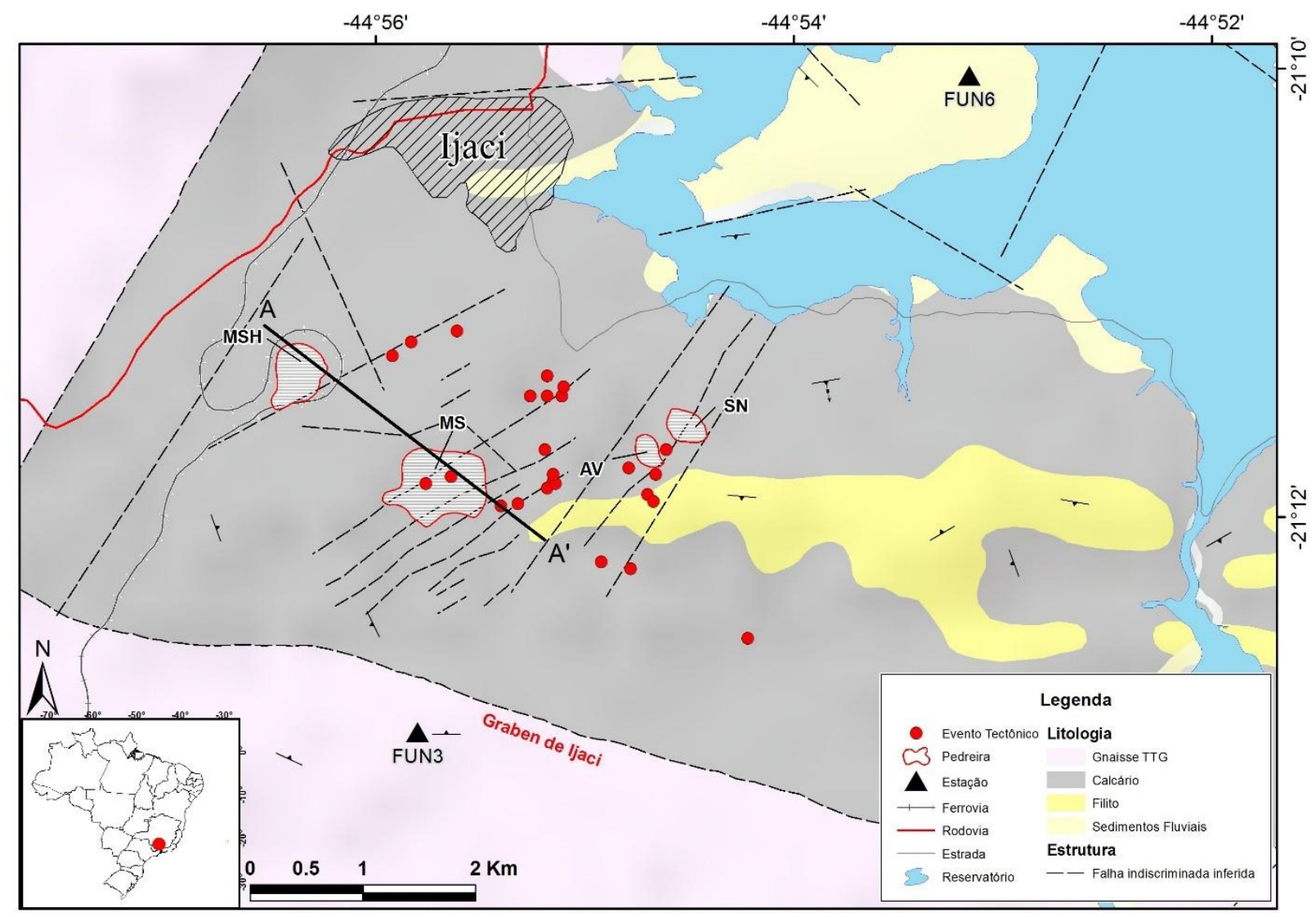

Figura 5-2 - Mapa geológico da região de ocorrência da sismicidade. O graben de Ijaci está restrito a área de ocorrência dos calcários da Formação Barroso. As cavas das minas MSH, MS, AV e SN estão localizadas nos blocos Horst, ou seja, nos blocos elevados em relação aos vizinhos e que aproximam as camadas de calcários da superfície, ficando os blocos de graben (blocos rebaixados) cobertos por material terrígeno e menos interessantes prospectivamente. A localização do perfil AA' (Figura 5-1) está indicado pela linha negra contínua.

\subsubsection{Sismicidade e a extração de minério}

Atividade de mineração consiste em retirar material de interesse econômico e transportálo para distante de seu local de origem. O resultado é um estado permanente de ausência de uma grande quantidade de material no local da mina.

Nos carbonatos da Formação Barroso, as cavas das mineradoras estão assentadas sobre o hanging wall das falhas reversas do graben de Ijaci, que estão sofrendo alívio de pressão devido à remoção constante de material rochoso e rebaixamento do nível freático.

A associação entre sismicidade e as falhas condicionantes do graben, previamente mapeadas, são apresentadas na Figura 5-2. 
O mecanismo focal, tanto dos eventos de melhor precisão, quanto do principal evento de Ijaci, indicam um sistema compressivo atuante na região, sendo as falhas reversas responsáveis pela sismicidade tectônica. São sobre estas falhas reversas que estão assentadas as cavas das mineradoras de calcário e a remoção de uma grande quantidade de material e um grande volume de água, tem provavelmente ocasionado alteração no regime de esforços locais. Falhas reversas estão sujeitas a um estresse pré-existente, resultante de forças naturais. Elas são orientadas de forma diferente das falhas normais e esta diferença faz com que esforços externos, como os derivados de atividades de mineração, tenham grande efeito fazendo com que esta falha se movimente de forma mais rápida. De fato, falhas reversas, em áreas com remoção de material, parecem desencadear terremotos devido a mudanças de massa que é cerca de 1/10 a 1/20 da massa necessária para desencadear sismos em falhas normais (Klose,2013)

Os metacalcários tem sido intensamente explorado por 4 pedreiras atuantes na região. Iniciada nos anos 60 pela Mineração Alvarenga e Indústria de Cal SN, a mineração foi intensificada com a reativação da Mina Santa Helena e início das atividades da Mina Sul, no ano de 2002. As minas Sul e Santa Helena são pertencentes a Intercement, uma das 20 maiores empresas de cimento do mundo, pertencente ao Grupo Camargo Corrêa. Juntas a Mina Sul e Mina Santa Helena alimentam uma das maiores plantas de cimento do Brasil. Estimativas atuais indicam que são extraídas anualmente, em média, dois milhões de toneladas de calcário da Mina Sul (MS) e meio milhão de tonelada de calcário da Mina Santa Helena (MSH). Não foram feitas estimativas para o volume de material movimentado pela Mineração Alvarenga ou Indústria de Cal SN, entretanto, análises in situ e por imagens de satélite permitem afirmar que ambas apresentam capacidade produtiva muito inferior às minas Sul e Santa Helena.

Dados fornecidos pela Intercement indicam que foram extraídos aproximadamente 26 milhões de toneladas de calcário entre 2008 e 2016 das minas Sul e Santa Helena. Considerando a razão estéril/minério como 1.3, isso se traduz em uma carga negativa de aproximadamente 60 milhões de toneladas, ou $5,9 \times 10^{11} \mathrm{~N}$.

Para o sismo principal de 14 de agosto de 2011, a carga negativa aproximada era de aproximadamente 30 milhões de tonelada, ou $2,9 \times 10^{11} \mathrm{~N}$.

É esperado que esse alívio de carga tenha reduzido a tensão vertical $\left(\sigma_{3}\right)$ bem como as tensões horizontais $\left(\sigma_{1}\right)$, mas em menor quantidade. Em falhas reversas esse processo reduz a tensão normal e eleva os esforços de alívio de modo a aproximá-la da ruptura. 
Seeber et al., 1998 demonstraram que a sequência sísmica em Cacoosing Valley (máxima magnitude $\mathrm{M}_{\mathrm{w}}=4,3$ ), próximo a Reading, PA, nos Estados Unidos foi originada por uma falha oblíquo-reversa, localizada diretamente abaixo da pedreira de calcário. A lavra em um pit de 800m de largura por $15 \mathrm{~m}$ de profundidade gerou um alívio de pressão da ordem de $1,1 \times 10^{11} \mathrm{~N}$ e foi determinante no desencadeamento dos sismos.

As cavas das minas, especialmente da Mina Sul tem uma longa dimensão de aproximadamente $1 \mathrm{~km}$, vem sendo escavada desde 2001. Atualmente tem uma profundidade de 100m. Na Figura 5-3 é apresentado a série histórica do volume de calcário mensal (minério) extraído da Mina Sul e a evolução sísmica. Observe que o período de iniciação da mina, entre janeiro de 2008 e janeiro de 2010, foi marcado pelo elevado volume de remoção de material e não é possível associá-lo a qualquer sismicidade local devido à ausência de monitoramento, iniciada em 2011. Apesar das variações não apresentarem relação direta com movimentação de material, é possível afirmar que a sismicidade esteve ativa durante todo o período de atividade da mina.

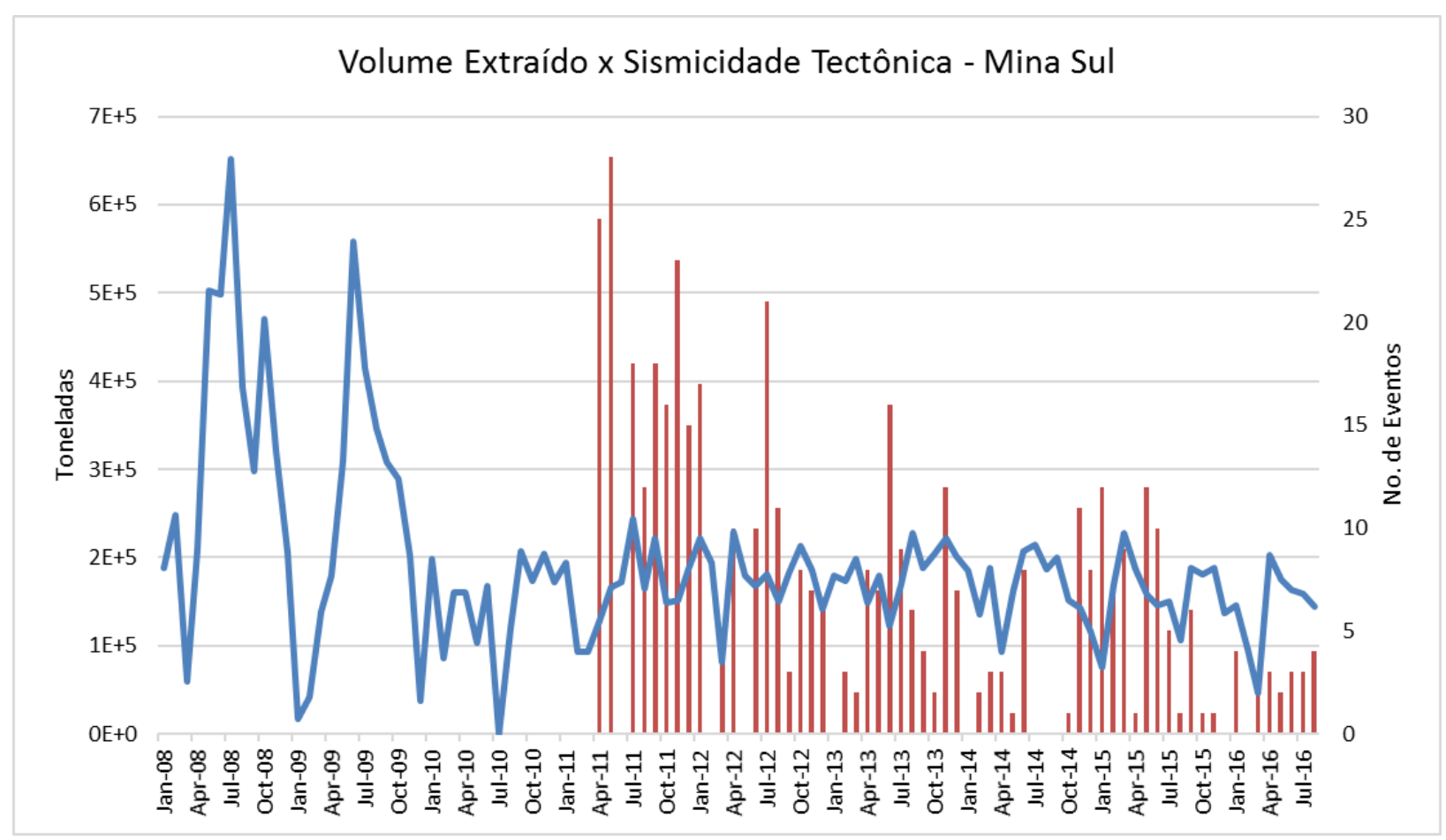

Figura 5-3 - O volume extraído na mina sul (linha azul), entre janeiro de 2010 e junho de 2015 é apresentado no eixo primário (esquerda). Observe o elevado volume de material movimentado durante os anos iniciais das minas Sul e Santa Helena. A evolução da sismicidade é representada no eixo secundário pelas barras vermelhas.

Para ilustrar as condições de tensão e falha, a Figura 5-4, apresenta o círculo de Mohr (Mescua e Giambiagi, 2012). Onde $\sigma_{1}$ representa a máxima tensão compressiva principal que será 
assumida como sendo horizontal e $\sigma_{3}$ é a tensão mínima principal que, próxima a superfície representa a pressão da cobertura.

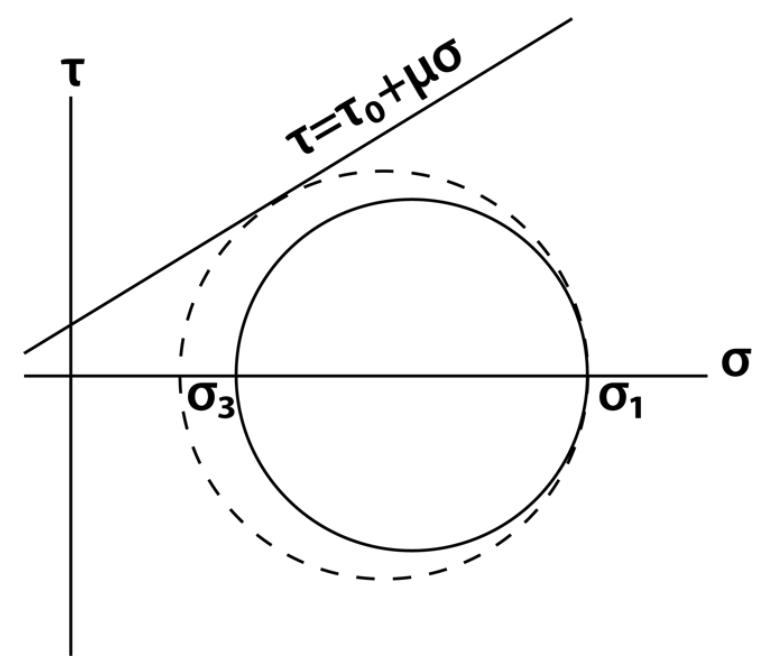

Figura 5-4 - Círculo de Mohr representando a ruptura devido à redução em $\sigma_{3}$, a tensão mínima compressiva. Para os sismos de Ijaci, $\sigma_{3}$ é assumido como sendo vertical devido às falhas reversas existentes na área e cuja redução de $\sigma_{3}$, ocorre devido a retirada de material rochoso e bombeamento de água nas cavas hospedadas no hanging wall das falhas reversas do horst de Ijaci. A linha representada pelo critério de fratura Coulomb-Navier é indicada pela equação $\tau=\tau 0+\mu \sigma$ (modificado de Sbar e Sykes, 1973).

A linha $\tau=\tau_{0}+\mu \sigma$ na Figura 5-4 representa a critério de fratura de Coulom-Navier e $\sigma$ e $\tau$ representam as tensões normais e tangenciais, respectivamente. Conforme a exploração das cavas evolui, $\sigma_{3}$ é progressivamente reduzido, aproximando o círculo de Mohr do envelope de ruptura, enquanto $\sigma_{1}$ se mantém inalterado. O resultado é o aumento do diâmetro do círculo e deslocamento do centro do círculo para a esquerda ( $\sigma$ menor). Este cenário evolve até que o círculo toque a linha de critério de fratura Coulomb-Navier. Neste momento ocorre a fratura e o sismo é iniciado. Este momento é indicado pelo círculo pontilhado na Figura 5-4. A ruptura da falha ocasiona o alívio da tensão $\sigma_{1}$ e o círculo é estabelecido ao seu estado original (círculo contínuo).

Com a continuidade das operações das minas, o processo se repete. A recorrência de sismicidade até os dias atuais corrobora esta teoria. Assumindo uma constância na remoção de material e bombeamento da água surgente na cava, os sismos podem ocorrer em menor magnitude.

Importante ressaltar que as mudanças de tensão envolvendo a remoção de material são pequenas se comparadas a energia necessária para movimentar os blocos do sistema horst/graben. Os esforços regionais submetem esta região a uma tensão que torna suas falhas próximas ao limite de ruptura; a nova condição estimulada pelo alívio de tensão apenas atuou como um gatilho que 
rompeu rochas pré tensionadas. A redução da tensão vertical leva à condição de falha somente quando a tensão vertical é a tensão principal mínima $\sigma_{3}$. Se as atividades de mineração forem cessadas, o nível freático reestabelecido, preenchendo a cava com água e isso ocasionar em uma alteração nos estados dos esforços, tornando a tensão vertical a principal máxima ( $\left.\sigma_{1}\right)$ (como ocorre em regiões de falha normal), então a Figura 5-4 apresentará uma redução na tensão vertical (se tornando $\sigma_{1}$ ) fazendo com que ocorra uma redução no raio do círculo, se distanciando da condição de ruptura.

A detecção e identificação de pequenos sismos na área de mineração de Ijaci só foi possível graças ao monitoramento do reservatório de Funil com instalação da estação sismológica de banda larga FUN1. As detonações feitas rotineiramente para extração do material carbonático se tornam um claro problema na distinção entre eventos tectônicos induzidos e detonações. Esta dificuldade de distinção não ocorre apenas na região de Ijaci, mas em todos locais em que são encontradas grandes minerações com desmonte de material feito por explosivos. Este fato, pode ser a razão pela qual no Brasil ainda não foram identificados outros casos de sismicidade induzida pela remoção de material em regiões com condições de esforços estruturais favoráveis à ocorrência de sismicidade.

A presença de esforços regionais que colocam as falhas do sistema graben/horst de Ijaci em uma condição de tensão compressiva é o fator responsável pela sismicidade em Ijaci e as atividades de mineração atuam apenas como um gatilho para disparar a sismicidade.

\subsection{Extração de Fluidos}

Mudanças na pressão de fluidos subterrâneos são consideradas como um dos principais mecanismos facilitador da movimentação de falhas facilitando a reativação de falhas pré-existentes ocasionando seu deslizamento.

A injeção de fluidos subterrâneos sob alta pressão é normalmente associada ao descarte de resíduos industriais. A água injetada é difundida pelos poros e fraturas do meio rochoso até atingir falhas potencialmente sísmogênicas.

Em Soultz, França, a injeção de fluidos em dois reservatórios profundos, 3500m e 5000m geraram sismicidade com magnitudes máxima de 2.9. (Evans et al., 2005). O caso mais conhecido deste tipo de sismicidade ocorreu em Denver, estado do Colorado, Estados Unidos, nos anos 1960, 
quando a injeção de fluidos no maciço rochoso de Rocky Mountain Arsenal desencadeou sismos de magnitude 5.5.

Embora a sismicidade desencadeada por injeção de fluidos seja comum em países exportadores de petróleo e produtores de hidrocarbonetos (Healy et al., 1968; Wetmiller, 1986; Rayleigh et al. 1976; Fletcher \& Sykes, 1977; Talwani \& Acree, 1985), no Brasil, casos de sismicidade por injeção de fluidos em poços profundos não são conhecidos. Entretanto, existem casos de sismicidade por extração de fluidos na bacia do Paraná, nos municípios de Nuporanga e Bebedouro onde o poço tubular profundo conectou a água de uma fratura rasa, com uma fratura profunda seca e até então assísmica (Yamabe \& Hamza, 1996)

A exploração de água subterrânea também pode ter sido a responsável pela sismicidade na cidade de Fernando Prestes, em 1959. Entretanto, a falta de instrumentos apropriados não permitiu conclusões definitivas (Berrocal et al., 1984).

\subsubsection{Aquífero cárstico}

Aquíferos cársticos são formações geológicas de sedimentos ou rochas inconsolidadas que é capaz de transmitir volumes significante de água subterrânea. Em aquíferos, a água é transmitida através dos poros presentes no meio rochoso. A porosidade é o percentual de espaços vazios presentes no meio rochoso e é tipicamente dividida em duas categorias: Porosidade primária e porosidade secundária. A porosidade primária está relacionada aos espaços vazios formados no momento da deposição dos sedimentos e/ou litificação sendo composta por espaços intergranulares vazios. A porosidade secundária se refere aos espaços vazios formados após a deposição devido ao faturamento, dissolução ou outro processo (Fetter, 2001).

Permeabilidade é a capacidade da rocha de transmitir fluido através dos espaços dos poros no meio (Ford \& Williams, 2007). De forma geral, esta é a medida de interligação dos espaços vazios na rocha e consequentemente a medida da capacidade do meio de transportar água. Aquíferos em unidades rochosas que apresentam baixa permeabilidade transmitem menos água que aquíferos com unidades rochosas com alta permeabilidade.

O termo carste é geralmente definido como um terreno suportado por rochas que são altamente solúveis, por exemplo, calcários com porosidade secundária bem desenvolvida, onde os 
terrenos exibem sistema hidrológico distinto e formas de relevo que podem apresentar cavidades subterrâneas, rios subterrâneos, dolinas e cavernas (Ford \& Williams, 2007) (Figura 5-5).

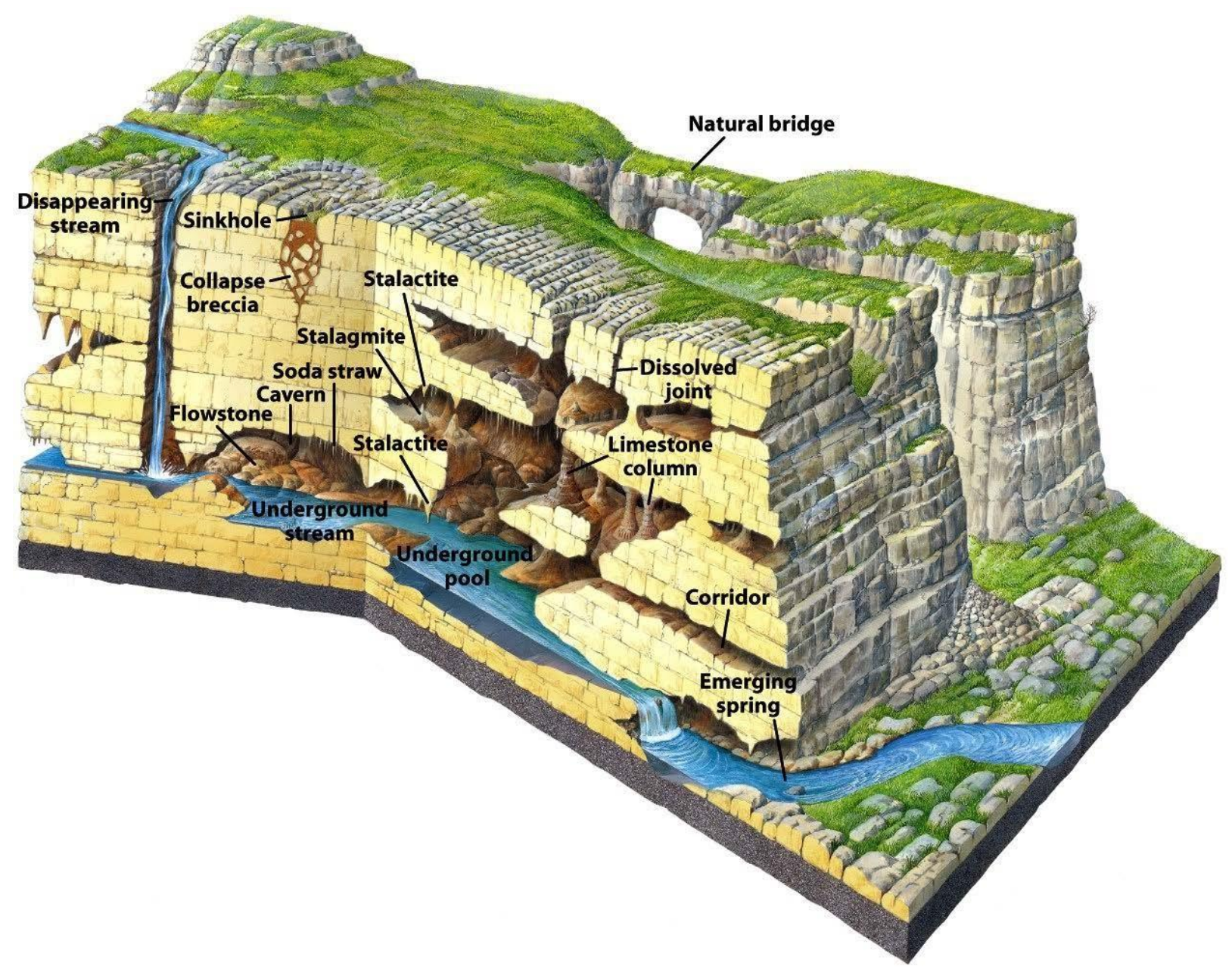

Figura 5-5 - Aquífero cárstico. Características de um aquífero cárstico como cavidades de dissolução, cavernas e fraturas com fluxo de água. Feições como cavernas e fraturas podem estar parcialmente ou totalmente submersas em água. Figura de Marshak, 2008.

\subsubsection{Hidrogeologia local}

Nos arredores de Ijaci estão localizadas as pedreiras de calcário SN, Alvarenga, Mina Santa Helena e Mina Sul que, para explorarem o calcário, efetuam bombeamento contínuo da água surgente no fundo da cava, por vezes superiores a $350 \mathrm{~m}^{3} /$ hora.

Por apresentarem baixa representatividade, tanto no volume de água, quanto no de material extraído, para fins práticos serão desconsiderados neste estudo as minas Alvarenga e Indústria de Cal SN, embora tenha sido observada sismicidade próxima a essas minas. 
Localizada na junção entre três rios importantes do sul de Minas Gerais, na Bacia Hidrográfica do Rio Paraná, as Minas Sul e Santa Helena estão localizadas às margens do Rio Grande.

Os fatores geológicos influenciam diretamente na condução de água subterrânea na região em estudo, dentre eles podemos destacar a litoestratigrafia, as falhas normais e as fraturas.

Um fato importante na litoestratigrafia é que as camadas têm direção Leste-Oeste e se estendem até o Rio Grande a leste.

Levantamentos realizados por HIDROVIA (2003) e sumarizados na Tabela 5-1, indicaram a presença de 3 (três) sistemas hidroestratigráficos na área investigada, quais sejam, da base para o topo: Sistema Hidroestratigráfico Embasamento Cristalino; Sistema Hidroestratigráfico Carbonatos; e, Sistema Hidroestratigráfico Superior.

Os sistemas hidroestratigráficos considerados correspondem aproximadamente às formações rochosas de mesmo comportamento hidráulico, conforme apresentado a seguir.

\section{- Sistema Hidroestratigráfico Embasamento Cristalino}

Este sistema pode abranger localmente pelo menos duas unidades hidroestratigráficas.

A primeira é descrita pelo corpo rochoso cristalino mais coeso e menos fraturado situado nas porções profundas do assoalho gnáissico. Nesta unidade, os processos tectônicos e metamórficos são menos influentes no deslocamento da água subterrânea, pois pouco, ou quase nada, se pode admitir quanto a sua capacidade de fluxo e de armazenamento. Já a zona de topo, cuja espessura é pouco expressiva, pode ser interpretada como uma unidade independente, onde um maior grau de fraturamento e de alteração propiciam uma dinâmica diferenciada do fluxo subterrâneo, no contato com as rochas carbonáticas sobrepostas.

\section{○ Sistema Hidroestratigráfico Carbonatos}

Este sistema corresponde à faixa hidroestratigráfica de calcários que pode se apresentar em determinados trechos, como totalmente maciça e com uma matriz primária de porosidade nula; ou ainda, com faixas de porosidades secundárias determinadas por processos de dissolução, as quais geralmente são coincidentes com os trechos de maior incidência de falhamentos ou mesmo planos de fraturas da rocha calcária, que acabam por adquirir um condicionamento hidráulico diferenciado das demais porções da matriz rochosa. 
Faixas de maior dissolução/faturamento apresentam valores de condutividade hidráulica bastante distintos, constituindo-se em uma unidade hidroestratigráfica diferenciada. Assim, a diferenciação entre as unidades hidroestratigráficas deste sistema é feita pela identificação das zonas de incidência de estruturas tectônicas capazes de modificar a dinâmica de fluxo das águas subterrâneas. Ademais, cabe ressaltar que esta tem potencial para representar a principal unidade de armazenamento e de deslocamento das águas subterrâneas em profundidade. Nela podem estar desenvolvidos processos específicos de dissolução do material carbonático, revelando um meio de elevada anisotropia do sistema de infiltração.

\section{- Sistema Hidroestratigráfico Superior}

Este sistema corresponde, predominantemente, ao material de capeamento das rochas (solos de cobertura) e, subordinadamente, às rochas fissuradas xistosas e quartzíticas do Grupo Andrelândia, que em sua maioria possuem materiais de baixa capacidade de condução hidráulica, constituindo-se em unidades diferenciadas. Em geral, os solos de cobertura compreendem materiais porosos argilosos ou silto-argilosos com uma espessura variável. Estes materiais manifestam-se como meios aquíferos pobres, ou mais comumente como aquitardes, que podem armazenar grandes quantidades de água, porém, apresentam deficiência em relação a sua capacidade de fluxo. 
Tabela 5-1 - Materiais litológicos distintos com a identificação das respectivas unidades hidroestratigráficas, compilado de Hidrovia (2003).

\begin{tabular}{|c|c|c|}
\hline \multicolumn{2}{|c|}{ Lito-estratigrafia } & \multirow{2}{*}{ UNIDADES HIDROESTRATIGRÁFICAS } \\
\hline Grupo & Formação & \\
\hline \multicolumn{2}{|c|}{$\begin{array}{c}\text { Depósitos elúvio-coluvionares indivisos } \\
\text { (coberturas inconsolidadas) }\end{array}$} & $\begin{array}{l}\text { Unidade } 1 \text { - Aqüífero livre / freático } \\
\text { (Porosidade intersticial primária). }\end{array}$ \\
\hline Andrelândia & Biotita xistos e quartzitos & $\begin{array}{c}\text { Subunidade - Aquitarde fissurado } \\
\text { (materiais fissurados a base de xistosidades } \\
\text { e fraturas apertadas, baixíssimos valores } \\
\text { de condutividade hidráulica). }\end{array}$ \\
\hline São João Del Rei & $\begin{array}{l}\text { Formação Barroso } \\
\text { Mármore silicosos, cálcio- } \\
\text { xistos, margas e calcário } \\
\text { granoblástico }\end{array}$ & $\begin{array}{l}\text { Unidade } 2 \text { - Aqüífero Carbonático } \\
\text { (Porosidade fissural secundária, baixos a } \\
\text { médios valores de condutividade } \\
\text { hidráulica; elevados localmente). }\end{array}$ \\
\hline $\begin{array}{l}\text { Embasamento } \\
\text { Cristalino }\end{array}$ & Granitos e gnaisses, & $\begin{array}{c}\text { Unidade } 3 \text { - Aqüiclude (Porosidade } \\
\text { secundária desprezível; Baixíssimos valores } \\
\text { de permeabilidade). }\end{array}$ \\
\hline
\end{tabular}

\subsubsection{Modelagem Hidrogeológica}

A partir de 2001, considerando a necessidade de se rebaixar o nível d'água referenciado ao aquífero carbonático, em função do aprofundamento das cavas de lavra abaixo do nível de base local representado pelo Rio Grande e suas sub-bacias, fez-se imperativa a elaboração de um estudo de rebaixamento para a previsão dos impactos potenciais decorrentes das atividades exploratórias ao longo da vida útil da Mina Sul e Mina Santa Helena (Hidrovia, 2006).

Para acompanhamento da oscilação dos níveis d’água do aquífero carbonático, nos anos que se seguiram foi executado um conjunto de atividades de implantação da rede de monitoramento dos recursos hídricos superficiais e subterrâneos, através da instalação de dispositivos de medição de descargas: conjuntos de calhas Parshall e réguas milimétricas, bem como a construção de poços tubulares e escavados e poços piezométricos.

Em 2006 a empresa Hidrovia, Hidrogeologia e Meio Ambiente LTDA foi contratada pela Camargo Correia Cimentos, por meio de sua subsidiária Intercement, para executar avaliação sobre as condições de rebaixamento do nível d'água, no domínio de influência das minas Sul e Santa Helena. Tal estudo foi baseado no monitoramento contínuo ao longo do tempo em regime 
transiente com o intuito de produzir avaliação temporal e espacial das condições de rebaixamento do nível freático, apontando as interferências do avanço das lavras abaixo do nível d'água dos aquíferos carbonáticos, com base na criação de cenários preditivos de avanço da lavra em profundidade.

Um modelo hidrogeológico computacional foi desenvolvido em condição temporal transiente. As simulações futuras para as minas Sul e Santa Helena, foram baseadas em cenários especulativos concebidos para a evolução das lavras a 37.5\%, 50.0\%, $75.0 \%$ e $100.0 \%$ da cota de fundo planejada para as cavas das referidas minas.

Nestes cenários especulativos, a cota de fundo da cava da mina Santa Helena seria rebaixada cerca de 133,0 metros, variando do valor médio original de 913,0 m até a cota final de $780,0 \mathrm{~m}$, correspondente ao estágio final de $100 \%$ da lavra. De maneira similar, e simultaneamente, a cota de fundo da Mina Sul também seria rebaixada, em uma extensão um pouco maior, de cerca de 150,0 metros, variando de $880,0 \mathrm{~m}$ até a cota final de 730,0m (100\% da lavra).

A Figura 5-6 representa os cenários especulativos concebidos para a evolução da lavra da Mina Sul (MS) e Mina Santa Helena (MSH), com a indicação das respectivas cotas de fundo das cavas. Como ambas as cavas se encontravam em 2006, na cota 840,0, percebe-se que o cenário evolutivo de lavra para Mina Santa Helena correspondia a cerca de 55\% do avanço previsto, enquanto que para a Mina Sul correspondia a cerca de 27\% do avanço previsto no plano de lavra. 


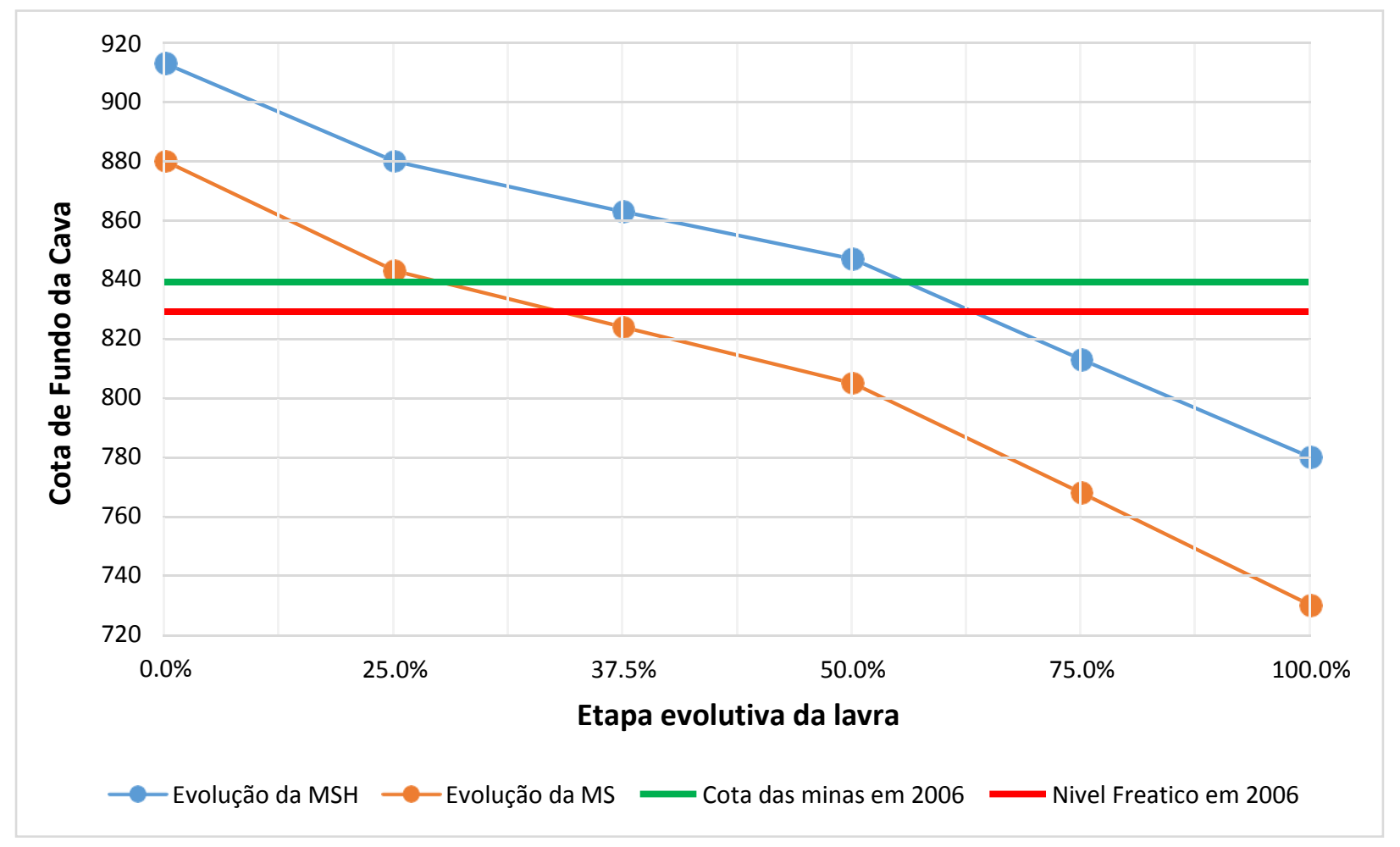

Figura 5-6 - Evolução das cotas de fundo das cavas das minas Sul (MS) e Santa Helena (MSH) em função dos estágios de avanço da lavra, com a indicação da cota de fundo atual de ambas as cavas (cota 840,0 m) e da cota atual estimada para o nível freático (cota 830,0 m) (Hidrovia, 2006).

No primeiro cenário, com avanço a 37,5\%, que correspondeu ao ano de 2008/2009, estimava-se que a zona de influência do rebaixamento das águas subterrâneas seria pouco significativa, mantendo-se numa condição similar à encontrada em 2006, onde apenas a Mina Sul havia iniciado o processo de rebaixamento do nível freático de forma pouco acentuada, permanecendo o aquífero praticamente inalterado. Nesta condição o escoamento das águas subterrâneas se daria ainda das zonas de cotas mais elevadas para as zonas de cotas mais baixas, i.e., em direção ao Rio Grande, conforme Figura 5-7. 


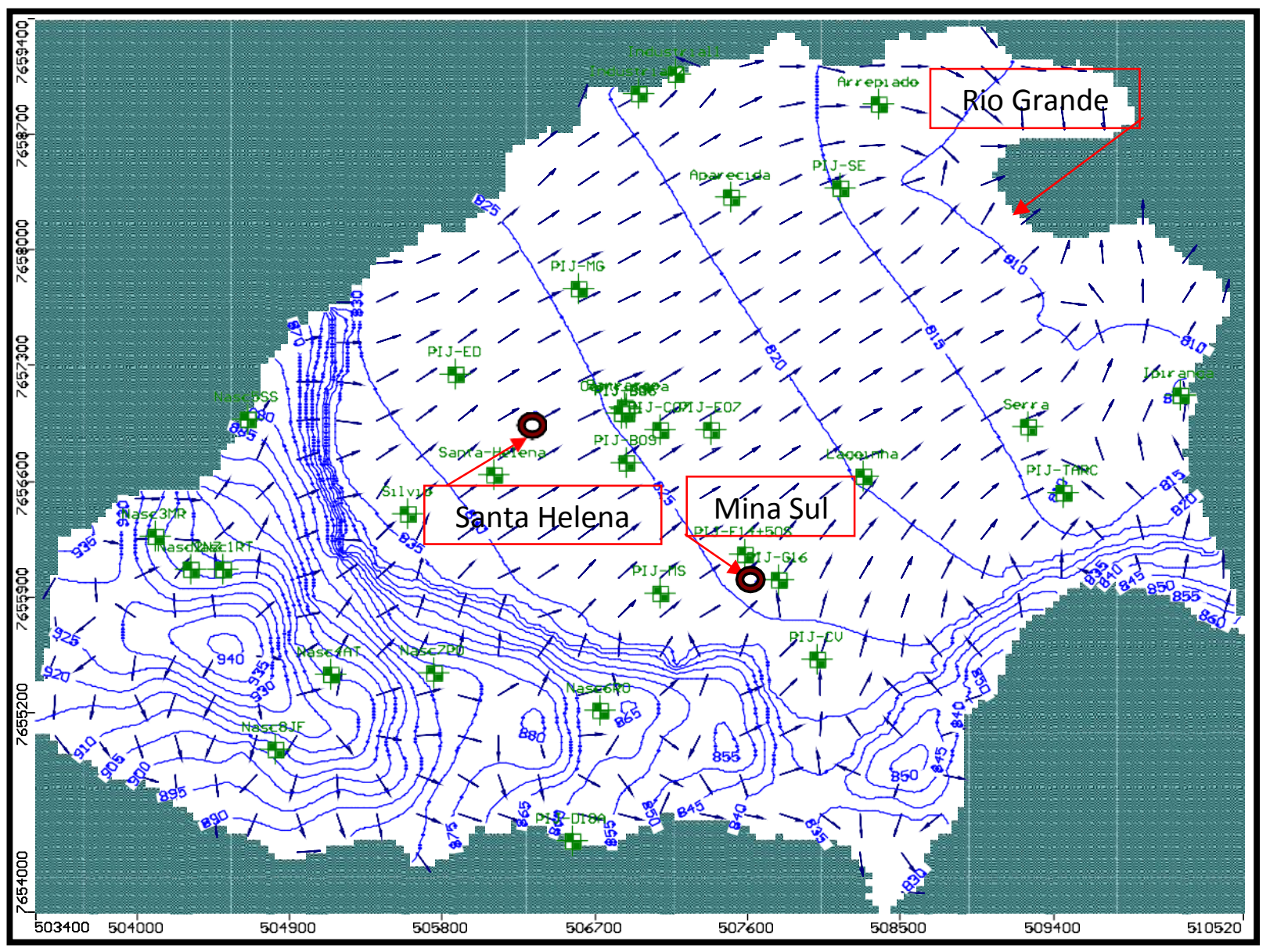

Figura 5-7 - Distribuição das cargas hidráulicas e dos vetores direcionais de fluxo das águas subterrâneas, representativos para o estágio de lavra a 37,5\% da cota de fundo planejada para as minas Sul e Santa Helena. Nota: As linhas em azul representam as curvas de isovalor de carga hidráulica. As setas em azul representam os vetores direcionais de fluxo. Os quadrados verdes indicam a localização dos piezômetros. Seção horizontal na cota 805 metros (modificado de Hidrovia, 2006).

No segundo cenário, com avanço a 50,0\%, o que correspondeu aos anos 2011/2012, estimava-se que a zona de influência do rebaixamento das águas subterrâneas se estenderia por todo o domínio em questão, principalmente nas regiões de cotas inferiores, localizadas a norte e nordeste das minas. Este rebaixamento deveria alterar as cotas nos poços e piezômetros e era esperado que houvesse um rebaixamento no nível d'água na ordem de 10 a 15 metros nas proximidades da Mina Santa Helena e em até 24 metros no entorno da Mina Sul.

Além disso, era esperado que neste cenário $(50,0 \%)$ a distribuição potenciométrica do aquífero se alterasse significativamente no entorno da Mina Sul. Nesta condição, haveria uma inversão na direção em uma parte do fluxo subterrâneo e as águas subterrâneas seriam direcionadas ao fundo da cava da Mina Sul e não mais para o Rio Grande, conforme apresentado pela Figura 5-8. Esta inversão não seria observada na Mina Santa Helena. 


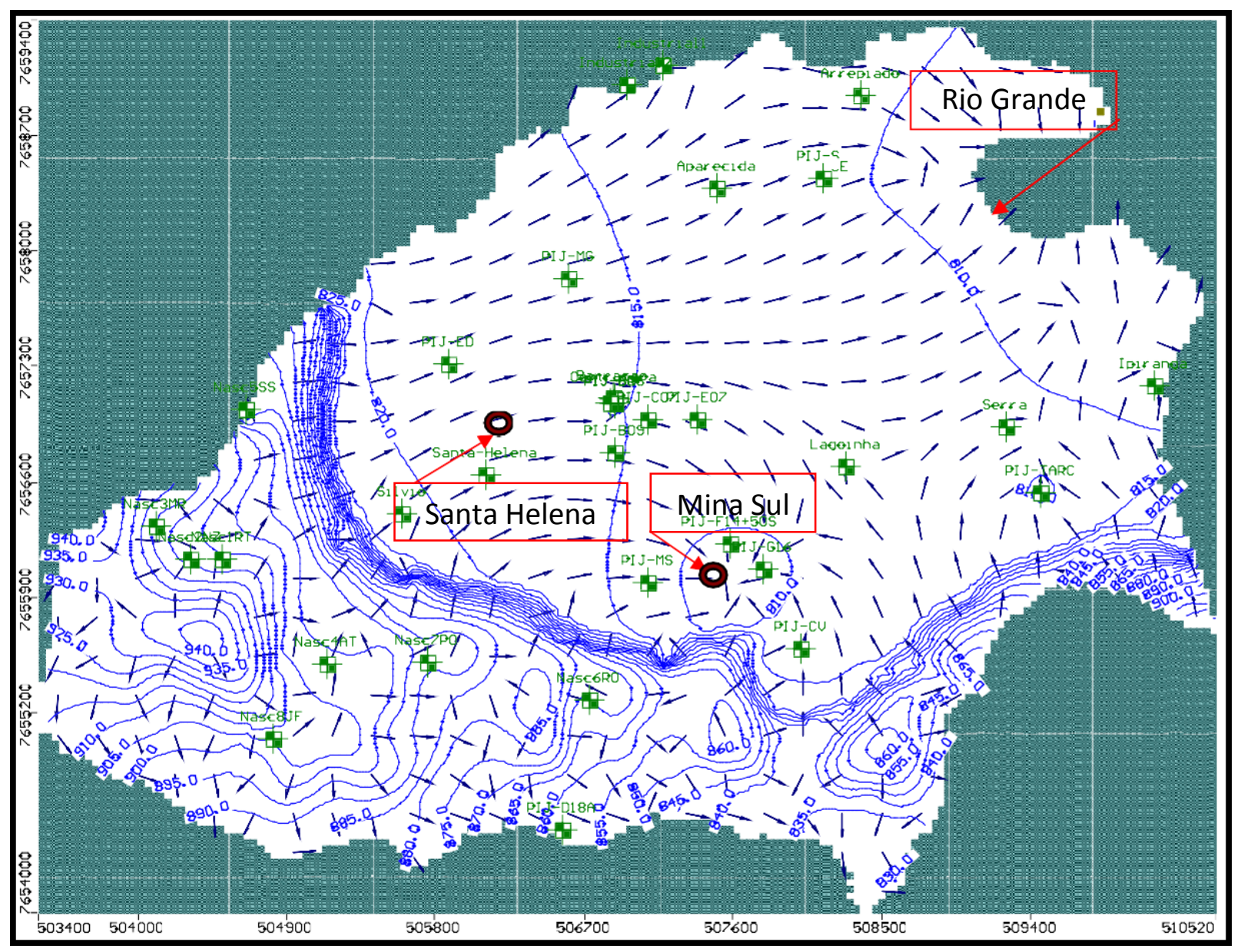

Figura 5-8 - Distribuição das cargas hidráulicas e dos vetores direcionais de fluxo das águas subterrâneas, representativa para o estágio de lavra a 50,0\% da cota de fundo planejada para as minas Sul e Santa Helena. Nota: As linhas em azul representam as curvas de isovalor de carga hidráulica. As setas em azul representam os vetores direcionais de fluxo. Os quadrados verdes indicam a localização dos piezômetros. Seção horizontal na cota de 775 metros (modificado de Hidrovia, 2006).

Desta forma, no cenário com $50 \%$ de avanço de lavra, correspondente a cota $805 \mathrm{~m}$, na Mina Sul, abaixo da cota do lago (808m). O aporte de água subterrânea esperada deveria ser da ordem de $6040 \mathrm{~m}^{3} / \mathrm{dia}$. 


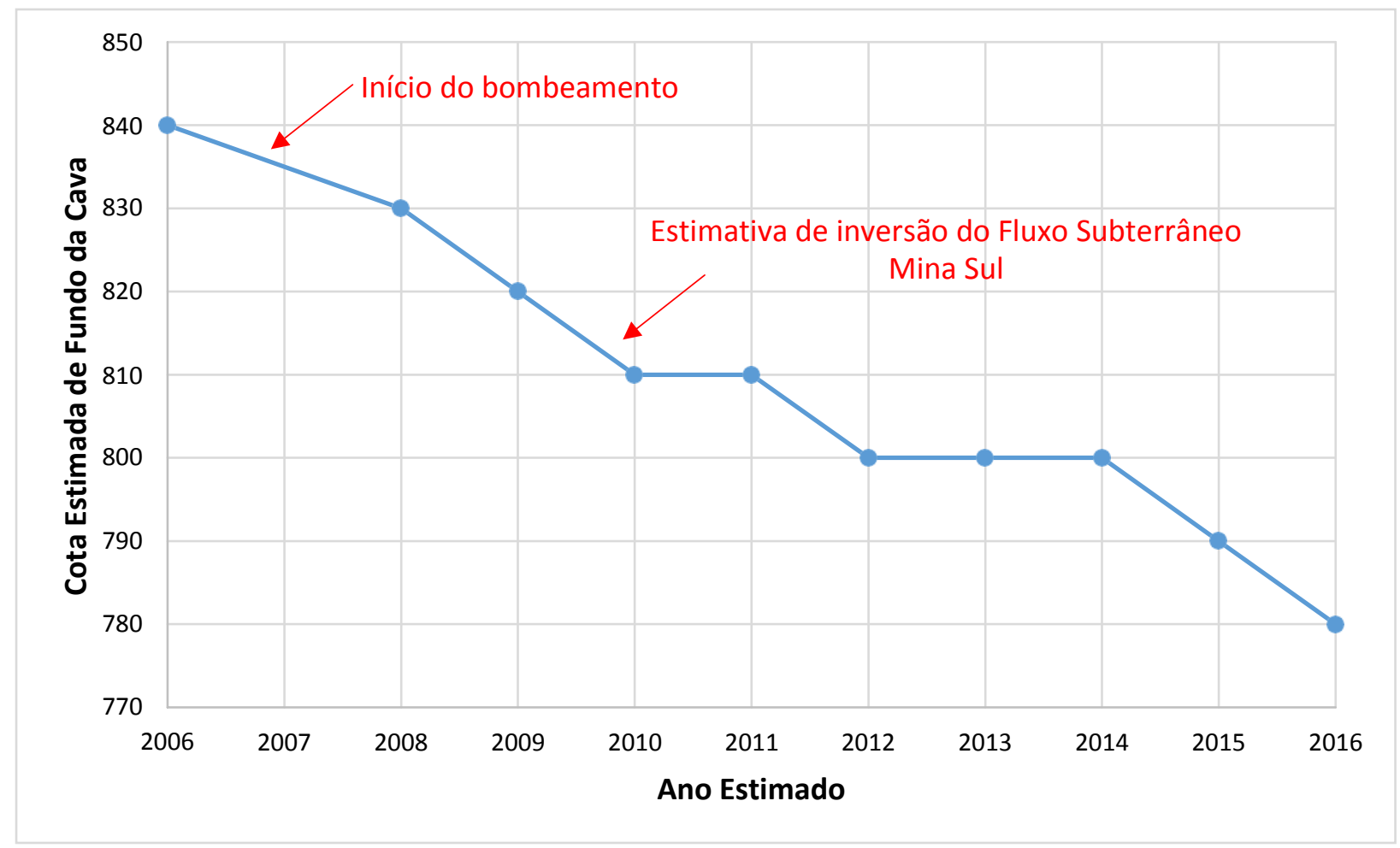

Figura 5-9 - Evolução estimada da lavra da Mina Sul (MS) nos últimos 10 anos com base em comunicação pessoal (Intercement, 2015).

\subsubsection{Análise do modelo hidrogeológico}

Na Figura 5-10 são apresentadas as medidas de piezômetros obtidas em poços situados no entorno das minas Sul e Santa Helena, localizações indicadas na Figura 5-11.

As análises das medidas de piezômetro permitem concluir que, o nível freático no entorno das cavas sofre pouca influência das variações de bombeamento apresentadas principalmente na Mina Sul.

As recargas superficiais exercem pouca influência sobre as variações do nível freático pois as medidas de piezômetros tanto na estação seca quanto chuvosa são similares, de modo que a superfície d'água é inicialmente horizontal.

As elevações de nível observadas nos poços 4, 8 e 11 (Figura 5-11) estão, muito provavelmente, relacionadas a ausência de bombeamento na Mina Santa Helena. Apesar de espacialmente os poços 11 e 4 estarem próximos à cava da Mina Sul, conforme citado nos capítulos anteriores, os aquíferos cársticos apresentam uma singularidade no que diz respeito a conectividade de fraturas e este parece ser o caso. As fraturas que abastecem o nível freático nestes 
poços parecem estar conectadas aqueles que abastecem a cava da Mina Santa Helena e não apresentam qualquer relação com os que abastecem a Mina Sul.

Os picos anômalos observados nos poços 10, 7 e 9 podem estar relacionados a erros em medidas, pois são temporariamente isolados e não se repetiram em outros pontos.

O poço 6 parece ser o mais sensível às variações de bombeamento da Mina Sul, indicando um sistema conectado e com uma única fonte. A queda do nível freático observada a partir do mês de janeiro de 2016 tem relação direta com a constância e elevação no volume de água bombeada, conforme observado na Figura 5-12. Também a partir da Figura 5-12 é observado ausência de sismicidade no período em que as atividades de bombeamento cessaram. Nos períodos em que houve intermitência no bombeamento desta cava, o nível foi rapidamente estabelecido, impossibilitando que fosse observada esta conexão. No momento em que o bombeamento se tornou constante, o sistema não demonstrou fluxo suficiente para reestabelecer o nível no cone de depressão formado pelo bombeamento e com isso o rebaixamento do nível pôde ser observado.

O poço 9, parece ser o único que sofre influência do lago. Sua total constância nas medidas, com exceção de uma medida obtida em setembro, e cota idêntica ao nível máximo do lago indicam, que o aquífero neste ponto está sendo condicionado pela elevação do nível ocasionado pelo reservatório de Funil. Nos demais pontos, não foi observada essa relação. 


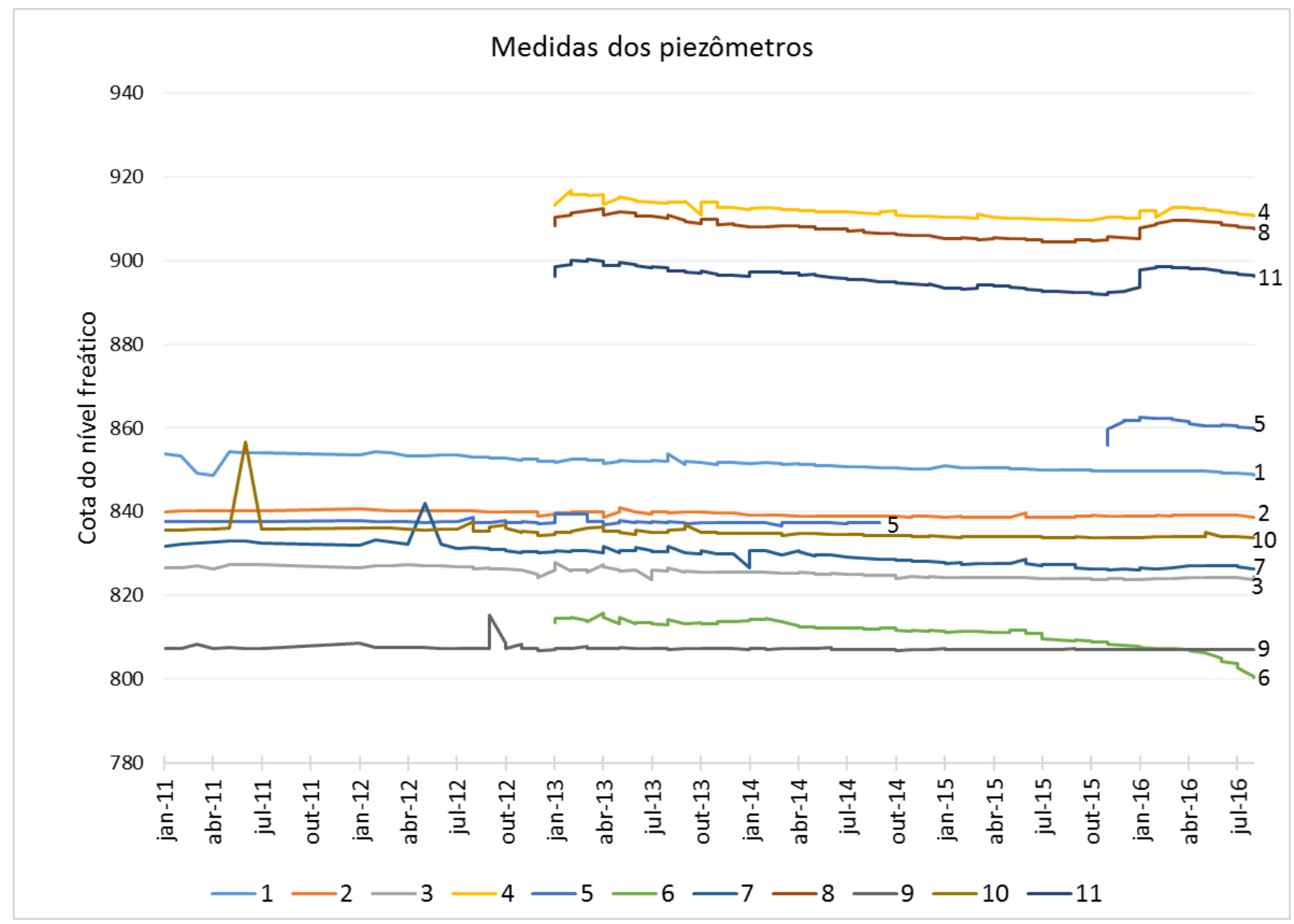

Figura 5-10 - Variação nas medidas dos piezômetros entre janeiro de 2011 e agosto de 2016. As descontinuidades nas linhas (medidas das cotas) se referem a períodos sem coleta de medidas. Os números de 1 a 11 estão relacionados com os piezômetros apresentados pela Figura 5-11. 


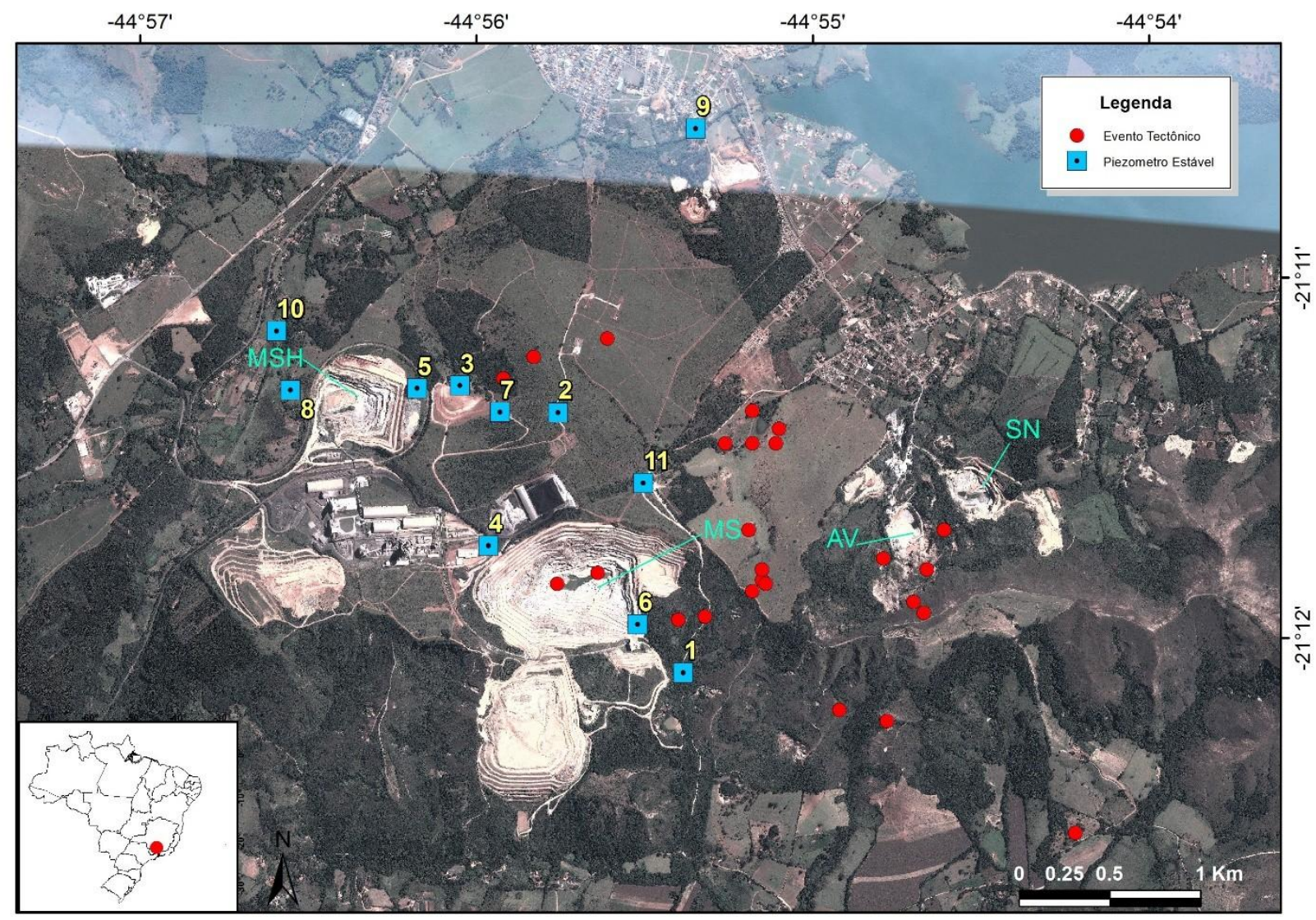

Figura 5-11 - Mapa com a localização dos piezômetros de monitoramento do nível freático nos arredores da MS (Mina Sul) e MSH (Mina Santa Helena). No empreendimento existem outros piezômetros, entretanto, neste trabalho serão considerados apenas os que apresentaram medidas em períodos superiores a 6 meses. 


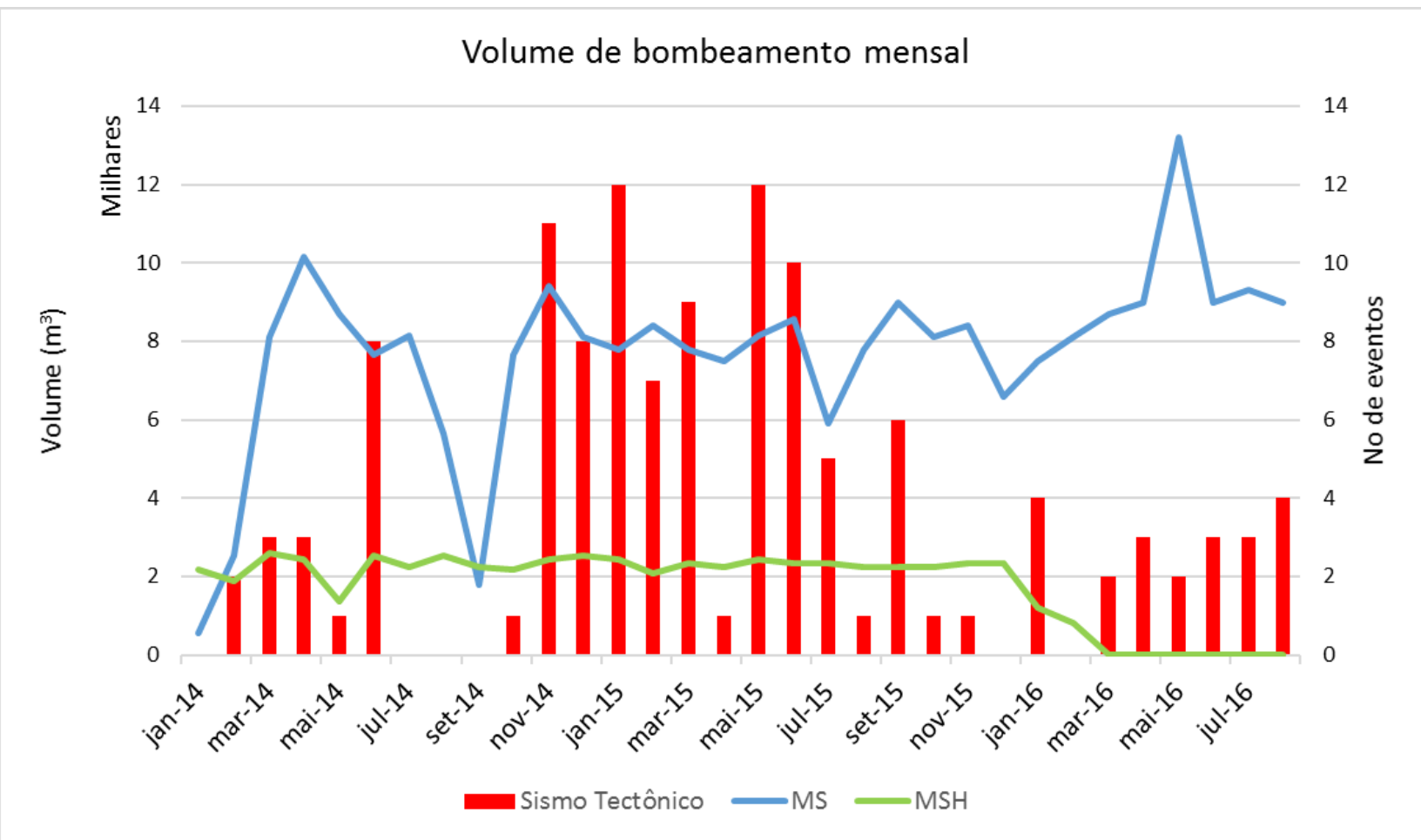

Figura 5-12 - Variações no volume de bombeamento ( $\left.m^{3}\right)$ d'água que é efetuado nas Mina Sul (MS) e Mina Santa Helena (MSH) com o objetivo de rebaixar o nível freático e liberar o fundo da cava para exploração do minério. A escala vertical está em milhares.

\subsubsection{Discussão}

Considerando o estágio atual estimado de desenvolvimento das cavas, onde Mina Sul estaria desenvolvida entre 44 e $48 \%$, próxima às simulações apresentadas pelo segundo cenário. Neste cenário as expectativas davam conta de que o rebaixamento do nível d'água seria da ordem de 10 a 16 metros no entorno da Mina Santa Helena, podendo chegar a 24m no entorno da Mina Sul.

Alguns fatores corroboraram para que houvessem discrepâncias entre as estimativas de Hidrovia 2006 e o observado durante a evolução da cava. Dentre eles, podemos citar como um dos principais, o fato de todas as simulações terem sido executadas com o código computacional denominado Visual MODFLOW - Modular Three-Dimensional Ground Water Flow Model, licenciado por Waterloo Hydrogeologic Software (Guiguer \& Franz, 1998). Este pacote de softwares foi desenvolvido para modelagem tridimensional por diferenças finitas, centradas no bloco para fluxo de água subterrânea, permitindo simulações com complexas condições 
hidrogeológicas apresentadas por aquíferos homogêneos ou heterogêneos, confinados ou não confinados, isotrópico e anisotrópico. Também pode ser aplicado para fluxos variáveis e não variáveis. Uma infinidade de equações e modelos podem ser solucionados por este pacote de softwares com algumas exceções, dentre elas, o modelo de aquífero fissural/cárstico, que é justamente o sistema sob o qual as minas estão assentadas e que regem os aquíferos da região em questão.

Uma atualização deste sistema, desenvolvida pelo Serviço Geológico dos Estados Unidos (USGS) (Harbaugh, 2005), intitulada MODFLOW 2005, trouxe o pacote de programas CFP Conduit Flow Process, que ajusta estes algoritmos para aquíferos fissurais/cársticos.

Estima-se que, caso as simulações estivessem sido executadas com o pacote MODFLOW 2005 - CFP os modelos estariam mais adequados à realidade.

\subsubsection{Sismicidade e extração de água}

Apesar do contexto geológico e hidrogeológico favorável para a indução de sismicidade a partir da extração de água no fundo da cava, este não parece ser o fator determinante para o desencadeamento da sismicidade em Ijaci.

As medidas dos piezômetros indicam que o nível freático nos arredores das minas Sul e Santa Helena está acima da cota do lago (808m), com exceção do Poço 6 (Figura 5-10 e Figura 5-11) onde a constância de bombeamento na Mina Sul rebaixou o nível freático neste ponto. Esta variação corrobora com a afirmação de que o cone de depressão gerado pelo bombeamento é vertical e restrito ao entorno da mina. Observe que o Poço 1, mesmo estando próximo e topograficamente abaixo do Poço 6, não apresentou qualquer variação no mesmo período.

O sistema de aquífero é heterogêneo, diferentemente do apontado por Hidrovia (2006) e o fluxo de água subterrânea parece ocorrer através de fendas com diferentes orientações. Esta afirmação é validada pela variação de nível apresentada pelos Poços 4, 8 e 11, que apesar de espacialmente distantes (Poço 8 nos arredores da Mina Santa Helena e Poço 4 nos arredores da Mina Sul) apresentam comportamento temporal similar, indicando a existência de uma conexão entre eles.

Diferentemente do observado em aquíferos homogêneos e estimado por Hidrovia (2006), não é observado incremento no aporte de água com o avanço da cava em profundidade. A variação 
no volume de água extraída aparenta estar unicamente relacionado aos períodos de aumento e redução no volume do material minerado nas minas.

A elevação da cota do lago não exerce qualquer influência no nível freático da área, com exceção da orla do lago, como apontado pelo Poço 9. Desta forma, é possível concluir que a água proveniente do fundo da cava não provém do lago e que a reversão de fluxo proposto pelo Segundo Cenário (50\%) de Hidrovia (2006) não ocorre. Esta inversão e alteração no fluxo de água subterrâneo poderia ter sido o responsável por uma mudança no estado de esforços na região e consequente desencadeamento da sismicidade. A não ocorrência destes fatores, inviabilizam essa associação.

O cone de depressão vertical é restrito a poucos metros das cavas das minas Sul e Santa Helena, sendo observado apenas no Poço 6. Este fato faz com que o impacto do bombeamento no meio rochoso seja reduzido e pouco alteraria o estado dos esforços na região. Essa pequena alteração muito provavelmente não teria energia suficiente para ser responsável pelo desencadeamento da sismicidade observada em Ijaci.

\subsection{Reservatórios de barragens}

$\mathrm{O}$ enchimento de reservatórios, historicamente apresenta um maior potencial para a indução de sismos de maior magnitude, com capacidade inclusive de causar danos a edificações. O maior sismo induzido, de magnitude 6,3, ocorreu no reservatório de Koyna, Índia, causou 200 mortes, 1200 feridos e diversos danos a estrutura da barragem (Gupta, 1976, 1992).

Entretanto, em geral, os sismos induzidos por outras atividades humanas comumente apresentam baixa magnitude e raramente causam danos (Cypser e Davis, 1994).

Dois mecanismos podem ser associados com a Sismicidade Induzida por Reservatório (SIR): a resposta do meio rochoso à carga do reservatório; e a difusão das pressões de poros do reservatório (Simpson et al. 1988; Simpson \& Narasimhan 1990; Rajendran \& Talwani 1992; Chen \& Talwani 2001; Talwani et al. 2007).

Os sismos desencadeados por reservatórios foram divididos, conforme suas características temporais, por Harris e Simpson (1998) em duas classes; sismos de rápida resposta (inicial) e sismos de resposta atrasada. Os sismos de rápida resposta (inicial) são associados à carga (ou descarga) e pela difusão da pressão porosa exercida sob o reservatório no período de iniciação do enchimento. Nesse caso, a sismicidade ocorre logo após o enchimento do lago com um período 
curto de maior atividade e decresce a níveis anteriores ao surgimento do reservatório. Normalmente, o sismo de maior magnitude ocorre após o reservatório atingir sua cota máxima (Barros et al., 2016). Talwani (1997) descreveu como sismicidade prolongada àquela que ocorre após o enchimento do reservatório de forma contínua e sem uma redução na frequência ou na magnitude. Este tipo de sismicidade ocorre raramente e é observada em reservatórios com grandes ciclos de enchimento e reestabelecimento de nível.

Vários fatores estão associados ao desencadeamento de SIR, como por exemplo, a altura da lâmina d'água, a velocidade do enchimento, a amplitude e periodicidade das variações do nível do lago (Gupta, 2002), a taxa de incremento da pressão nos poros (Talwani et al., 2007).

A pressão dos poros nas rochas sob o reservatório é aumentada à medida que o reservatório é preenchido e sismos podem ocorrer imediatamente durante este processo.

Uma complexa relação entre esforços induzidos pelo reservatório e o contexto tectônico será decisiva para o desencadeamento de sismicidade. Os efeitos do esforço vertical, somado a pressão dos poros tendem a desencadear sismicidade principalmente em locais onde o esforço compressional máximo é vertical, em falhas normais (Snow, 1972). Em locais caracterizados por esforço compressional horizontal, falhas reversas, a ocorrência de sismicidade induzida é baixa, mas não nula. Geralmente neste contexto a pressão exercida pela criação do reservatório poderá até cessar uma sismicidade pré-existente, causando assismicidade.

No Brasil, o primeiro caso importante de SIR foi relatado após a ocorrência de um sismo de magnitude 3,7, intensidade V-VI (MM) no reservatório de Carmo do Cajuru/MG, em janeiro de 1972, localizado a aproximadamente 100km de Ijaci.

Simpson, 1976 demonstra que a profundidade da coluna d'água tem maior importância que o volume total do reservatório, e que a atividade sísmica induzida é mais comum em reservatórios com profundidade igual ou superior a 100m. Entretanto, este não é um fator único na determinação do potencial sísmico de um reservatório, como por exemplo o reservatório de Itaipu/PR (196m) e São Simão/MG (128m), com lâminas d'água superior a 100m e que nunca registraram SIR; e os reservatórios de Carmo do Cajuru/MG (20m) e Balbina/AM (35m) com lâmina d'água bem inferior a 100m e com SIR associada (Veloso e Assumpção, 1989).

Para Barros et al., 2016, a probabilidade de ocorrência de SIR no Brasil não é desprezível e deve ser levada em consideração no projeto de segurança de barragens uma vez que $50 \%$ dos reservatórios com altura superior a 100m apresentam sismicidade induzida. 


\subsubsection{Sismicidade e a UHE Funil}

A barragem do reservatório de Funil forma um lago com $40 \mathrm{~km}^{2}$ de área inundada e um volume de $0,26 \mathrm{~km}^{3}$. Tem altura máxima de $40 \mathrm{~m}$, com uma extensão de $30 \mathrm{~km}$. De acordo com estatísticas apresentadas por Barros et al., 2016, a probabilidade de o reservatório de Funil desencadear sismos é inferior a $2 \%$.

Do ponto de vista geológico, a área alagada pelo reservatório da UHE Funil recobre parcialmente rochas pertencentes a dois domínios. O primeiro $\left(20 \mathrm{Km}^{2}\right)$ equivale a área pertencente ao domínio de rochas gnáissicas do Complexo Gnáissico-Migmatítico e o segundo $\left(19,9 \mathrm{Km}^{2}\right)$ corresponde à área de domínio dos metassedimentos carbonáticos denominado Formação Macaia. A região do lago situada próxima à área de Ijaci (Figura 5-2) recobre a interface entre o Complexo Gnáissico-Migmatítico e os metassedimentos carbonáticos (Figura 2-3). Esta interface, localizada no extremo norte do Graben de Ijaci, ocorre através de falhas com mergulho subvertical e direção N80E (Silva, 1978).

Zonas de interface litológica marcadas por falhas tendem a apresentar maior permeabilidade quando submetidas a elevações de pressão, como o caso da criação do lago sobre as falhas norte do Graben de Ijaci. Entretanto, a distribuição espacial apresentada pelos sismos, não parece associada a qualquer falha nesta direção ou mesmo na área de ocorrência desta interface.

Kumar, 2012, demonstrou que as variações no nível d'água no reservatório de Koyna e Warna, Índia são responsáveis pelo desencadeamento de sismos. Gupta (1983) sugeriu que sismos com magnitudes superiores a 5,0 são esperadas quando a taxa de carga excede 40ft por semana, em contrapartida, Simpson e Negmatullaev (1978) observaram que na barragem de Nurek, sul da antiga União Soviética, ocorria uma elevação na atividade sísmica com o rebaixamento do nível do reservatório.

Dados fornecidos pelo consórcio Aliança Energia, operadora da UHE Funil, demonstram que as variações do nível do lago desde seu enchimento (final do ano de 2002) são inferiores a 0.2 $\mathrm{m}$, permitindo considerar este reservatório como sendo tendo cota invariável. 


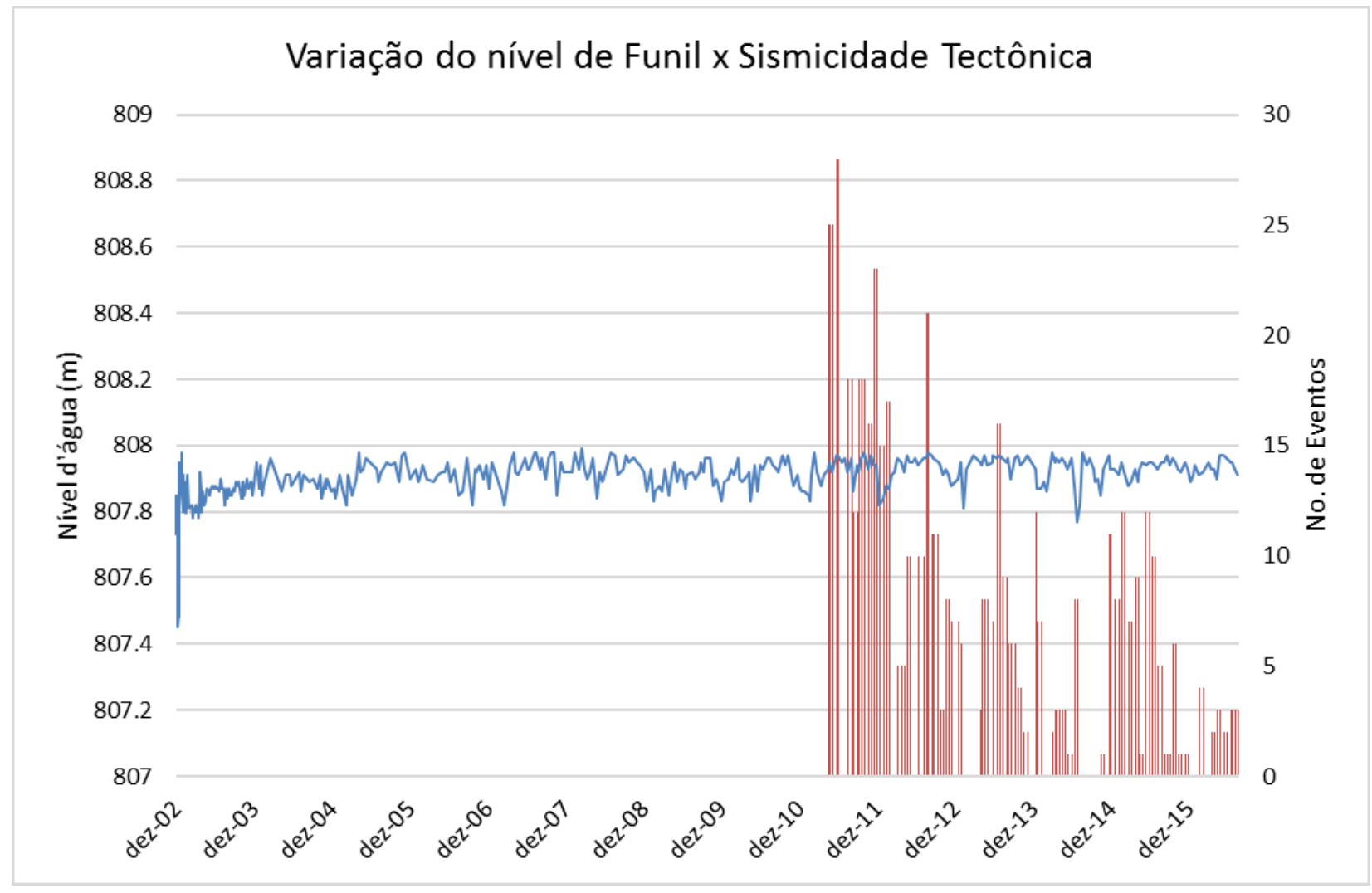

Figura 5-13 - A estabilidade da cota do lago (linha azul), entre dezembro de 2002 e julho de 2016 é apresentado no eixo primário (esquerda). Observe que após o enchimento do reservatório (dezembro de 2002) a cota do lago variou entre 807,8 e 808m. A evolução da sismicidade entre abril de 2011 e junho de 2015 é representada no eixo secundário pelas barras vermelhas.

A Figura 5-13 monstra a estabilidade do reservatório na cota média de 807,9 e que é contrastante com as variações do número de eventos registrados mensalmente entre abril de 2011 e junho de 2015, indicando que a sismicidade observada próxima ao reservatório da UHE Funil não parece estar relacionada com as variações no nível da água do reservatório.

Ademais, o mecanismo focal apresentado no Capítulo 4 -, concordante com a orientação de estruturas potencialmente sismogênicas mapeadas na área, indica um sistema de falha inversa (compressão horizontal NNW - ESE). Neste contexto, espera-se que a criação do reservatório trouxesse estabilidade aos esforços presentes na área, aumentando a tensão $\sigma_{3}$ e estabilizando uma possível atividade sísmica relacionada a esse sistema de falhas reversas. Mas este não parece ser o caso.

Outros fatores que corroboram para a exclusão do reservatório com possível causador da sismicidade, é a distribuição espacial dos eventos, concentrados nos arredores das minas Sul e 
Santa Helena, particularmente, em falhas previamente mapeadas e relacionadas ao sistema graben/horst de Ijaci. A pequena espessura da lâmina d'água que, de acordo com Barros, et al., 2016, teria probabilidade inferior a $2 \%$ de desencadear sismos, e por último, mas não menos importante, a prolongada e constante atividade sísmica registrada até os dias atuais.

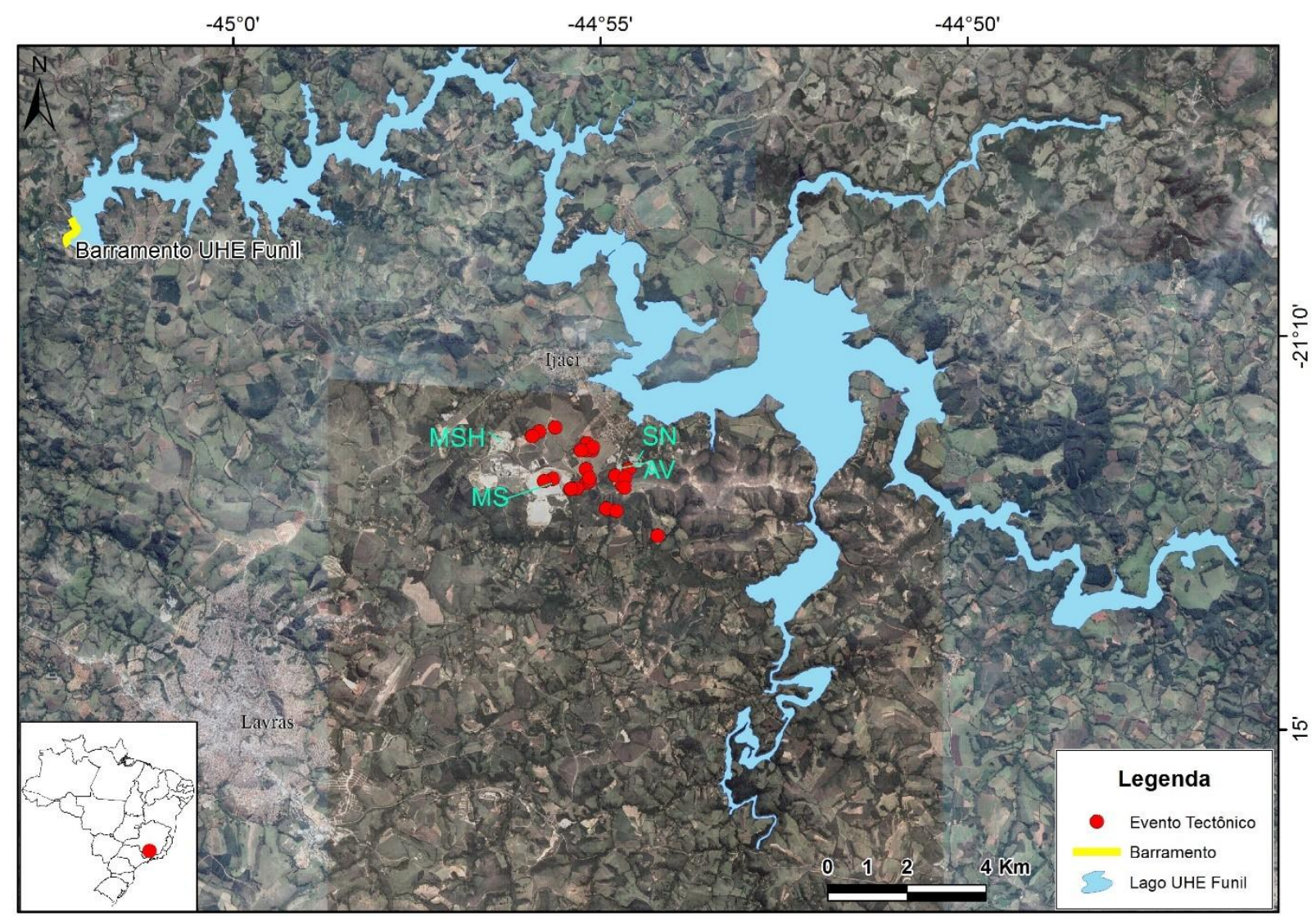

Figura 5-14 - Área de inundação do reservatório da UHE Funil e indicação, em amarelo, da posição do barramento, distante aproximadamente $15 \mathrm{~km}$ da área de ocorrência dos sismos. A menor distância entre a margem do lago e os sismos é $1,3 \mathrm{~km}$. 


\section{Capítulo 6 - Discussão e Conclusões}

A atividade sísmica, observada próxima à cidade de Ijaci, sul de Minas Gerais, foi estudada com uma rede de monitoramento sísmico local composta por sete estações de banda larga, que operou entre dezembro de 2011 e agosto de 2012. A partir de maio de 2012 o monitoramento da região voltou a ser feito apenas com a estação FUN1. Durante o período de funcionamento da rede mais de 1000 eventos foram registrados e, cerca de 500 foram localizados, dos quais 241 foram considerados como artificiais (detonações) e 276 tectônicos. O maior evento ocorreu em 14 de agosto de 2011, foi detectado apenas pela estação FUN1, às 13h50m (hora local) e teve magnitude de 3,2 na Escala Richter. Desde então a região de Ijaci vem apresentando sismicidade e relatórios obtidos junto ao Observatório Sismológico da Universidade de Brasília, datados de dezembro de 2016, indicam que essa sismicidade é persistente.

A dispersão nas localizações dos eventos artificiais está relacionada com a precisão na localização dos epicentros, considerando ser esperado que as detonações sejam aquelas que estão apresentadas na Figura 3-13 e que estejam associadas exclusivamente ao interior das pedreiras. Não há informações acerca de detonações em regiões externas às pedreiras. Entretanto, erros de 1 - 1,5 km são aceitáveis, considerando inclusive a dificuldade de se identificar a fase $\mathrm{S}$ de detonação.

Como pode ser visto na Figura 3-1, historicamente não há registros de sismicidade na área em questão. Existem, entretanto, três novos fatos a serem considerados: A instalação do reservatório de Funil; a reativação da Mina Santa Helena e início das operações da Mina Sul e o início do bombeamento com objetivo de rebaixamento do nível freático nas minas Sul e Santa Helena.

Toda a sismicidade local observada está relacionada à Megasequência Carandaí que ocorre no Graben de Ijaci. Quatro pedreiras atuam na área e exploram os calcários da Formação Barroso. Estão localizadas sobre o hanging wall das falhas reversas e efetuam diariamente bombeamento d'água a fim de rebaixar o nível freático.

O reservatório da UHE Funil está localizado a pouco mais de $1 \mathrm{~km}$ das duas principais minas e seu enchimento ocorreu concomitantemente ao início das atividades de uma das maiores minas de calcário do Brasil, a Mina Sul, operada pelo Grupo Intercement (Figura 6-1). 


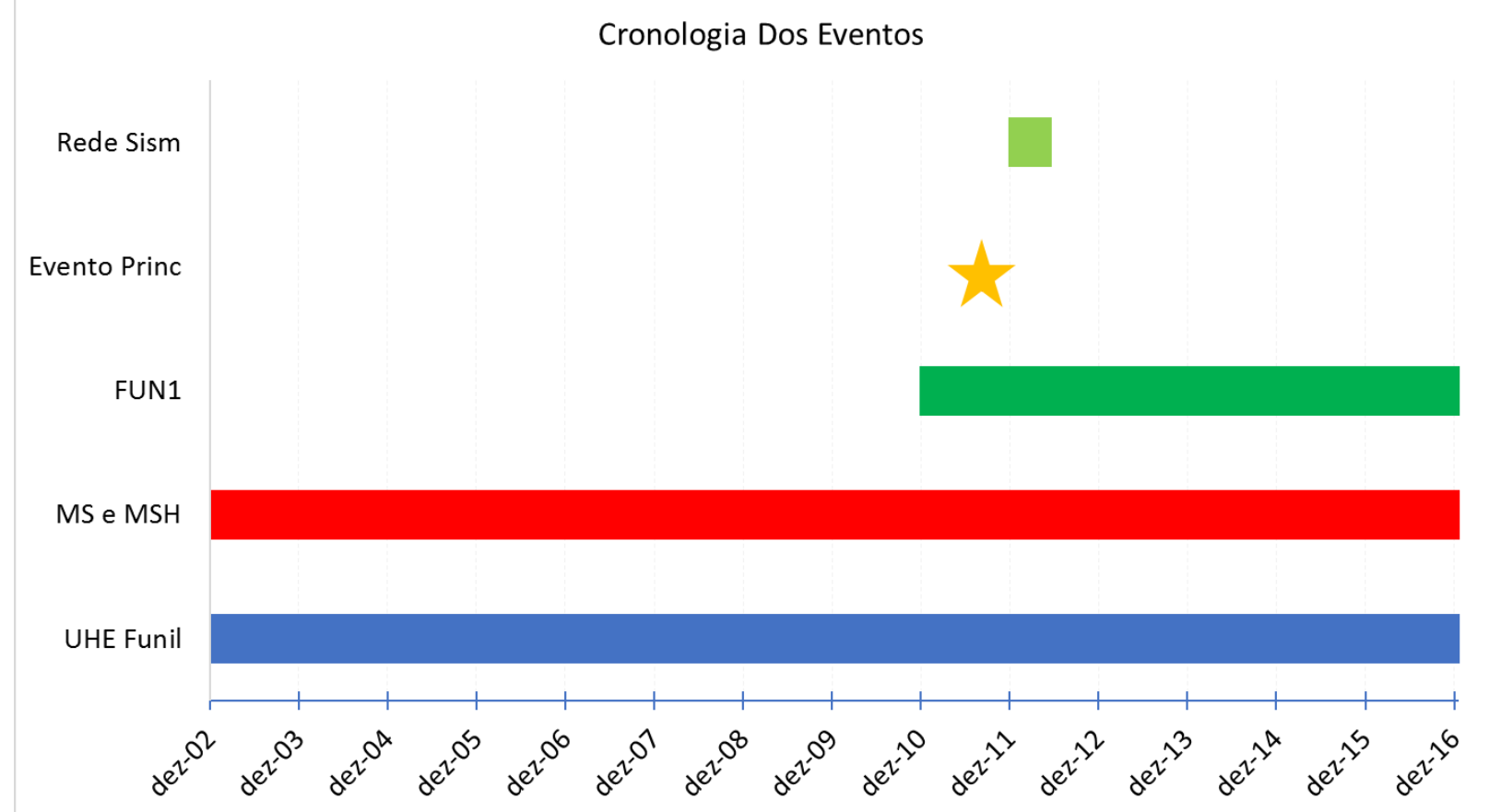

Figura 6-1 - Cronologia dos eventos. Observe que tanto as Minas Sul (MS) e Mina Santa Helena (MSH) foram ativadas/reativadas concomitantemente ao enchimento do lago da UHE Funil.

Parâmetros de fontes obtidos por inversão de forma de onda, tanto do evento principal quanto de abalos secundários e mecanismo focal indicam que as falhas responsáveis pela sismicidade apresentam strike geral NE-SW, concordante com as principais falhas mapeadas na região por Quéméneur et al. (2003), Ribeiro et al., (2003a), Hidrovia, (2003), Dehler et. al., (1995) e Ebert, (1984)

Medidas de piezômetros indicam que o bombeamento diário executado pelas pedreiras de calcário, forma um cone de depressão restrito ao entorno das minas, exercendo pouca influência sobre o aquífero cárstico local. A reversão de fluxo simulado por Hidrovia (2003) durante a evolução das minas, que poderia alterar o regime de esforços locais, não foi observada.

A localização dos eventos tectônicos, a estabilidade do nível do lago, pequena espessura da lâmina d'água, prolongada atividade sísmica associado aos resultados de mecanismo focal, que indicam falhas reversas como responsáveis pela sismicidade, tornam baixa a probabilidade dos sismos de Ijaci serem desencadeados pelo reservatório da UHE Funil.

Grande maioria dos eventos estão localizadas no entorno das pedreiras de calcário, principalmente das minas Sul (MS) e Santa Helena (MSH). A maior mina da região, Mina Sul, movimenta cerca de 7.5 milhões de toneladas de material rochoso para longe da cava. Entre 2008 
e 2016 a remoção de carga sobre o hanging wall da falha reversa sob a Mina Sul, com orientação NE-SW, foi da ordem de $5,9 \times 10^{11} \mathrm{~N}$. Alívios de carga com razão similares aos apresentados neste trabalho foram responsáveis pela geração de sismicidade em Cacoosing Valley (Seeber et al., 1998).

A prolongada atividade sísmica pode ser explicada pelo critério de fratura CoulombNavier, onde o alívio de carga reduz a tensão vertical $\left(\sigma_{3}\right)$ de modo a aproximar as falhas reversas do sistema horst/graben de Ijaci da ruptura. Outra situação interessante a ser observada é apresentada pela Figura 5-12, onde a ausência de bombeamento entre os meses de agosto e outubro de 2014 aparenta ter relação direta com a ausência de sismicidade. Provavelmente a recomposição do nível freático no interior da cava, fez com que a lâmina d'água compensasse a ausência de material rochoso e a pressão exercida por ele, tornando $\sigma_{3}=\sigma_{1}$ ou mesmo invertendo os esforços de modo a tornar $\sigma_{1}$ vertical.

Indubitavelmente a extração de fluidos, o enchimento de reservatórios e as atividades de mineração podem desencadear sismicidade, juntos ou agindo separadamente. Entretanto, não se pode afirmar qual deles é o responsável pelo desencadeamento da sismicidade observada na área, apesar de grande parte dos dados convergirem para estabelecer as atividades de mineração como o principal fator de desencadeamento da sismicidade.

Outro fator importante a ser ressaltado sobre a sismicidade de Ijaci, é sua baixa magnitude e a ausência de monitoramento prévio, o que se traduz em uma incerteza sobre a indução de sismicidade no local. 


\section{Capítulo 7 - Referências}

Assumpção, M., Ardito, J. e Barbosa, J.R., 2010. An improved velocity model for regional epicenter determination in Brazil. IV Simpósio Brasileiro de Geofísica, Brasília, 13-16 de novembro de 2010.

Assumpção, M., Yamabe, T. H., Barbosa, J. R., Hamza, V., Lopes, A. E. V., Balancin, L., \& Bianchi, M. B., 2010. Seismic activity triggered by water wells in the Paraná Basin, Brazil, Water Resour. Res., 46, W07527, doi:10.1029/2009WR008048.

Assumpção, M., Yamabe, T. H., Barbosa, J. R., Lopes, A. \& Balancin, L., 2007. Seismic Activity Induced by Water Wells, Paraná Basin, Brazil, 10th International Congress of the Brazilian Geophysical Society held in Rio de Janeiro, Brazil, 19-22 November, Extended Abstract.

Assumpção, M.; Marza, V.; Barros, L.; Chimpliganond, C.; Soares, J.E. ; Carvalho, J. ; Caixeta, D.;

Amorim, A. ; Cabral, E. . Reservoir-induced Seismicity in Brazil. Pure and Applied Geophysics, Italia, v. 159, p. 597-617, 2002.

Assumpção, M.; Yamabe, T.H. ; Barbosa, J. ; Lopes, A.E.V. ; Balancin, L. . Seismic Activity Induced by Water Wells, Paraná Basin, Brazil. In: X Int.Congr. Braz. Geophys. Soc., 2007, Rio de Janeiro. Proceedings, CD-ROM, 2007.

Assumpção, M.; Yamabe, T.H.; Barbosa, J.R.; Balancin, L. \& Lopes, A., 2007a. Seismic Activity Induced by Water Wells Exploring a Fractured Aquifer in the Paraná Basin, Brazil. AGU Joint Assembly, Acapulco-Mexico, abstract.

Assumpção, M.; Yamabe, T.H.; Barbosa, J.R.; Lopes, A.E.V. \& Balancin, L., 2007b. Atividade Sísmica no Distrito de Andes, Bebedouro, 2005-2006, e sua Relação com a Perfuração de Poços Tubulares. (Relatório não publicado: www.iag.usp.br/ marcelo/bebedouro ).

Assumpção, Marcelo; Yamabe, Tereza H. ; Barbosa, José Roberto ; Hamza, Valiya ; Lopes, Afonso E. V.

; Balancin, Lucas ; Bianchi, Marcelo B. . Seismic activity triggered by water wells in the Paraná Basin, Brazil. Water Resources Research, v. 46, p. W07527, 2010.

Barbosa O. 1954. Evolution du geossinclinal Espinhaço. In: Inter. Geol. Congr., Comptes. Rendus, section XIII, 19e session: 1-37, 1952, Argélia.hh

Barros, L. V., Assumpção, M, Ribotta, L. C, Ferreira, V. M., 2016. Sismicidade Induzida por Reservatório (SIR): casos brasileiros, SBGf, Boletim 96/2016 
Barros, L. V., Assumpção, M., Quintero, R., \& Caixeta, D. (2009). The intraplate Porto dos Gaúchos seismic zone in the Amazon craton - Brazil. Tectonophysics, 469(1-4), 37-47. doi:10.1016/j.tecto.2009.01.006

Barros, L. V.; Albuquerque, D. F. ; Von Huelsen, M.G ; Mourao, V. ; Fontenele, D. P. ; SILVAS, F. S. ; Soares, J. ; Soares, W . Seismicity of Ijaci, south of Minas Gerais state, near the FUNIL UHE reservoir and mineral extraction areas. In: 13th International Congress of the Brazilian Geophysical Society, 2013, Rio de Janeiro.

Barros, L. V.; CAixeta, D. F. . Induced Seismicity at Miranda Reservoir - A fine example of immediate seismic responsev. In: VIII Congress International of the Brazilian Society of Geophysics, 2003, Rio de Janeiro.

Barros, L. V.; Caixeta, D. F. ; Chimpliganond, C. N. ; Fontenele, D. P. . Evolution of the Areado/MG seismic sequence - started in January, 2004. In: 9th International Congress of the Brazilian Geophysical Society, 2005, Salvador.

Barros, L. V.; Ferreira, V. M. . Recurrent Seismicity at Areado Minas Gerais State. In: II Simpósio Brasileiro de Geofísica, 2006, Natal., 2006, Natal.

Barros, L. V.; Fontenele, D. P. . Sismicidade Induzida por Reservatório (SIR) e o Programa de Monitoramento Sismológico do Reservatório de Estreito. Estreito: O Novo Cenário da Água. 1ed.Rio de Janeiro: E-PAPERS, 2012, v. , p. 33-58.

Barros, L.V., 2001. Sismicidade Induzida por Reservatórios, Caracterização e Análise de Casos no Brasil. Exame de qualificação ao doutorado, Observatório Sismológico, Instituto de Geociências da Universidade de Brasília, 102p.

Barros, L.V., 2011. Relatório Especial Nº 1, Observatório Sismológico da Universidade de Brasília, 31 de janeiro de 2012, 22pp.

Barros, L.V., 2012. Relatório Especial Nº 2, Observatório Sismológico da Universidade de Brasília, 31 de janeiro de 2013, 42pp.

Barros, L.V., Albuquerque, D.F., Ferreira, V.M., Von Huelsen, M.G., Mourão, V.F., Fontenele, D.P., Silva, F.S. Soares, J.F and Soares, W.S. 2013. Seismicity of Ijaci, south of Minas Gerais state, near the Funil UHE reservoir and mineral extraction areas. XIII International Congress of the Brazilian Geophysical Society. Rio de Janeiro, August 2013. 
Barros, L.V., Caixeta, D.F., Chimpliganond, C.N., Fontenele, D.P., 2005. Evolution of the Areado/MG seismic sequence - started in January, 2004. 9th Int. Cong. of the Brazilian Geophys. Soc., 11- 14 September, Salvador -BA, 6p.

Bell, M.L. and Nur, A. (1978) Strength changes due to reservoirinduced pore pressure and stress and application to Lake Oroville. Jour. Geophys. Res., v.83, pp.4469-4483.

Berrocal, J., Assumpçao, M., Antezana, R., Dias Neto, C. M., Ortega, R., França, H., and Veloso, J. (1984), Sismicidade do Brasil. IAG-USP/CNEN, São Paulo, Brazil, 320 pp.

Berrocal, J., Assumpção, M., Antezana, R., Dias Neto, C., Ortega, R., França, H., Veloso, J.A., 1984. Sismicidade do Brasil. Published by IAG/USP and Comissão Nacional de Energia Nuclear, Brazil, 320 p.

Berrocal, J., Assumpção, M., Antezana, R., Dias Neto, C., Ortega, R., França, H., Veloso, J.A., 1984. Sismicidade do Brasil. Published by IAG/USP and Comissão Nacional de Energia Nuclear, Brazil, 320 .

Berrocal, J., Assumpção, M., Antezana, R., et al. (1983). Seismic activity in Brazil in the period 15601980. Earthquake Prediction Research, 2191 - 208.

Bouchon, M. (1981). A simple method to calculate Green`s functions for elastic layered media”, Bull. Seis. Soc. Am., 71, 959-971.

Bouchon, M. (1981). The rupture mechanism of the Coyote Lake earthquake of August 6, 1979, inferred from near-field data, presented at the USGS-NRC workshop on strong motion, Lake Tahoe, October 1981.

Brady, Barry HG. Rock mechanics: for underground mining. Springer, 2004.

Campos Neto, M.C.; Perrota, M.M.; Peloggia, A.U.G.; Figueiredo, M.C.H. (1990) A porção occidental da Faixa Alto Rio Grande (SP-MG). In: Cong. Bras. Geol., 35, Natal, 1990. Anais. Natal, SBG, v.6, p.2615-2630.

Carder, D. S. (1945), Seismic In6estigations in the Boulder Dam Area, 1940-44 and the Influence of Reservoir Loading on Local Earthquake Acti6ity, Bull. Seismol. Soc. Am. 35(4), 175-192.

Chen L. Talwani P., 2001. Mechanism of initial seismicity following impoundment at the Monticello Reservoir, South Carolina, Bull. seism. Soc. Am. , 91, 1582-1594.

Chimpliganond, C.N., 2002. Caracterização da Sismicidade Induzida no Reservatório de Nova Ponte/MG, Brasil. Dissertação de Mestrado, IG-UnB. 
Chimpliganond, Cristiano ; Assumpção, Marcelo ; Von Huelsen, Mônica ; França, George Sand . The intracratonic Caraíbas Itacarambi earthquake of December 09, 2007 (4.9 mb), Minas Gerais State, Brazil. Tectonophysics (Amsterdam), v. 480, p. 48-56, 2010.

Chimpliganond, Cristiano, et al. "The intracratonic Caraíbas-Itacarambi earthquake of December 09, 2007 (4.9mb), Minas Gerais State, Brazil." Tectonophysics 480.1 (2010): 48-56.

Codemig - Companhia Mineradora de Minas Gerais. Geologia e Recursos Minerais do Sudeste Mineiro. Projeto Sul de Minas - Etapa I. Belo Horizonte: COMIG/UFMG/UFRJ/UERJ, 2003. v. 1, p. 259319.

Cook, N. G. W. "Seismicity associated with mining." Engineering Geology 10.2 (1976): 99-122.

Cook, N.G.W., et al. (1965). J. South Afr. Inst. Mining Met. 66, 435-528.

Cypser, D.A. and S.D. Davis (1994). J. Environ. Law Litigation 9, 551-589.

Dehler, N. M., Machado, R.; Endo, I.; Simonato, M. D. (1995) Contribuição ao estudo estrutural e cinemático de metassedimentos correlacionáveis ao Grupo São João Del Rei na região de Ijaci, norte de Lavras, MG. Simp Geol. Minas Gerais, 8 Diamantina, 1995. Anais. Diamantina, SBGMG, bol. 13, p. 123-124.

Dehler, Nolan Maia, and Rômulo Machado. "Analise geométrica e cinemática das rochas metassedimentares da região de Ijaci, sul de Minas Gerais." Brazilian Journal of Geology 28.4 (1998): 413-418.

Dehler, Nolan Maia, and Rômulo Machado. "Analise geométrica e cinemática das rochas metassedimentares da região de Ijaci, sul de Minas Gerais." Brazilian Journal of Geology 28.4 (1998): 413-41

Do Nascimento, A.F., 2002. The role of pore pressure diffusion in a reservoir-induced seismicity site in NE Brazil. Tese de doutorado, Univ. de Edinburgue, 203 p.

Ebert, H. (1956) A tectônica do sul do Estado de Minas Gerais e regiões adjacentes. Rel. An. Dir.DGM, ano de 1956, p. 97-107.

Ebert, H. (1968) Ocorrências de fácies granulíticas no sul de Minas Gerais e áreas adjacentes em dependência da estrutura orogênica: hipóteses sobre sua origem. An. Acad. Bras. Cienc., vol. 40 (Suple.) Rio de Janeiro, RJ., p 215-229.

Ebert, H. A estrutura Pré-Cambriana do sudoeste de Minas Gerais e áreas adjacentes. B. Paran. Geociênc., Curitiba, v. 26, p. 42-44, 1967. 
Ebert, H. A tectônica do sul do Estado de Minas Gerais, Relatório Anual Div. Geo. Mineral.. DNPM, p. 97-107 e 136-137. 1957.

Ebert, H. Baustil und Regionalmetamorphose in präkambrischen Grundgebirge Brasiliens. Tschermaks Mineral. Petrogr. Mitt, v. 8, p. 49-81, 1962.98

Ebert, H. Beitrag zur Gliederung des Präkambriums in Minas Gerais. Geol. Rundsch., v. 45, p. 471-521, 1956a.

Ebert, H. D.; Hasui, Y.; Quade, H. Aspectos da evolução estrutural do Cinturão Móvel Costeiro na região de Mina do Perau, vale do Ribeira-PR. In: CONGRESSO BRASILEIRO DE GEOLOGIA, 35., 1988, Belém. Anais. Belém: SBG, 1988. v. 5, p.2318-31.

Ebert, H. Ocorrência da Fácies Granulíticas do Sul de MInas Gerais e em Áreas Adjacentes, em Dependência da Estrutura Orognética: Hipótese Sobre Sua Origem. Anais da Academia Brasileira de Ciências, Rio de Janeiro, n. 40, p. 215-229, 1968.

Ebert, H. Os Paraibídes entre São João Del Rei (MG) e Itapira (SP), e a bifurcação entre Paraibides e Araxaídes. São Paulo: SBG-SP/Pró-Minério, 1984. Pub. 12/84: 72-103. (in memorian).

Ebert, H. Os paraibides entre São João Del Rei (Minas Gerais) e Itapira (São Paulo) e a birfurcação entre Paraibides e Araxaídes. FFCLRC. Rio Claro, p. 37. 1971.

Ebert, H. Pesquisa na parte sudeste do Estado de Minas Gerais. Relatório Anual Div. Geol. Mineral., Rio de Janeiro, p. 79-89, 1955

Evans, D.M., 1966. The Denver area earthquakes and the Rocky Mountain Arsenal Disposal Well. Mt. Geol., 3: 23-26.

Evans, K. F., A. Genter, and J. Sausse (2005), Permeability creation and damage due to massive fluid injections into granite at $3.5 \mathrm{~km}$ at Soultz: 1. Borehole observations, J. Geophys. Res., B04203, doi:10.1029/2004JB003168.

Fernàndez, M., I. Marzán, A. Correia, and E. Ramalho (1998), Heat flow, heat production, and lithospheric thermal regime in the Iberian Peninsula, Tectonophysics, 291, 29-53, doi:10.1016/S00401951(98)00029-8.

Ferreira J. M., G.S. França, C.S. Vilar, A.F., Do Nascimento, F.H.R. Bezerra, M. Assumpção, (2008) Induced seismicity in the Castanhao reservoir, NE Brazil -- Preliminary results, Tectonophysics, V 456, I 1-2, The Monitoring of Induced Seismicity: Observations, Models and Interpretations, Pages 103-110. 
Ferreira, J. M., Oliveira, R. T., Assumpção, M., Moreira, J. A. M., Pearch, R. G., Takeya, M. K., 1995. Correlation of seismicity and water level in the Açu reservoir - an example form northeast Brazil. Bull. Seism. Soc. of Am. v. 85, 1483-1489.

Fetter, C. W. (2001). Applied hydrogeology (4th ed.). Upper Saddle River, N.J.: Prentice Hall.

Fletcher, J.B. \& L.R. Sykes, 1977. Earthquakes related to hydraulic and natural seismic activity in western New York state. J.Geophys.Res., 82, 3767-3780.

Ford D.; Williams P. Karst hydrogeology and geomorphology. Wiley : 562 p. 2007.

Gibson, G. \& Sandiford, M., Seismicity and induced earthquakes, A background paper for the Office of the Chief Scientist of NSW. June, 2013

Gomide, L. C., 1999. Nature and History of Reservoir Induced Seismicity in Brazil. Dissertação de Mestrado Univ. South Caroline, USA.

Guiguer, N. \& Franz, T. 1998. Visual MODFLOW. Waterloo Hydrogeologic, Inc., Waterloo, Canada

Guiguer, N. and Franz, T. 1998. Visual MODFLOWNser Manual. Waterloo Hydrogeologic. 3 15p.

Gupta, H. K. \& Rastogi, B. K., 1976. Dams Earthquakes. Develop.in Geotechnical Engineering, Amsterdam-Oxford- New York: Elsevier Scientific Publishing Company.

Gupta, H. K. \& Rastogi, B. K., 1976. Dams Earthquakes. Develop.in Geotechnical Engineering, Amsterdam-Oxford- New York: Elsevier Scientific Publishing Company.

Gupta, H. K., 1992. Reservoir Induced Earthquakes. Developments in Geotechnical Engineering. Amsterdam - London - New York - Tokyo: Elsevier Scientific Publishing Company, 64, 243-250,

Gupta, H. K., 2002. “A review of recent studies of triggered earthquakes by artificial water reservoirs with special emphasis on earthquakes in Koyna, India.” Earth-Science Reviews 58 279-310.

Gupta, H. K., 2002. A review of recent studies of triggered earthquakes by artificial water reservoirs with special emphasis on earthquakes in Koyna, India, Earth Sci. Rev., 58(3-4), 279-310.

Gupta, H. K.: Induced seismicity hazard mitigation through water level manipulation at Koyna, India: a suggestion, Bull. Seismol. Soc. Am., 73, 679-682, 1983

Gupta, H.K, 1992. Reservoir-Induced Earthquakes Elsevier, Amsterdam, 364 pp.

H. K. Gupta and K. Rajendran. Large artificial water reservoirs in the vicinity of the Himalayan Foothills and reservoir-induced seismicity - Bulletin of the Seismological Society of America, February 1986. $76: 205-215$

Hao, H. (2010) Reconnaissance report of structural damage in the Kalgoorlie-Boulder area. The Australian Earthquake Engineering Society, Kalgoorlie earthquake - Prof Hong Hao's report and photos of 
earthquake damage in Kalgoorlie, 2010 Apr 29. http://www.aees.org.au/wpcontent/uploads/2013/11/14-Edwards.pdf

Harbaugh, A.W., 2005, MODFLOW-2005, The U.S. Geological Survey modular Groundwater modelthe Groundwater Flow Process: U. S. Geological Survey Techniques and Methods 6-A16, variously $\mathrm{p}$

Harbaugh, A.W., 2005, MODFLOW-2005, the U.S. Geological Survey modular ground-water model -the Ground-Water Flow Process: U.S. Geological Survey Techniques and Methods 6-A16. This report describes the theory and input instructions at the time of the initial MODFLOW-2005 v1.00 release.

Harris, R.A. and R.W. Simpson (1998). J. Geophys. Res. 103, 24439-24451.

Havskov, J. \& Ottemöller, L. (Eds.). SEISAN: The Earthquake Analysis Software, Version 8.1. Inst. of Solid Earth Physics, University of Bergen, Norway, 2008. 227 p.

Havskov, J. \& Ottomöller, L. (Eds.). SEISAN: The Earthquake Analysis Software, Version 8.1. Inst. of Solid Earth Physics, University of Bergen, Norway, 2008. 227 p.

Healy, J. H., W. W. Rubey, D.T. Griggs, and C. B. Raleigh, The Denver earthquakes, Set, 767(3848), 1301,1968 .

Hedley, D. G. F. and Wetmiller, R. J.: 1985, 'Rockbursts in Ontario Mines During 1984'. Canada Centre for Mineral and Energy Technology, Mining Research Laboratories, Special Report SP85-5, 36p Heilbron, M.; Graduado, A. D. R.; Silva, L. G. E.; Nogueira, J. R.; Trouw, R. A. J.; Polonia, J. A. L. (1994) A compartimentação tectônica da seção Conceição do Ibitipoca - Valença, segmento central da Faixa Ribeira. In: Cong. Bras. Geol, 38, Camboriú, 1994. Bol. Res. Exp. Camboriú, SBG, v.2. p. 55-56.

Henry Fountain (March 28, 2013). "Study Links 2011 Quake to Technique at Oil Wells". The New York Times. Retrieved March 29, 2013.

Kikuchi, M., \& Kanamori., (1991). "Inversion of complex body waves III”, Bull. Seis. Soc. Am. 81, 6, 2335-2350.

Kissling, E., 1995. Program and VELEST user's guide - Short introduction. Institute of Geophysics, ETH Zuerich \& Swiss Seismological Service, ETH-Hoenggerberg. 26 p.

Kissling, E., 1995. Program and VELEST user's guide - Short introduction. Institute of Geophysics, ETH Zuerich \& Swiss Seismological Service, ETH-Hoenggerberg. 26 p.

Kisslinger, K. (1976) - A review of theories of mechanisms of induced seismicity. Eng. Geol, 8:85-90 
Klose, C. D., 2012.Mechanical and statistical evidence of the causality of human-made mass shifts on the Earth's upper crust and the occurrence of earthquakes, J. Seismol.

Klose, C.D. (2013) Mechanical and statistical evidence of the causality of human-made mass shifts on the Earth's upper crust and the occurrence of earthquakes, Journal of Seismology 17(1), 109-135.

Lienert, B. R. Hypocenter 3.2: A computer Program for Locating Earthquakes Locally, regionally and globally. Hawaii Institute of Geop. \& Planetology, Corea, 1994.

Lienert, B. R. Hypocenter 3.2: A computer Program for Locating Earthquakes Locally, regionally and globally. Hawaii Institute of Geop. \& Planetology, Corea, 1994.

Marshak, S. (2008). Earth: Portrait of a Planet (3rd ed.). New York, N.Y.: Norton \& Company Inc.

Marza, V. I., Barros, L. V., Soares, J. E. P., Carvalho, J. M., Fontenelle, D. P., Chimplignond, C, N., Caixeta, D. F., Gomes, I. P., Furtado, G. O., Carim, A. L., Souza, I. F., Caliman, E. H., and Barros J. B. (1999), Some Aspects of Reservoir-induced Seismicity in Brazil, Proc. 23rd Brazilian Congr. on Large Dams, Belo Horizonte, Brazil, vol. 1, 199-211.

McDonald, A.J. (1982). MSc Thesis, University of Witwatersrand, Johannesburg.

McGarr, A., D. Simpson, and L. Seeber (2002), Case histories of induced and triggered seismicity, in International Handbook of Earthquake and Engineering Seismology, vol. 81A, pp. 647-661, Academic Press, San Francisco, Calif.

Mescua, José F., and Laura B. Giambiagi. "Fault inversion vs. new thrust generation: A case study in the Malargüe fold-and-thrust belt, Andes of Argentina." Journal of Structural Geology 35 (2012): 5163.

Miljanovic, V. “Geotool - Software User Tutorial, CTBTO/IMS/IDC 1.0 13.07.2007. Vera Miljanovic Software User Tutorial <GT_tutorial_ver01.pdf $\rangle$.

Quéméner, J. J. G., Geologia da Folha Lavras. In: COMPANHIA MINERADORA DE MINAS GERAIS. Geologia e Recursos Minerais do Sudeste Mineiro. Projeto Sul de Minas - Etapa I. Belo Horizonte: COMIG/UFMG/UFRJ/UERJ, 2003. v. 1, p. 259-319.

Quéméneur, J.J.G.; Ribeiro, A.; Trouw, R. A. J.; Pcaciullo, F. V. P. \& Heilbron, M. (2003) Geologia da Folha Lavras. Projeto Sul de Minas, Etapa I, Capítulo 7. COMIG, UFMG, UFRJ, UERJ p 259319.

Rajendran, K. \& Talwani, P., 1992. The role of elastic, undrained, and drained responses in triggering earthquakes at Monticello Reservoir, South Carolina, Bull. seism. Soc. Am., 82, 1867-1888. 
Rastogi,B.K., Sarma,C.S.P., Chadha,R.K., et al. , Current seismicity at the Koyna reservoir, Maharashtra, India (1983-1984) (With German summary), Beitr. Geophys., 99, 229-237 (1990).

Rayleigh, C.B., J.H. Healy \& J.D. Bredehoeft.,1976. An experiment in earthquake control at Rangely, Colorado. Science, 191, 1230-1236.

Redmayne, D.W. (1988) Mining induced seismicity in UK coalfields identified on the BGS National Seismograph Network. Geological Society, London, Engineering Geology Special Publications; vol. 5; pp. 405-413

Ribeiro A., Paciullo F.V.P., Trouw R.A.J., Valença J.G., 2003a. Síntese Geológica Regional do Bloco Ocidental, Campos das Vertentes e Sul de Minas. In: Pedrosa Soares, A.C.; Noce, C.M.; Trouw, R.A.J.; Heilbron, M.. (Org.). Geologia e Recursos Minerais do Sudeste Mineiro. Projeto Sul de Minas Etapa I (COMIG, UFMG,UFRJ,UERJ), Relatório Final.. Belo Horizonte: COMIG, 1:51152.

Ribeiro, A., Trouw, R. A. J., Paciullo, F. V. P., Heilbron, M., Geologia da Folha Lavras. In: COMPANHIA MINERADORA DE MINAS GERAIS. Geologia e Recursos Minerais do Sudeste Mineiro. Projeto Sul de Minas - Etapa I. Belo Horizonte: COMIG/UFMG/UFRJ/UERJ, 2003. v. 1, p. 259319.

Ribeiro, A.; Paciullo, F. V. P.; Andreis, R.; Trouw R. A. J.; Heilbron, M. 1990. Evolução policíclica prolerozóica no sul do Cráton do São Francisco: análise da região de São João Del Rey e Andrelândia (MG). In: SBG, Congresso Brasileiro de Geologia, 36, Natal, Anais. 6:2605-2614.

Ribotta, L. C., Mioto, J. A. e Regina, J.V. M., 2006a,b. Sismicidade na área do reservatório de Machadinho, SC/RS. Anais do XLIII Cong. Brasileiro de Geologia, Aracaju, SE.

Ribotta, L. C., Mioto, J. A., Manuzzi, J. L., Carvalho, A. M. B. e Vinciprova, G., 2008. Sismicidade na área do reservatório de Barra Grande, SC/RS. Anais do III Simpósio Brasileiro de Geofísica, Belém, PA.

Ribotta, L.C., 1989. Aspectos da sismicidade na área do reservatório de Paraibuna/Paraitinga. Dissertação de Mestrado, IAG-USP.

Roeloff, E.A., (1988) Fault stability changes induced beneath a reservoir with cyclic changes in water level. Jour. Geophys. Res., v.93, pp.2107-2124.

Sbar, M. L., and L. R. Sykes (1973). Contemporary compressive stress and seismicity in Eastern North America: An example ofintra-plate tectonics, Bull. Geol. Soc. Am. 84, 18611882.

Seeber, L., et al. (1998). J. Geophys. Res. 103, 24505-24521. 
Silva N. Projeto Mantiqueira Furnas. CPRM, 1978

Simpson, D. W. and Narasimham, T. N. (1990), Inhomogeneities in Rock Properties and their Infuence on Reservoir-induced Seismicity, Gerlands Beitr. Geophys. 99, $205 \pm 219$.

Simpson, D. W. and Negmatullaev, S. Kh.: Induced seismicity studies in Soviet central Asia, Earthq. Inf. Bull., 10, 208-213, 1978.

Simpson, D. W. Triggered earthquakes. Annual Review of Earth and Planetary Sciences, v. 14, p. 21, 1986.

Simpson, D. W., Leith, W. S., and Schcolz, C.H., 1988. Two Types of Reservoir-Induced Seismicity. Bulletin of the Seismological Society of America, Vol. 78, No. 6, pp. 2025-2040. December.

Simpson, D.W. (1976) Seismicity changes associated with reservoir impounding. Engg. Geol., v.10, pp.371-385.

Simpson, D.W., et al. (1988). Bull. Seismol. Soc. Am. 78, 2025-2040.

Simpson, D.W., et al. (1990). Gerlands Beitr. Geophys. 99, 191-204.

Snoke J.A.. Lee W.H.K., Kanamori H., Jennings P.J., Kisslinger C.. FOCMEC: FOCal MEChanism Determinations, The IASPEI International Handbook of Earthquake and Engineering Seismology , 2003. Academic Press(pg. 1629-1630).

Snoke, J.A., Munsey, J. W., Teague, A.G., Bollinger, G.A., 1984. A program for focal mechanism determination by combined use of polarity and SV-P amplitude data. Earthquake Notes, 55(3), 15.

Snow, D. J., 1972. Geodynamics of seismic reservoirs, Proc. Symp. On Percolation through Fissured Rocks, Dtsch. Gps, Suttgart, p. 1-19.

Snow, D.T. (1972) Geodynamic of seismic reservoirs. Proc. Symposium on percolation through Fissured Rocks. No. T2.J, Stuttgart, Gesellshft fur Erdund, Grundbau, P.19.

Sokos, E. \& Zahradnik, J., 2013. Evaluating Centroid- Moment-Tensor Uncertainty in the New Version of ISOLA Software. Seismological Research Letters, 84(4), pp.656- 665.

Sokos, E. N. \& J. ZAHRADNÍK, J., (2008). ISOLA a Fortran code and a Matlab GUI to perform multiplepoint source inversion of seismic data, Comput. Geosci. 34, 967-977.

Sokos, E.N. \& Zahradnik, J., 2008. ISOLA a Fortran code and a Matlab GUI to perform multiple-point source inversion of seismic data. Computers \& Geosciences, 34(8), pp.967-977.

Talwani, P. \& S. Acree, 1984/85. Pore pressure diffusion and the mechanism of reservoir-induced seismicity. Pure and Appl. Geophys., 122, 947-965. 
Talwani, P. (2000), Seismogenic Proprieties of the Crust Inferred from Recent Studies of Reservoirinduced Seismicity - Application to Koyna.

Talwani, P., 1997. On the nature of reservoir-induced seismicity, Pure appl. Geophys., 150, 473-492.

Talwani, P., Chen, L. \& Gahalaut, K., 2007. Seismogenic permeability, ks, J. geophys. Res., 112, B07309, doi:10.1029/2006JB004665.

Talwani, P., L. Chen, and K. Gahalaut, (2007), Seismogenic permeability, J. Geophys. Res., 112, B07309, doi:10.1029/2006JB004665.

Trouw, R. A. J. (1995) Uma avaliação dos modelos cinemáticos propostos para o megassinformal do Vale do Paraíba do Sul, baseada em lineações de estiramento. In: Simp. Nac. Est. Tect., 5, Gramado, 1995. Bol. Res. Exp. Gramado, SBG-RS, p. 103-104.

Veloso, J. A V. \& Assumpção, M., 1989. Reservatórios sísmicos e assísmicos: uma experiência no estudo de SIR no Brasil, 4th Int. Cong. Braz. de Geophys. Rio de Janeiro.

Veloso, J. A. V., 1992a. Terremotos induzidos pelo homem. Ciênc. Hoje, 14: 66-72.

Veloso, J. A. V., 1992b. Cases of RIS in the Brazilian Amazon Area. In Proc. Tenth World Conference on Earthquake Engineering, Madrid, Spain, Vol. I, 269-273,.

Veloso, J. A.V., Barros, L.V. \& Carvalho, J.M., 1995. Progress in reservoir monitoring technology for induced seismicity in Brazil, Proc. ISORIS'95, Beijing, 304-312.

Wernick, E.; Fiori, A. P.; Beltcncourt, J. S.; Choudhuri, A. 1981. A Tectônica Rígida do fim do ciclo Brasiliano e sua implicação na estruturação da borda sul c sudoeste do Cráton do São Francisco: tentativa de um modelo preliminar. In: SBG-BA, Simpósio do Cráton do São Francisco c suas Faixas Marginais, 1, Salvador, Anais...: 164-168.

Wessel, P., and Smith, W. H. F., 1995. "New version of the Generic Mapping Tools", released, EOS 76, 329.

Wetmiller, R.J., 1986, Earthquakes near Rocky Mountain House, Alberta, and their relationship to gas production: Canadian Journal of Earth Sciences, v. 23, p. 172-181.

Yamabe, T. H. \& Hamza, V. M., 1996. Geothermal Investigations in an Area of Induced Seismic Activity, Northern São Paulo State, Brazil. Tectonophysics, v. 253, 209-225.

Yamabe, T. H., 1999. Estudos Geofísicos para Explicar a Sismicidade Induzida e Orientar a Exploração de Água Subterrânea em Nuporanga - SP. Tese de Doutorado, IAG/USP.

Zahradnik, J., and Plesinger, A., 2005. Long-period pulses in broadband records of near earthquakes. Bull. Seism. Soc. Am., 95, 1928-1939. 
Zahradnik, J., and S. Custódio (2012). Moment tensor resolvability: Application to southwest Iberia. Bull. Seism. Soc. Am., 102, 1235-1254, doi: 10.1785/0120110216. 